Portland State University

PDXScholar

Persistence Influences on the Minority Student Attending a Predominantly White Postsecondary Urban Institution: the Student Perspective

Annmarie O'Brien

Portland State University

Follow this and additional works at: https://pdxscholar.library.pdx.edu/open_access_etds

Part of the Higher Education Commons

Let us know how access to this document benefits you.

Recommended Citation

O'Brien, Annmarie, "Persistence Influences on the Minority Student Attending a Predominantly White Postsecondary Urban Institution: the Student Perspective" (1994). Dissertations and Theses. Paper 1276. https://doi.org/10.15760/etd.1275

This Dissertation is brought to you for free and open access. It has been accepted for inclusion in Dissertations and Theses by an authorized administrator of PDXScholar. Please contact us if we can make this document more accessible: pdxscholar@pdx.edu. 


\title{
PERSISTENCE INFLUENCES ON THE MINORITY STUDENT ATTENDING A PREDOMINANTLY WHITE POSTSECONDARY URBAN INSTITUTION: \\ THE STUDENT PERSPECTIVE
}

by

ANNMARIE O'BRIEN

A dissertation submitted in partial fulfillment of the requirements for the degree of

\author{
DOCTOR OF EDUCATION \\ in \\ EDUCATIONAL LEADERSHIP: \\ POSTSECONDARY EDUCATION
}

Portland State University
01994 


\section{DISSERTATION APPROVAL}

The abstract and dissertation of Annmarie O'Brien for the Doctor of Education in Educational Leadership: Postsecondary Education were presented July 15, 1993, and accepted by the dissertation committee and the doctoral program.

COMMITTEE APPROVALS:

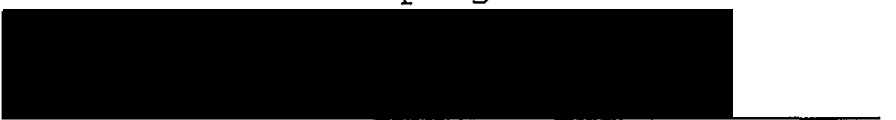

Mary K. Kinnick, Chair

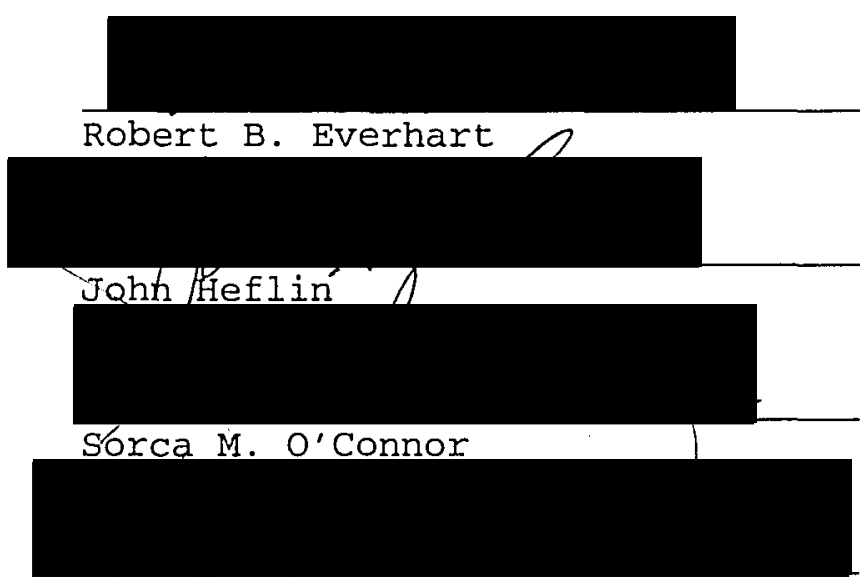

Bernard V. Burke Representative of the office of Graduate Studies

DOCTORAL PROGRAM APPROVAL:

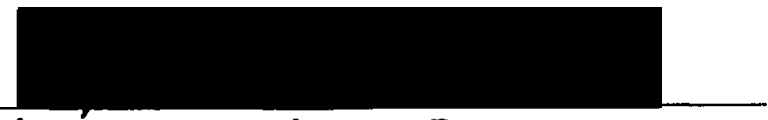

Robert B. Everhart, Dean

School of Education

ACCEPTED FOR PORTLAND STATE UNIVERSITY BY THE LIBRARY

by

on $2 n<0$ denelex 1944 


\begin{abstract}
An abstract of the dissertation of Annmarie o'Brien for the Doctor of Education in Educational Leadership: Postsecondary Education presented July 15, 1993.
Title: Persistence Influences on the Minority student Attending a Predominantly White Postsecondary Urban Institution: The student Perspective

This dissertation is an examination of influences that have contributed to the retention of a group of minority students attending a predominately white postsecondary institution. The focus of the study is on the students' perspectives and the meaning and personal interpretation students draw from influences that impinge upon them and from their interactions with the college experience. From a sociological perspective this view and emphasis on meaning is described as the sociology of everyday life. The component of the sociology of everyday life which directed the methodology is symbolic interactionism.

The data collection instrument was a focused interview. Variables from the Metzner and Bean (1987) Conceptual Model of Nontraditional Student Attrition and Tinto (1987) Student Integration Model served as the starting point for the formation of the open-ended questions. 
The selected group of students were participants in a collaborative program between a school district, a community college, and a state university designed to encourage minorities to pursue careers in education. Twelve out of 25 qualified participants volunteered for the study. They represented a heterogeneous group of African-American, Hispanic-American, and Asian-American students.

The data indicated that while the students had divergent family and educational experiences prior to entering the college, certain circumstances took place that were in many instances similar. The findings were multifaceted and represent institutional, environmental, and personal influences.

Institutional influences included the encouragement of faculty and staff, introduction of college as a choice either early in their lives or when they were ready to make career changes, academic supports, ethnic and multicultural studies, a familiar site on campus to go for assistance, and the availability of supportive administrators and faculty. Environmental influences included familiarity with the lack of employment opportunities without a college degree, and experience in racially integrated environments. Personal influences included assistance with college expenses from a family member, awareness of the economic limitations without advanced training, and personal commitment and determination to persist. 
Supportive relationships within the context of the students' families, educational experiences and the broader society of which they were an integral part all played influential roles in the persistence of the students. 
DEDICATION

To the memory of my parents, Hugh and Margaret O'Brien. 
TABLE OF CONTENTS

PAGE

LIST OF TABLES. • . . . . . . . . . . . . . . . . v

LIST OF FIGURES . . . . . . . . . . . . . . . . . vi

CHAPTER

I BACKGROUND ON PROBLEMS OF MINORITY RETENTION • 1

Introduction . . . . . . . . . . . . 1

Statement of the Problem . . . . . . 5

Purpose and Broad Research Questions . . 6

Operational Definitions. . . . . . . 7

Study Limitations. . . . . . . . . . 8

II REVIEW OF THE LITERATURE

Introduction . . . . . . . . . . 10

Models of Retention/Attrition. . . . . . 11

Tinto's Student Integration Model. . . . 13

Metzner and Bean's Model of student Student Attrition. . . . . . . . . 15

Institutional practices. . . . . . . . 19

Minority student Experiences in Higher

Education. . . . . . . . . . . . . 24

The Transfer Process . . . . . . . . 32

Retention from the student Perspective . 36

Summary of the Literature Review . . . . 43

Summary: What we know and What's

Missing. . . . . . . . . . . . . 45 
III METHODOLOGY. . . . . . . . . . . . . 48

Research Questions .. . . . . . . 48

Research Design. . . . . . . . . . 48

Setting and Background of the Special

Program. . . . . . . . . . . 54

organizational structure . . . . . . 55

Overview of the Program. . . . . . . 57

Sample . . . . . . . . . . . . 59

Instrument: The Focused Interview. . . . 62

Procedures . . . . . . . . . . . 64

Analysis ... . . . . . . . . 66

IV THE INTERVIEW RESULTS. . . . . . . . . . . 68

Introduction to the Findings . . . . . 68

Findings . . . . . . . . . . . . 71

Common Themes. . . . . . . . . . 102

Institutional Influences

Environmental Influences

Personal Influences

Success Factors. . . . . . . . . 113

Summary. . . . . . . . . . . . . . 119

V CONCLUSIONS AND RECOMMENDATIONS. . . . . . . 122

Conclusions. . . . . . . . . . . . 122

Implications . . . . . . . . . . . 131

Elementary and Secondary Schools

Community colleges and Universities

Collaborations

Broad Policy and Practices

Future Research. . . . . . . . . . 138

Summary. . . . . . . . . . . . . . 141 
REFERENCES. . . . . . . . . . . . . . . . . 143 APPENDICES

A Introductory Letters to students . . . . . 152

B Focused Interview Guide. . . . . . . . 155

C Interview summaries. . . . . . . . . . 158 


\section{LIST OF TABLES}

TABLE

PAGE

1. Comparison of Interview Participants vs. Non-participants ......... 61

2. Demographic Data from Participants in the study. . . . . . . . . . . . 70 


\section{IIST OF FIGURES}

FIGURE

PAGE

1. Tri-institutional collaboration organizational Chart... . . . . . 56 


\section{CHAPTER I}

\section{BACKGROUND ON PROBLEMS OF MINORITY RETENTION}

Introduction

As we advance through the 1990s, African-Americans, Hispanic-Americans, and Native-Americans continue to be underrepresented in the student population completing bachelors, masters, doctorates, and first professional degrees. There is reason for concern. Commitment to ethnic diversity is growing among employers representing the professional job market, yet our system of higher education continues to graduate dwindling numbers of minority students. The most significant change pertains to the increase of minority populations and their declining representation in higher education (Carnegie Foundation for the Advancement of Teaching, 1987, 1990; Hodgkinson, 1985).

Current and projected statistics pertaining to the enrollment of minority students in postsecondary education (Mortenson, 1991) support a recommendation to take action to reverse the declining numbers of minorities completing degrees. Significant evidence was presented in a study by Mingle (1987).

Minorities are a growing proportion of the traditional college-age population. By the year 
2025, they are expected to make up nearly $40 \%$ of the 18-24 year old age group nationwide. . . Except for Asian-Americans, the representation of minorities drops dramatically at the graduate and professional level. Blacks, who make up about $13 \%$ of the college-age youth, are $9.5 \%$ of all undergraduates and only $4.8 \%$ of graduate students - . Many minorities begin their education in two-year institutions, and success to the baccalaureate depends on transfer to a four-year institution. National and state studies, however, point to a decreasing number of transfers from community colleges . . . Anecdotal reports from the campuses indicate that little progress has been made in race relations. Racial and ethnic groups often go their separate ways, creating a climate that may isolate students and reinforce stereotypes. Minority students may become disconnected from the life of the campus, a situation that lessens their retention and success - . Effective remedial and counseling programs are critical to retention, yet many programs are poorly funded and receive low priority from institutional leaders . . Minorities cannot achieve full participation without access to institutions, but access is not enough. Successful completion of a demanding high-quality undergraduate curriculum is the key to minority success. (pp. $i x-x)$

Statistics suggest that to attain a representative balance of college attendance and graduation, each state or community should first identify their underrepresented minority enrollment populations. Of all degrees awarded in the state studied the percentages of each that were earned by minorities were in 1989-1990: Associate (7.4\%), Bachelor (7.1\%), Master (5.1\%), Doctor (3.6\%), and First Professional (9\%) (Oregon Research on Education, 1990). A review of college demographics for that state showed minorities to be 8.8\% of the total population. 
Minority representation in these statistics included Native-American, Asian and/or Pacific Islander, AfricanAmerican, and Hispanic-American. of these subgroups, the Asian and/or Pacific Islanders who represent $1.8 \%$ of the population account for the following percentages of degrees awarded to the minority student population: Associate (3.9\%), Bachelor (4.3\%), Master (2.7\%), Doctor (2.4\%), and First Professional (4.5\%) (Oregon Research on Education, 1990). African-American, Hispanic-American, and NativeAmerican representation in degrees earned remains an underachieved goal of a representative balance, while Asian and/or Pacific Islander graduates exceed a proportional representation. These figures make clear the need for making greater efforts to retain underrepresented minorities beyond initial access.

Postsecondary credentials are essential for entry into the mainstream workforce beyond the minimum wage service sector. More energy needs to be put into making success possible for more minority students.

As we move toward the year 2000 , almost everyone will need some form of post-high school education if he or she is to remain personally empowered, economically productive, and civically prepared. (Boyer, 1987, p. 276)

The subject of retention in the nation's colleges and universities extends to the general population, too. While not as problematic as for minorities, statistics for 
retention of all undergraduate students in a predominantly

white urban commuter institution show that

the percentages of those students who enter new from high school who graduate after $4,5,6$, and 7 years are very low. And the percentages we lose from this same group after one term and after one year appear high . . . And retention rates for students who have been admitted as part of the special admissions program suggest the university has most likely been irresponsible, perhaps even unethical in admitting them--retention has been at or near zero. (Task Group on Undergraduate Retention, 1990, p. 7)

However, problems for minority students are far more severe.

As we moved into the mid-1980s, it was becoming become increasingly clear that the promise inherent in the availability of education was not being realized for minorities. Although the number of minority high-school graduates continued to increase in the 1980s, we experienced a stabilization if not an outright decline in the percentage of some minorities attending colleges and universities. White enrollments increased at a pace not realized by minority groups. Blacks and Hispanic students sustained higher attrition rates, lower graduation rates, and generally were less successful academically. Black and Hispanic graduate students were at a premium. Black doctoral students were virtually nonexistent. (Eaton, 1991, p. 135)

Mingle (1987) and Mortenson (1991) examined the

progress toward full participation of minority students from the 1960 s to the present and found that, while the minority college-age population is increasing, there continues to be a decline in college completion rates for Blacks and Hispanics, particularly Mexican-Americans. The lack of progress suggests a pressing need for improving retention efforts aimed at minority students who began college with the intention to persist. 
Initial enrollment in college is only the first step toward full participation in the economic marketplace. Adjusting institution policies and practices requires the understanding of retention theories and their application to the needs of individual students, specific minority groups, and types of institutions. The present study is designed to augment existing quantitative research on the topic by examining the perspective of the students. It also considers the influences, as perceived by the students, within the college environment and society at large that contribute to a successful postsecondary experience.

statement of the Problem

Too few minority students are graduating from our nation's institutions of higher education. At the same time, the minority population is growing and the increasing disparity of degree attainment for minority and non-minority students is undermining attempts to diversify the professional work force. In teacher preparation programs, there is a need for greater numbers of minority educators to reflect, and who are able to serve, the racial and ethnic diversity of the student population. The necessity is clearly articulated by Donald Sands (cited in Middleton \& Mason, 1988), Vice Chancellor for Academic Affairs at the University of Kentucky.

As Americans, we live in a heterogeneous society. That I think, is the special strength of our 
country. This nation cannot prosper and may not survive, however, unless all groups, races, and cultures participate in its most important work-the education of its youth. Black children need Black teachers and they need white teachers. And so do white children. Teachers are the role models, the patterns of success, the images of respect. They are also the bridge to cultural understanding, which is so vital to whether or not such a diverse society as ours can endure. (p. vii)

\section{Purpose and Broad Research Questions}

The primary purpose of this study is to add data to the existing theory base regarding effective environments and programs that support nontraditional minority students, specifically African-American, Hispanic-American, and in the School of Education at the institution involved in this study, Asian-Americans, through degree completion.

Two questions are addressed in the study.

1. What are the experiences of a selected group of minority students, who attend a predominantly white urban institution, that have contributed to their persistence?

2. Do these students share common past and present institutional, environmental and personal experiences which have contributed to their success?

From a group of 25 minority students who were accepted into a special program designed to assist them with a number of required steps in attaining their degrees and teaching credentials, 12 students consented to be interviewed. The study explores, documents, and interprets information 
gathered from their reported experiences. They answered questions about how they were faring in and outside of the educational institution and what they understood to be influential in their persistence.

\section{Operational Definitions}

Certain words, which have been used with restricted meanings, are defined below.

Attrition: The voluntary withdrawal from a college prior to degree completion.

Minority: Ethnic groups statistically underrepresented in the college graduate population. These groups include African-American, Hispanic-American, and Native-American. In this study, Asian-Americans have been included, because they are underrepresented in the teaching profession in this urban city although not in the student population.

Nontraditional college student: A student who is

older than twenty-four, or does not live in a campus residence e.g., is a commuter, or is a part time student, or some combination of these factors; is not greatly influenced by the social environment of the institution; and is chiefly concerned with the institution's academic offerings (especially courses, certification, and degrees). (Bean \& Metzner, 1985, p. 489)

Special program: Instituted in 1988, the program is a cillaborative venture of an urban public school district, a community college, and a public urban university, to implement programs and policies designed to increase the 
numbers of historically underrepresented ethnic groups in the teaching profession.

Program member: For the purpose of this study, a student who meets a minimum grade point average (GPA) standard (2.5), has reached junior level standing or better, and is enrolled at the university full-time.

Retention: Continuous full-time enrollment culminating in degree completion.

Traditional college student: A residential college student, under 24, attending a four-year college or university on a full-time basis.

\section{Study Limitations}

Because the researcher is a member of the white majority and conducted the research on a minority student population, at first there were fears of the possibility of self-imposed censorship of the information volunteered by participants. Two strategies were used in the hope of offsetting this drawback: (a) an explanation of the study presented by the researcher to the student group at a scheduled program meeting, and (b) an introductory letter mailed from the program director and the researcher (Appendix A) explaining the study and encouraging participation.

Another possible limitation of the study is its lack of generalizability to other, particularly non-urban 
institutions and, due to the lack of demographic information on the students who did not participate, to the other students in the program. However, due to its exploratory nature, the study is not intended to prove or disprove an existing theory but only to further inform existing research on persistence by illuminating the subjective experience of a group of 12 minority students. 
CHAPTER II

REVIEW OF THE LITERATURE

Introduction

With the release in 1983 of the National Commission on Excellence in Education's report, A Nation At Risk, national awareness was drawn to the crisis described in chapter I. Now in its second decade, the focus on the plight of educational institutions continues but is magnified by decreasing revenues from local, state, and federal resources.

The growing disengagement of the country's minority population from undergraduate and graduate degree programs is drawing anxious attention in the 1990s. Increasingly colleges and universities are exploring and implementing programs designed to graduate appropriate proportions of minority students. Educators will have to respond to the crippling displacement with solutions that will empower this country's minority population through higher education.

Research on persistence/withdrawal behavior over the past 20 years provides salient information useful in developing strategies that could reverse current trends. To demonstrate the need for vigilance and to identify variables that influence retention and graduation, the literature 
review includes five areas: (a) models of traditional and nontraditional student attrition that attempt to account for why students leave college prior to degree completion, (b) institutional policies and practices related to student retention, (c) the minority experience at predominantly white postsecondary institutions, (d) the transfer function as a deterrent to the persistence of minority students who enter postsecondary education at the community college level, and (d) the use of qualitative research methods in student retention studies.

\section{Models of Retention/Attrition}

The theories and research findings discussed in this section support an underlying assumption that persistence/ withdrawal decisions are complex. Different types of students leave for different reasons. Some leave because they do not fit in, although fitting in depends on the actions of students and the institution (Hossler \& Bean, 1990). The models may be limited in facilitating understanding of this complex behavior when applied to specific minority students at specific educational institutions. Comprehensive studies of minority students may require an in-depth examination of factors influencing persistence/withdrawal decisions. Also, studies may need to consider the role institutions play in compensating for or integrating those factors which impact the decision. 
Tinto (1986) examined theories which account for behaviors which influence persistence/withdrawal decisions. The key theories he described include psychological, environmental/social, economical, organizational, and interactional. Psychological theories focus on individual actions and characteristics that determine success or failure in the completion of tasks associated with college life. Environmental/societal theories emphasize the impact of social and economic forces on the behavior of students involved in higher education and examine the external forces influencing retention or withdrawal. Economic theories concentrate on the financial aspects and tie retention to individual finances and available financial aid programs. organizational theories move the issues of retention beyond personal, societal, and economic forces to focus on institutional characteristics and influences on students' decisions to persist or withdraw. Interactional theories are concerned with a combination of individual and organizational characteristics.

The two most widely tested models of student retention include Tinto (1987) Student Integration Model for traditional college students, and Metzner and Bean (1987) Retention and Attrition model for nontraditional students. Both models incorporate an interactive perspective combining psychological, environmental, economic, and organizational variables. Similarities in the two models exist in the 
utilization of multiple variables that contribute to a student's decision to persist or depart an institution.

Differences pertaining to the type of student, traditional or nontraditional, show up in an array of influential variables considered by each model.

$$
\begin{gathered}
\text { Tinto's Student Integration } \\
\text { Model }
\end{gathered}
$$

In Tinto's (1987) student Integration Model influences that contribute to decisions to remain or withdraw from an academic system include: preentry variables, goals and commitments (intentions, goals, and institutional commitments), institutional experiences, personal/normative integration, and goals and external commitments.

The [Tinto's] theory asserts that, other factors being equal, the match between an individual's characteristics and those of the institution shape two underlying individual commitments, a commitment to completing college (goal commitment) and a commitment to his/her respective institution (institutional commitment). Accordingly, the higher the goal of college completion and/or the level of institutional commitment is, the greater the probability of persistence. (Cabrera, Castaneda, Nora, \& Hengstler, 1990, p. 2)

Tinto's (1987) theoretical model expands his initial (1975) theory by including intentions and environmental variables. The addition of these two variables was based on Van Gennep's (1960) work on rites of passage. Tinto (1988) proposed that attrition occurs when an individual's rites of passage are incomplete: 
These so-called rites of passage were referred to as the stages of separation, transition, and incorporation. Each stage serves to move individuals from youthful participation to full membership in adult society, providing, through the use of ceremony and ritual, for the orderly transmission of the beliefs and norms of the society to the next generation of adults and/or new members. (p. 440)

Tinto's (1987) expanded model of institutional

\section{departure:}

argues that individual departure from institutions can be viewed as arising out of a longitudinal process of interactions between an individual with given attributes, skills, and dispositions (intentions and commitments) and other members of the academic and social systems of the institution. The individual's experiences in those contexts, as indicated by his/her intellectual and social (personal) integration, continually modify those intentions and commitments. Positive experiences-that is, integrative ones--reinforce persistence through their impact upon heightened intentions and commitments both to the goal of college completion and to the institution in which the person finds him/herself. Negative or malintegrative experiences serve to weaken intentions and commitments, especially commitments to the institution, and thereby enhance the likelihood of leaving. (pp. 114-115)

A major limitation in Tinto's (1987) model is that it primarily reflects the lives of full-time traditional students attending residential colleges and universities. It is assumed that the academic and social environment of the college or university plays a significant part in the life of the student and serves to minimize exterral influences by the near total absorption in the college experience. 
Pascarella and Chapman (1983); Pascarella, Duby, and Iverson (1983); and Pascarella, Duby, Miller, and Rasher (1981) tested Tinto's (1975) model on students attending urban commuter institutions. In these settings, the social integration factors in the model were found to play less of a role in the students' decisions to persist or withdraw than at residential institutions. Reduced opportunities available to the commuter student for social interaction suggests that che less opportunities there are for social interaction, the greater the influence of background characteristics and academic integration.

The limited significance of social integration in comparison to academic integration for the non-traditional student was substantiated by Fox (1986). In his study, Tinto's student Integration Model was applied to a group of academically and socially disadvantaged students attending an urban, primarily non-residential university. The findings emphasized the importance of attention to the development of academic skills and behaviors to foster retention.

\section{Metzner and Bean's Model of student Attrition}

While a strong theoretical foundation has been laid for understanding attrition/persistence decisions, studies examining nontraditional students at commuter colleges and universities have expanded and altered Tinto's (1987) model 
to include a more diverse and representative student population. Metzner and Bean (1987) proposed a conceptual model of attrition for the nontraditional student, one who is defined as:

older than twenty-four, or does not live in a campus residence e.g., is a commuter, or is a part time student, or some combination of these factors; is not greatly influenced by the social environment of the institution; and is chiefly concerned with the institution's academic offerings (especially courses, certification, and degrees). (Bean \& Metzner, 1985, p. 489)

The definition encompasses an increasing percentage of older students currently enrolled to attend part-time who commute and whose representation in higher education is more often the rule rather than the exception. Due to the limited nature of their social interaction, the academic and environmental aspects of these students' postsecondary experiences outweigh the influence of campus social activities.

This model for nontraditional student attrition/ retention decisions is based on four sets of variables: (a) academic variables such as study habits, absenteeism, GPA, academic advising, other support systems, and course availability relative to the certainty of a major; (b) intent to leave as influenced by the psychological outcomes of satisfaction, goal commitment, and stress; (c) background and defining variables such as age, enrollment status, residence, educational goals, high school performance, ethnicity, and gender; and (d) environmental variables such 
as finances, hours of employment, and family

responsibilities.

Bean and Metzner (1985) found two compensatory effects

important to decision-making which result in attrition. The

first is environmental support.

For non-traditional students, environmental support compensates for weak academic support, but academic support will not compensate for weak environmental support. (p. 492)

The second effect on decision-making comes from the melding

of a student's academic outcome, GPA, and psychological

outcomes (utility, satisfaction, goal commitment, and stress) .

The nonacademic factors compensate for low levels of academic success, while high levels of academic achievement only result in continued attendance when accompanied by positive psychological outcomes from school. (p. 492)

Both Tinto's (1987) student interaction model and Metzner and Bean's (1987) nontraditional student attrition model aid comprehension of the process whereby a student decides to persist or withdraw from an institution of higher education. Both theories:

are correct in presuming that college persistence is the product of a complex set of interactions among personal and institutional factors, as well as in presuming that Intent to Persist is the outcome of the successful match between the student and the institution. (Cabrera, Castaneda, Nora, \& Hengstler, 1990, p. 20)

The existing models of student attrition may have limitations when applied to understanding the complex behavior of specific minority students at diverse 
educational institutions. Attinasi (1989) exposed the shortcomings of current student attrition models by noting that while they provide useful information on significant variables, they neglect to explore the context in which the student's decision to attend college was made.

Tierney (1992) also challenged existing theoretical models of student attrition, particularly Tinto's (1987) concept of college attendance as a rite of passage. Tierney argues that Tinto:

has misinterpreted the anthropological notions of ritual, and in doing so he has created a theoretical construct with practical implications that hold potentially harmful consequences for racial and ethnic minorities. (p. 603)

Using Native-American students as his sample, he argues that the college-going experience, this "rite of passage," is out of context from other cultural experiences and requires the student to separate from the culture, not advance to another stage as would a middle-class white student. This may set the aspiring student up for failure by forcing him to deny the known while embracing the unknown. He further calls attention to a necessity for reexamining the way attempts to solve minority retention problems are carried out. A new perspective may serve to reframe the issue to include an understanding of how the student perceives and interacts within and between varying social realities in a multicultural environment. He supports Attinasi's (1989) assumption that 
Yet, given the present level of our understanding of that decision, it is precisely those characteristics-the context of the decision and the student's perspective on the context--that investigators of student persistence in college must include. (p. 250)

Awareness and understanding of the insider's perspective may require an in-depth examination of the factors that influence persistence decisions as well as the role institutions can play in assisting students. The next section will discuss some of the studies of institutional policies and strategies which may contribute to the successful retention of minority students.

Institutional practices

Studies documenting the characteristics of postsecondary environments that are conducive to minority retention have found that any attempt to lower attrition rates requires recognition of certain factors. Policies and programs can be successful if their design is appropriate to institution needs, they involve the majority of staff and faculty, and they employ strategies that demonstrate an understanding of the unique needs of specific minority groups (Fox, 1986; Richardson \& Bender, 1985; Richardson, Simmons, \& de los Santos, 1987; wittstruck, Hess, \& stein, 1988). Strategies that were specific to the institution and its diverse minority population were a key factor in the success of retention programs at a variety of colleges and universities. 
Because the intention here is to focus on institutions seeking to diversify their student population, the studies reviewed will not include segregated schools. However, in view of the growing popularity of African-American colleges in the south and the increasing numbers of tribal colleges that successfully retain Native-American students, segregation is acknowledged as an option for particular minority groups.

For example, the retention rate for all students at Oglala Lakota College in South Dakota rose from 68 percent in the 1981 school year to 89 percent last year--far better than the general retention rate for Indian students. (Carnegie Foundation for the Advancement of Teaching, 1990, p. 30)

wittstruck, Hess, and Stein (1988) documented several types of programs and common strategies utilized by 33 states for increasing minority retention rates. Attention to the success of these strategies is useful for colleges and universities where traditional-age students and minority participation have declined.

The most commonly adopted were:

- collaborative programs between high schools and colleges emphasizing the academic preparation of high school students and their subsequent recruitment

- recruitment programs for undergraduate, graduate, and professional schools 
- comprehensive services designed to promote a positive learning environment for minority students

- preparatory programs that provide remediation or improve the academic preparation of high school graduates entering higher education

- recruiting programs targeted at hiring minority faculty and administrators

A federally funded study of 10 universities with records of awarding degrees to one or more of the three major underrepresented minority groups (Richardson, Simmons, \& de los Santos, 1987) provides examples of successes with minority retention. The indicators of successful retention efforts present at all institutions are listed below:

- A campus environment is recognized as a critical factor in student involvement and success.

- Deficient numbers of minority faculty members and limited involvement in equal opportunity strategies by all faculty members are problems recognized as urgently needing attention.

- There is visible evidence of the existence of administrative commitment.

- Strategies for promoting the success of minority students (in predominantly white institutions), or for promoting the success of all students (in multicultural institutions), are comprehensive 
and systematic rather than fragmented and sporadic.

- Compared to the other indicators, commitment and good educational practices of a university supported by a favorable state policy has yielded the most progress.

Although descriptions are available of intervention strategies utilized by educational institutions, little is documented regarding their effectiveness or longevity. What is known is that short-term programs are insufficient to reverse dismal retention rates for some minority groups. While aggressive marketing techniques are effective in drawing students to an educational institution, the results are often short-lived, because little forethought has gone into the long-term commitment necessary for significant change to occur in graduation statistics (Cohen, 1980; Mortenson, 1991).

Educational institutions aspiring to increase retention rates need to understand the different academic as well as the social needs of the minority population they seek to assist. While many students upon entry express an intent to succeed, they often suffer severe academic deficiencies that frustrate their efforts. Other barriers confronting the students' efforts are fragmentation of the curriculum and lack of close personal contact with faculty and advisors (Fox, 1986; Richardson \& Bender, 1985; Richardson, Simmons, 
\& de los Santos, 1987). Institutions need to ascertain whether the services they provide are suitable ones for carrying minority students through to degree completion. Tinto (1987) acknowledged the need for both institution and student to recognize the benefits of leaving when the fit and intention to persist is not in the best interests of either.

Concurrent with the attention to retaining minorities, the environment of tolerance for ethnic diversity on campuses across the nation is waning. Crossen (1987) summarized a study of the racial and ethnic environment for minorities on campuses across the country and found that

While we do not know the scope and depth of racist and discriminatory attitudes and behavior and we do not know enough about the effects of such incidents on the total campus academic and social environment, it is clear that predominantly white four-year colleges and universities have somehow failed to live up to their ideals as civil and tolerant social communities that respect diversity and pluralism. It is also clear that many minority students perceive predominantly white campuses to be hostile to their interests and needs. (pp. 3-4)

Hedegard (1971) and Smith (1989) found the same sense of disaffection for minority students in colleges and universities nationwide.

The consistent theme of alienation experienced by students of nontraditional backgrounds in their campus environment is symptomatic of a deep underlying problem that had not been adequately addressed. (Smith, 1989, p. 19)

Discriminatory practices in our nation, whether obvious or subtle, have not been extinguished. Current racial, 
ethnic, and class antagonisms are fueled not only by declining resources but by conflicts over integrated or segregated programs; tension created by opposing pulls toward assimilation on the one hand or cultural pluralism on the other; and reaction to sustained efforts of the colleges and universities to challenge centuries old discriminatory attitudes and practices (Magner, 1990; Preer, 1981; Wambalaba, 1989).

Essential to efforts to retain greater numbers of minorities is to acknowledge the existence of experiences and needs of the minority population that are distinct from those of the majority population. The data available, while somewhat incomplete, is expanding to include the perspective of the targeted minority groups. Familiarity with their point of view is recognized as important to retention efforts, if the rate of degrees completed is to increase. The next section examines a group of minority students' experiences and responses the academic and social climate found in postsecondary institutions.

\section{Minority student Experiences in Higher Education}

Research indicates minority students at predominantly white postsecondary institutions have different, and often less positive experiences from those of non-minority students. 
Trujillo (1986) studied classroom interactions between faculty and minority students compared to faculty and nonminority students. The findings indicated that white students were asked more complex questions by professors, were pushed to clarify their responses to professors' questions, and received greater amounts of time during the professors' responses to their questions. In addition, the instructors had lower expectations of undergraduate minority students compared with majority students. Zachary (1982) examined the attitude toward affirmative action of community college personnel. He found that faculty who came in direct contact with students favored affirmative action less; they expressed concerns about the competence of minority students.

In another study of faculty and student interactions, the contexts of learning for minority students was compared to that of majority students (Vasquez, 1988). The study discovered that a higher proportion of minority students define themselves as possessing an external as opposed to an internal locus of control.

Students with an external locus of control tend to view influences outside themselves as responsible for what happens in their lives and "tend to invoke such factors as luck or the lack thereof, ease or difficulty of the task, and the presence of some powerful others in their lives" (Vasquez, 1988, p. 247). An opposite cognitive process is 
seen in students who view themselves as having an internal locus of control, which results in feelings of personal responsibility for success or failure.

A student's perception of academic challenge is correlated with the view of self, which influences his or her academic achievement and personal-social behaviors. The findings show that while internals are no more or less intelligent than externals,

such traits as self reliance, expectancy of success, level of aspiration, achievement motivation, skills in taking tests, and responsiveness to reinforcement have all been identified as characteristics more of the internal than of the external student. (Vasquez, 1988, p. 247)

The characteristics of students possessing an external locus of control suggest they are more influenced by negative factors in the school environment and less at home in settings requiring self reliance and competition. When influenced by faculty who perceive and treat them as less capable, minority students possessing an external locus of control may experience a deterioration in their performance and self-esteem, which leads toward withdrawal from the college experience.

Awareness of faculty impressions and responses to the minority student population may be essential before institutions can begin to improve retention rates. A major feature of a predominantly white institution's success in graduating minority students is that "these universities 
expect minority students to attend, to achieve, and to graduate in the entire range of majors they offer" (Richardson, Simmons, \& de los Santos, 1987, p. 25).

Different perspectives are evident among Hispanic students and are directly related to that group's success in higher education. The term Hispanic is inclusive of a variety of ethnic backgrounds unique and distinct from one another. Recognition of the term's inclusiveness was all too often missed in the research reviewed.

In comparing Hispanic persisters to non-persisters Bennett and okinaka (1989) found persisters to be more satisfied with social relationships, better prepared academically, and to have a positive attitude toward instructors, social relationships, and their academic accomplishments. Also, persisters expressed a greater feeling of acceptance in the educational environment.

Duran (1986) found predictors of success among Hispanic students to be significantly distinct from non-Hispanic students. Predictors for non-Hispanics relied mainly on test scores and high school achievement, the most conventional indicators of college success, while determinants for Hispanic students were more complex and contrary to conventional determinants. For many of these students, success was influenced by such factors as language background, exposure to schooling in their native language, 
and the presence or lack of financial and other family obligations.

Olivas (1986) examined financial aid for Hispanic students and how this need related to success in completing college. The findings indicated that the majority of low income Hispanics received funding from only one source, mainly Pell grants that were seldom adequate to successfully complete a course of study. For these students, financial assistance from multiple funding sources, combined with work study, considerably improved the likelihood of low income Hispanics completing a degree.

Further confirmation of the various and complex components of the Hispanic experience was validated by studies of Chicano students (Cabrera, Castaneda, Nora, \& Hengstler, 1990; Nora, 1990). Their research results were consistent in finding that the ability to pay, family responsibility, and academic capabilities were key determinants in persistence.

Results of a retention study of 158 Chicano community college students (Nora, 1990) using Tinto's 1987 Student Attrition Model show that neither academic integration nor social integration affected retention rates for the subjects. Instead, institutional goal commitment was a major contributor to retention.

Chacon, Cohen, Camarena, Gonzalez, and Strover (1982) examined differences between persisters and non-persisters 
within Mexican-American males (Chicano) and Mexican-American females (Chicana). Distinct retention patterns became apparent for sub-groups among this student population group. The sub-groups less likely to complete their studies included students who worked over 20 hours per week; women, many single, with domestic responsibilities; and any who were experiencing academic difficulties. Chacon et al. (1982) also found the college a student chooses to attend makes a striking difference in completion rates, with those attending private college making better progress and those attending a community college making the least progress. At the community college:

Their progress through the college is much too slow; they take too many courses that are not transferable; they may go on for years without making significant progress in remediating underlying academic difficulties. (p. 99)

Chacon et al. maintained that:

Furthermore, we must move on from using the ethnic group as the unit of analysis and begin to break it down into different kinds of students who may experience very different kinds of problems as they interact with an institution. (p. 4)

The caution not to generalize experiences solely by ethnicity was supported by Lee (1985) who examined social class as a variable in studying retention. Lee found that for African Americans, Hispanic Americans, low socioeconomic status (SES) whites, and high SES whites, patterns of persistence with the college experience were found to be due more to social class than to racial or ethnic factors. 
However, Bennett and Okinaka (1989) and Bond, LeBold, and Thomas (1977) performed studies using race as the sole basis of distinction. They examined variables influencing African-American persisters when compared to non-persisters and discovered consistently recurring race based factors to be determinants of retention. Bond, LeBold, and Thomas found African-American engineering students more likely to persist and more achievement oriented. The students participated more often in professional activities and programs for their racial group, were experiencing success academically, and were provided with and involved in supportive programs.

Bennett and Okinaka (1989) found African-American persisters to be less favorable toward interracial dating, less comfortable in interpersonal multicultural situations, and more negative about multicultural relations in general than non-persisters. At the same time, the persisters felt more prepared academically and felt more positive about their instructors. Their negative perception of the quality of campus life was found to be characteristic of AsianAmerican persisters also. Bennett and Okinaka offered as an explanation that these attitudes may represent lower expectations for a harmonious racial climate. According to these results, some minority students, while feeling alienated from some aspects of the college environment, are satisfied academically and have adapted by bonding with 
students who share similar experiences on the predominantly white campuses.

The findings challenge some current positions on integrated programs and confirm that the controversy over the integration or segregation of minority students is ongoing. Whether students find support and encouragement when they stay closer to their own sub-group requires a deeper analysis of individual needs as well as an understanding of experiences supportive of persistence that are particular to integrated and segregated environments. Mingle (1987) stated his position in which he objects to the use of segregated programs as an institutional response to problems of retaining minority students in degree programs.

Institutional response to minority adjustment problems has nearly a 20 -year history. Marvin Peterson and other researchers, in a 1978 study of several institutions that rapidly increased their minority enrollments in the late 1960 s and early 1970s, identified what until recently has been the standard for institutional response: an array of special, and often separate, programs targeted at the minority problems. These included recruitment and admissions efforts, financial aid programs, academic support services, curricula responses (e.g., ethnic studies) and social and cultural programming. This special programming mirrored what the Peterson group observed in the social and intellectual life of the student community as well --an absence of meaningful integration. (p. 22)

The conflicting findings in the studies cited above regarding student satisfaction with integrated or segregated college environments demonstrate the difficulty institutions will have in retaining minority students, unless they 
conduct their own inquiries into their particular minority groups' requirements for successful completion of college. What may work for one group at a particular institution may have the opposite effect for another. It may inadvertently subvert an institution's retention efforts to make generalizations about student needs without involving the students.

When minority students who seek a baccalaureate degree gain access by starting at the community college level, successful transfer will depend upon the transfer policies and practices of institutions. But attention to the transfer function is often hindered by the rationing of resources among other essential services offered to nondegree seeking students. The difficulties in the transfer function at two-year institutions is examined in the following section.

The Transfer Process

The community college is an entry point in the higher education system for a majority of the nation's minority students (El-Khawas, Carter, \& Ottinger, 1988; Kinnick \& Kempner, 1988; Olivas, 1979; Snyder \& Hoffman, 1992). preparation for successful transfer into degree awarding four-year institutions is essential to an increase in minority graduation rates. Yet evidence exists of the decline of transfer rates (Dougherty, 1992; Grubb, 1991) and 
degree attainment for those starting at the community college who had intended to complete their baccalaureate degrees. For the nontraditional students, the prospect of completing a degree, is further hindered by delayed entry following high school (Kempner \& Kinnick, 1990). Community colleges provide diverse educational experiences including "preparation for transfer, preparation for job entry, literacy development, career upgrading, and personal interest activity" (Cohen, 1990, p. 1). Thus transfer is only one function of the community college. Its role in increasing minority graduation rates is of utmost importance, and yet the necessity to provide other services to non-degree students often hinders the institutions efforts to be more effective. Richardson and Bender (1987) describe this ongoing conflict over resource allocation.

The preoccupation with remediating from 60 to 95 percent of their entering students, along with the need to provide social services and to prepare their clientele for immediate employment, leaves community colleges with little energy and few resources to offer challenging transfer programs to those who enrolled with the ultimate intent of earning a baccalaureate degree. ( $p .3)$

The community college must have a high level of commitment to begin with, otherwise most of their efforts to retain minorities are bound to fail. Increased attention to effective collaboration with the four-year institution is essential to increasing the number of minority students who graduate and enter the professional workforce and/or advanced degree programs (Cohen \& Brawer, 1987; O'Banion, 
1989). A weak or diminished transfer function will only

further disadvantage minority students. Kinnick and Kempner (1988) articulated this concern for the growing numbers of community college students:

Eliminating the transfer role of the community college could serve to stratify further the current postsecondary system, effectively denying access to the bachelor's degree among those from whom the two-year institution has become the point of entry to college: minorities, particularly Hispanics; those from lower socio-economic backgrounds; those with less clear goals; and those for whom family and other circumstances dictate remaining in a geographic area in which a four-year institution is unavailable. (p. 315)

McGrath and Spear (1991) claimed:

successful transfer function depends less on what specific courses students take than on the strength of the classroom, on closeness of the fit between the academic culture of the community college and that of the university. (p. 40)

They also found a difference in the responses of students when they were questioned about the transfer process between a community college and university in a suburban community. In this type of community, course and program offerings and location were found to be the primary reasons for transferring. Secondary reasons included convenience of transferring, quality of instructors and availability of financial aid. The findings point to the necessity of coordinating transfer efforts between the community college and university by developing a profile of student needs and institutional resources from a holistic view of the educational process. 
Cohen and Brawer (1987) saw the transfer function as a complex issue within the community college defined within a context of student behavior, institutional and organizational behavior, and academic practices. The institution trying to improve its practices, according to Kempner (1990), can succeed if they infuse their efforts with a knowledge of the specific culture affected.

The faculty and administration need to understand how culture affects the ability of the faculty to teach and the opportunity for students to learn, especially those students who do not share the dominant culture. (p. 231)

Pascarella and Terenzini (1991) provided some recommendations and guidelines for institutions which are intent upon increasing the transfer rates. These include:

At two-year colleges, efforts would also probably involve more intensive remedial programs in reading, writing, mathematical, and general learning skills; more effective academic and personal support programs for transfer candidates; curricula and course offerings that would unequivocally satisfy four-year institutions' admissions and academic major requirements; and increased rigor in instruction and grading. At four-year colleges, easing the transition from two-year to four-year institutions and increasing the likelihood of degree completion would require simpler and more flexible admissions procedures, admissions criteria not limited to standardized test scores and prior academic performance records, greater flexibility in transfer credit policies and criteria (not standards), easier access to larger amounts and more varied forms of financial aid, more equitable opportunities for on-campus housing, and more sustained and aggressive academic and personal support programs, including remedial programs in basic academic skills. (pp. 643-644) 
Continued attention to student needs as well as to successful practices that enhance opportunity beyond access is essential for increasing the numbers of minority, and majority, traditional, and nontraditional graduates. Serious efforts of two-year and four-year institutions can pay off as transfer students continue to succeed.

The story of transfer has a happy ending. Most community college students who go on to the fouryear colleges and universities do quite well. There is an initial transfer shock, with the students' grade point averages generally dropping slightly in their first term after transfer, but most of them persist on to the baccalaureate, and, by the time they complete it, their records are little different from those who began at the senior institutions. (Cohen \& Brawer, 1987, pp. 100-101)

The research reviewed provides information on some influences and issues related to the role of the community college, a primary point of contact for minority students seeking a baccalaureate degree. This information is developed further by the inclusion of qualitative studies illuminating the student perspective.

\section{Retention from the student Perspective}

Two significant qualitative studies of retention/ attrition behavior from the student perspective are: Attinasi's (1989) on Mexican-American student experiences, and Neumann's (1985) on community college student experiences. Both studies explore the influences and 
behaviors that give rise to the decision to persist or withdraw from the college experience.

Attinasi (1989) reported on an exploratory study of the persistence/attrition decision from the perspective of the Mexican-American student. The study is based on two assumptions. The first is that persistence behavior is the consequence of a process in which the student is an active participant. The second is that persistence behavior is related to the manner in which the university becomes and remains, through everyday social interaction, a reality for the student. The data collection method used in the study consisted of a series of open ended interviews.

The interviews were in-depth modified "life history" interviews; the informants were encouraged to think back over their lives and recount experiences related to their own and others' college-going behavior. (pp. 252-253)

This method left the interviewer unconfined and unrestricted in the pursuit of any area of inquiry suggested by a response from the student. The student in turn was free to draw upon his or her own experience when responding to the questions. Such a method is distinct from the closed question or questionnaire approach, which limits the understanding of the phenomena by making assumptions that may not be considered by the student. Attinasi asserts the need to explore the student's perspective and avoid the limitations of collecting data from institutional records and questionnaires which "strip away the context surrounding 
the student's decision to persist or not to persist in college and exclude from consideration the students own perceptions of the process" (p. 250).

The study examined student behavior before enrolling and after enrolling in college. Two conceptual schemes for interpreting the college-going behavior of chicano university students emerged from the study. One of these schemes has applicability to behaviors and attitudes of the students prior to college matriculation, the other to behaviors and attitudes after matriculation. Each scheme was developed from a major organizing concept. For prematriculation experiences, the concept is "getting ready," for postmatriculation experiences, it is "getting in" (Attinasi, 1989, p. 255).

For the two categories, a chronological pattern emerged in the development of college going behaviors for this minority group. The "getting ready" scheme was manifested in students' initial expectations, fraternal modeling, mentor modeling, direct and indirect simulation focusing on expectations, and on-campus experiences prior to attendance. The "getting in" scheme was observed in the students' orientation to the physical geography, social geography, and academic and cognitive geography of the campus environment. Academic and cognitive geography included two additional events which led to the "getting in" scheme of college attendance. One was getting to know the layout and the 
other was scaling down based on expectations of the campus. The latter is a process of narrowing the geographies of the campus in order to enable the student to find a comfortable and negotiable place in the university environment.

Attinasi's (1989) findings regarding the MexicanAmerican student's decision to persist included the following: (a) background variables on persistence are mediated by significant-others influences, (b) the nature of anticipatory socialization for college-going has an influence not only on the decision to go to college, but once there, on the decision to stay, (c) the extent of social integration that influences persistence is not the extent to which it promotes the individual's moral conformity to the institution, but rather the extent to which it provides the individual with the capacity to cognitively manage the university environment, and (d) persistence at the university is positively related to the development and use of cognitive maps of the physical, social, and academic geographies.

Neumann (1985) interviewed students, exploring the behavior of a group of persisters and leavers who started their education at the community college. The major finding of the comparisons between the persisters and leavers is that the decision process is complicated by many factors. It is rather the result of a complex process involving the interaction of a number of individual and institutional characteristics which over time lead students to decide at different 
points either to persist in or to leave college. (p. 280)

The findings of this study are presented in terms of individual characteristics, behaviors, and responses to the academic environment, and the unique institutional effects of the college on the student's decision.

Neumann's (1985) student profiles revealed far more similarities in the two groups than differences. Some shared characteristics of the two groups included similar patterns of: (a) family background, (b) parental formal education and occupation, (c) attendance at public high school, (d) level of involvement and interest in high school, (e) level of involvement in extracurricular activities in high school, (f) level of awareness of higher education and the community college, (g) number of applications to other colleges, (h) reasons for attending the community college, (i) clarity concerning future academic goals, and (j) concerns about academic ability. These similarities existed at the beginning of the college careers with behavioral differences emerging as the students progressed through their programs. Some unique experiences of the persisters were that: (a) persisters did better academically from the start, (b) they formed peer support groups and relationships that were supportive of their academic pursuits, (c) they established positive relationships with faculty members, (d) they were involved with campus work-study jobs, and (e) they perceived the 
faculty to be interested in their progress. These positive experiences aided the transition the students made into their academic environment. Tinto (1987) described this transition period as an essential time for moving ahead and experiencing a level of comfort and completeness as a student.

Neumann (1985) described these early positive or negative stages as decisive in the experience of the students and found lack of involvement to be a factor in the weakening resolve of the leavers.

After getting off to a generally good start, persisters seem to have become increasingly involved with the academic and social life of their community college, while for leavers we see a clear pattern of decreasing involvement with their colleges. . . Leavers did not enjoy that same level of involvement as persisters and consequently had nothing to increase their interest in school or excite and raise their level of motivation. (pp. 299-300)

Neumann (1985) and Attinasi (1989) provided similar recommendations for improving retention rates including early and intensive assistance with academic skills and frequent and specific feedback from instructors, opportunities to become familiar with the layout of the campus, and ample opportunities for academic and social integration into the campus environment. They also made informed recommendations specific to the particular experiences and needs of the student research subjects. They found that persistence behaviors of the community college students could be increased by fostering greater 
student participation in the intellectual and social life of the college and attending to the development of a positive community college ethos for incoming students. Increased faculty-student contacts helped as well as promoting the formation of informal peer support groups characterized by a common academic orientation. For the Mexican-American students providing anticipatory socialization for collegegoing by involving home and school when the students were still in high school or younger was found to increase retention later in college. Extended stays and visits to the university were also found to have a positive effect on retention. College faculty involved in the design of curricula for college prep classes was another way of keeping students engaged and interested in college careers.

As evidenced by the various recommendations, the studies point to the value of understanding the experiences and needs of the targeted students in order to increase retention rates. In those local settings that have had a history of high attrition, a growing understanding of the conditions and circumstances of a student's complex decision-making will lead to stronger commitments to, and wiser strategies for, the support of incoming student subgroups as those groups endeavor to complete their college educations. 


\section{Summary of the Iiterature Review}

Educational opportunity that will reach beyond access is essential for increasing the graduation rates of minority students. Models designed to understand the complexities of student attrition serve as the basis for examining the psychological, environmental, economical, organizational and conflicting forces influencing a student's decision to withdraw or persist through degree completion. Numerous studies detail the variables that influence decisions to withdraw (Cabrera, Nora, \& Castaneda, 1992; Richardson \& Bender, 1987; Richardson, Simmons, \& de los Santos, 1987; Stage, 1990; Tinto, 1987), but we are missing sufficient data regarding why and under what conditions students persist.

Nontraditional students have different needs and expectations from traditional-age middle-class white students when they enter an educational environment (Fox, 1986; Grosset, 1991; Metzner \& Bean, 1987), and minority students often have differing experiences from non-minority students (Chacon et al., 1982; Hedegard, 1971; Hurtado, 1992; Lee, 1985; Nora, 1990; St. John, 1991; St. John \& Noell, 1989; Trujillo, 1986). Traditional institutional supports, policies and programs, may or may not be transferable to programs designed for minorities. It is incumbent upon each institution to learn the specific needs 
of students and not rely solely on replicating programs and policies designed to fit other groups. By building a data base informed by the students' perspectives institutions will be able to bring a more enlightened understanding to the design of practices that result in retaining minority populations at their campus sites.

Open-ended interviews of students who describe not only their experiences but the experiences' meaning can serve three distinct purposes. The first is to learn what influences support or hinder a successful higher education experience. The second is to provide an opportunity for students to share and validate their experiences by allowing the students to control. the direction and content of their responses. The third purpose is to broaden our understanding of how specific interactions, policies, and practices are interpreted and internalized by the individuals an institution is attempting tc attract.

A more thorough analysis and research that emphasizes the student perspective regarding issues of retention in all areas of higher education, baccalaureate to doctoral degrees, is needed in institutions seeking to improve the graduation rates for all students. Hodgkinson (1985)

stressed its importance.

The rapid increase in minorities among the youth population is here to stay. We need to make a major commitment, as educators, to see that all our students have the opportunity to perform academically at a high level. There will be barriers of color, language, culture, attitude 
that will be greater than we have faced before, as Spanish-speaking students are joined by those from Thailand and Vietnam. The task will not be to lower the standards but to increase the effort. To do so will be to the direct benefit of all Americans, as a new generation of people become a part of our fabric, adding the high level of energy and creativity that has always been characteristic of groups who are making their way in America. Their numbers are now so large that if they do not succeed, all of us will have diminished futures. That is the new reality. (p. 18)

\section{Summary: What we know and} What's Missing

Research on persistence/withdrawal behavior over the past 20 years provides a significant source for understanding the variables that influence student decisions. We know that the decision-making process rests on the following underlying assumptions: (a) the decision is a complex behavior, (b) decisions develop over time, (c) fitting in with an institution depends on both the students and the institution, and (d) different types of students leave different institutions for different reasons (Hossler \& Bean, 1990). The last assumption takes into consideration the need for understanding the specific nature and experiences of the student population an institution is seeking to serve. While research on retention has much to tell us about the significance of psychological, environmental, economic, and organizational variables, our knowledge of how students interpret and internalize their experiences is limited. 
According to Attinasi (1989) the models for examining attrition have only very modestly explained the dynamics of attrition decisions. Twenty-six tested variables in the Metzner and Bean (1987) model of Nontraditional student Attrition accounted for only $29 \%$ of the variance in intent to leave in a sample of 624 nontraditional freshman at a midwestern urban university. The ability to predict attrition has not been very high when quantitative studies with undifferentiated groups--notably groups of traditional students in their freshman year--have been used.

There is much we do not know about students' decisions to persist or withdraw from a college or university, especially those of particular sub-groups of a student population at a specific type of educational institution. The majority of research on persistence and withdrawal decisions considers the institutional perspective and does not account for the meaning of the college experience to the student. However, a limited number of qualitative studies of specific sub-populations provide insight into the complex nature of the decision to persist. Two important descriptive studies on influences that persuade minority and nontraditional students to persist or withdraw are Attinasi's (1989) study of Mexican Americans and Neumann's (1985) study of community college students. Both provide insight into the student perspective when confronted with the need to make a decision to remain in or leave college. 
Those studies further help to build a solid foundation for a comprehensive understanding of diverse minority and nontraditional student experiences in higher education. 


\section{CHAPTER III}

\section{METHODOLOGY}

\section{Research Questions}

Two research questions are addressed in this study.

1. What are the experiences of a selected group of minority students, who attend a predominantly white urban institution, that have contributed to their persistence?

2. Do these students share common past and present institutional, environmental, and personal experiences which contributed to their success?

Twelve minority students involved in a special triinstitutional program designed to assist them with a number of required steps in attaining their degrees and teaching credentials answered questions about how they were faring in and outside of the educational institution and what they understood to be influential in their persistence.

\section{Research Design}

The use of the qualitative approach for a more thorough understanding of the student experience with higher education is well supported (Attinasi, 1989; Hossler \& Bean, 1990; Kinnick \& Ricks, 1993; Terenzini \& Pascarella, 1991). The approach enables the researcher to explore the meaning 
drawn from an experience by those most closely associated with the experience. Attinasi's (1989) study of MexicanAmerican students stressed the importance of questionnaires that allowed the interviewer to probe beyond first responses to questions pertaining to persistence and withdrawal decisions. He recommended the use of qualitative studies that would correlate the questionnaire responses to students' decisions pertaining to college attendance. Kinnick and Ricks (1993) stated "Qualitative methods can provide an understanding of local intervening variables that taken together affect the nature and quality of the student's educational experience" (p. 68).

The characteristics of qualitative research methodology that have been employed in the present study include: the research is descriptive; the concern is with process rather than simply outcomes or products; data is analyzed inductively; and finally, the meaning drawn by the participants from their experiences is of foremost importance (Bogdan \& Biklen, 1982).

The primary focus of the research is on the student participants' perspectives, and it has attempted to understand the student participants' subjective experience, or personal interpretation, of their social interactions within the college experience. The researcher wanted to learn from the students themselves what and how influences and circumstances in their everyday life affected their 
decision to persist in college. From a sociological perspective this emphasis on subjective meaning is described as a "sociology of everyday life." Douglas, Adler, Adler, Fonyana, Freeman, and Kotarba (1980) presented one aspect of this viewpoint as:
All analysis of everyday life, of concrete interactions in concrete situations, begins with an analysis of the members' meaning. . . Members' meaning is used to refer to the feelings, perceptions, emotions, moods, thoughts, ideas, beliefs, values, and morals of the members society. In short "meaning" refers to the internal experience of the members that is most relevant to a particular social interaction. (p. 2)
Symbolic Interactionism is the component of the Sociology of Everyday Life that directs this research methodology. This theory "approaches the study of the social world from the concrete and tangible perspective of human beings and the everyday reality they perceive" (Douglas et al., p. 20).

The origin of symbolic interactionism emanates from the work of Mead (1982), a social behaviorist who laid the foundation for this theoretical construct as a way to study human society.

Generally speaking, things according to Mead are socially constructed, they are constructed from a series of events or happenings . . All things are social constructions, and if things constitute what is real for us then we have a basis for the sociology of knowledge claim that the real is a social construction. (p. 15)

The purpose of this study is to understand events and experiences that contribute to a student's persistence with 
higher education. Mead's (1982) description of the self as a process as opposed to self as a structure provided a framework for comprehending the merits of exposing the influences which form an individual's perspective on a topic we endeavor to comprehend. In asserting that the human being has a self, Mead simply meant that the human being is an object to himself (cited in Blumer, 1969, p. 62). The human being may perceive himself, have conceptions of himself, communicate with himself, and act toward himself. As these types of behaviors imply, the human being may become the object of his own action. This gives him the means of interacting with himself--addressing himself, responding to the address, and addressing himself anew. Such self-interaction takes the form of making indications to himself and meeting these indications by making further indications. In short, the possession of a self provides the human being with a mechanism of self-interaction with which to meet the world--a mechanism that is used in forming and guiding his conduct.

The concept of symbolic interaction, guided by the view of the self as process, sets the groundwork for understanding behaviors and experiences of individuals or groups of individuals without imposing preexisting impressions which can underestimate, or fail to perceive, the subjective meaning of a phenomena under study. 
Attinasi (1989) described the significance of exploring the context around decisions leading to college going behavior. While supporting existing models of student retention (Metzner \& Bean, 1987; Tinto, 1987) as substantiated methods to explain a student's decision to persist or withdraw from college he maintains:

- . the models have been developed on the basis of, and tested with, data collected from institutional records and/or by means of fixed choice questionnaires. These are methods of data collection that effectively strip away the context surrounding the student's decision to persist or not to persist in college and exclude from consideration the student's own perceptions of the process. (Attinasi, 1989, p. 250)

Three major guiding principals of symbolic interactionism expounded by Blumer (1969) which served to further substantiate this theoretical construct as an approach to the study of human behavior include:

1. Human beings act toward things on the basis of the meaning that the things have for them.

2. The meaning of such things is derived from, or arises out of, the social interaction that one has with one's fellows.

3. These meanings are handled in, and modified through, an interpretive process used by the person in dealing with the things he encounters. (p. 2)

The concept of symbolic interactionism supports the premise of examining society or human beings by going directly to the source for the information to inform the explanation of events. It is "an approach designed to yield 
verifiable knowledge of human group life and human conduct" (Blumer, 1969, p. 21).

Blumer (1969) noted that:

a cardinal principal of symbolic interactionism is that any empirically oriented scheme of human society, however derived, must respect the fact that in the first and last instances human society consists of people engaging in action. (p. 7)

Through an analysis of the meaning behind these interactions a deeper understanding of human behavior emerges.

Initiating a forum for students to describe factors influencing their persistence for a study on retention, engages the researcher in the process of understanding social reality from the students' personal perspective. In this study the conduct under examination is persistence with higher education and with what influences and interactions which supported the persistence. The intent of this study is to provide a overview of these experiences from those who understand them best.

In studies lutilizing this approach, there are two steps to the inquiry: exploration and inspection. In the first, exploration, students who had become familiar with the setting and other relevant aspects of higher education, were interviewed and asked to elaborate on their experiences and also on the personal meaning which they had drawn from those experiences. The interviews were transcribed, summarized, reviewed, and validated for accuracy by the interviewee. In the final stage of inquiry, the responses were inspected and 
grouped according to the questions asked during the focused interview in order to expose patterns, similarities, and differences in student experiences and perceptions (Douglas, et al., 1980). Patterns and emerging themes were identified and coded according to the broad variable included in each separate focused interview question and from a scrutiny of the substantive findings of the research.

\section{Setting and Background of} the Special Program

The program, a tri-institutional partnership between an urban public school district, a community college, and a university is designed to attract, prepare and retain minority persons in the education community to enter the teaching profession. It was created in response to an existing and increasing minority teacher shortage. Within this large urban population few minorities were being prepared to pursue careers in education. The result was a disproportionate number of minority teachers compared with minority students in the cooperating public school district.

A task force consisting of educators and administrators from the public school, the community college, and the university developed a plan to counteract the shortage. The program reached out to targeted groups of underrepresented minority students from middle school through students holding baccalaureate degrees, as well as to others who wished to make mid-Iife career changes. Expert, experienced 
minority and non-minority educators at the cooperating institutions were recruited for the program.

\section{organizational structure}

The program is administered through a full-time director, coordinators from each of the partner institutions, and a three-member executive committee representing the partner institutions. An advisory council of community, education, and business leaders provides input and direction for program development. Under this arrangement, the three person executive committee oversees project activities; the project director coordinates all activities and assists the institutions in carrying out the responsibilities to both the students and the overall project goals; and coordinators at each site work directly with program members (see Figure 1). Initial funding for the program was provided by the United States Department of Education, office of Postsecondary Education, and continued long-range funding is provided through each separate institution, private sources, professional education associations, governments grants, and minority organizations. 


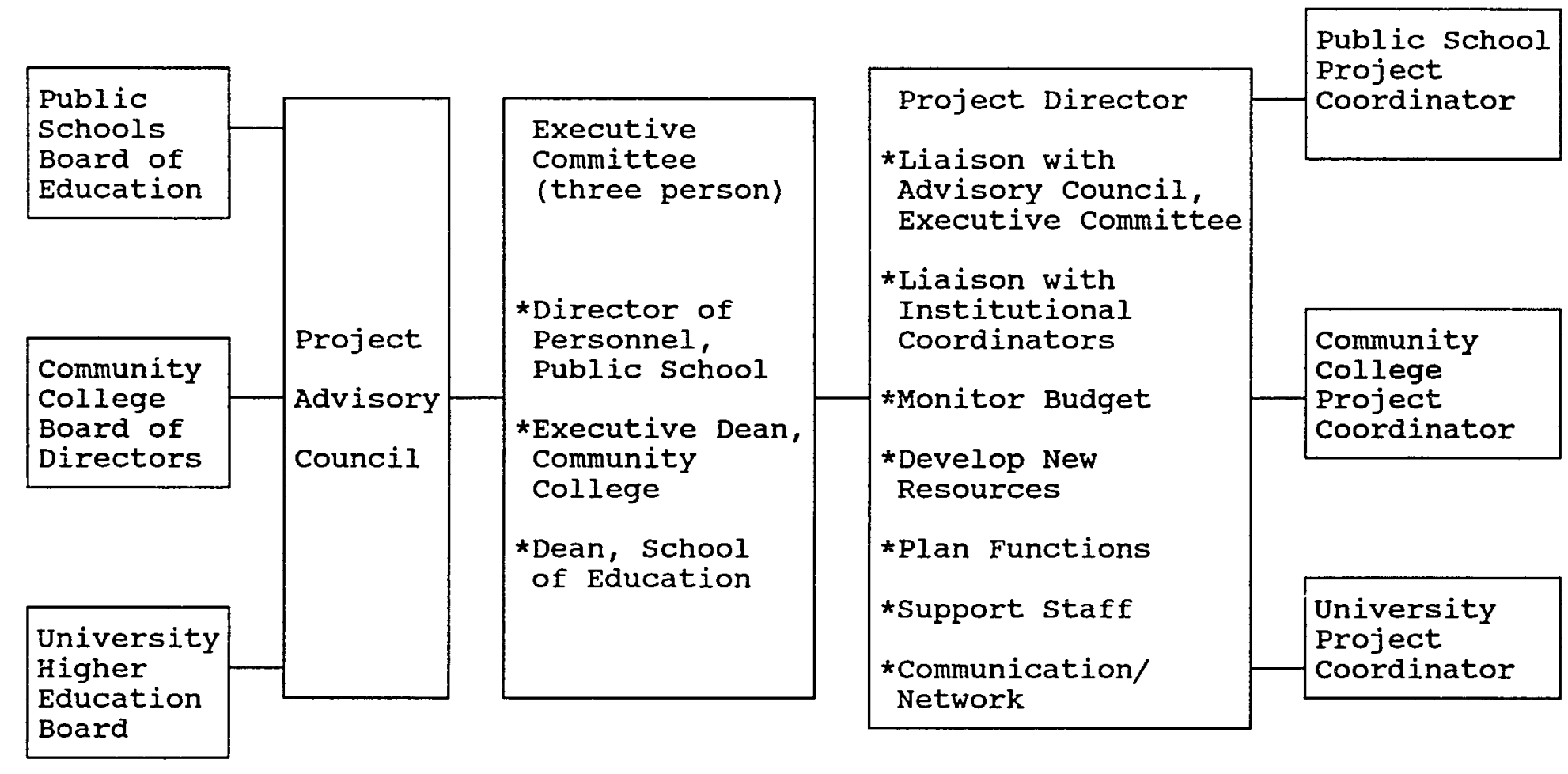

Fiqure 1. Tri-institutional collaboration organizational chart. 
Overview of the Program

Concern over the shortage of available minority teachers nationwide and the growing numbers of minority students attending our public schools provided the incentive to commit both time and resources to a long range plan to alleviate the shortage in this urban community. The overall plan includes strategies to encourage, train, and support a steady cohort of minority educators to train and work within the confines of this educational community.

The project commences in the middle schools through activities designed to build interest in education as a career and culminates with successful graduates given priority hiring consideration for assignments as teachers in the cooperating public school district.

Making the connection between the various stages of education through joint activities, workshops, and training institutes provides participants with the opportunity to form a connection to minority and non-minority educators in the community, and familiarizes them with the stages, procedures, and skills necessary to successfully complete their credentials for entry into the teaching profession. The program is ongoing. It began in 1989 and was set up to be carried out in four stages. The first stage, at the middle and high school levels, is school-based and introduces students to the idea of teaching as a career option. It also provides preparatory activities that will 
familiarize them with the college and university environment. Participants can be recommended for the program by faculty and community members, or they may join out of a personal interest. Parents of all students are encouraged to participate. At this stage a classroom teacher at the middle and high school levels is appointed as project coordinator at the school site.

The second stage of the program is carried out at the community college where students are provided career and personnel counseling, academic advising, tutorial services, tuition waivers, orientation, and field placement services to acquaint them with the teaching profession. Counselors assist them in selecting course-work that will transfer to a four-year degree program at the university. Students are recruited for participation in this level by faculty, counselors, and other interested community members.

The third stage at the university requires successful completion of a baccalaureate and/or the completion of the prerequisites for entrance into the fifth-year teacher training program. Those eligible are minority students attending school full-time who have completed all prerequisites for junior level courses with a cumulative grade point average of 2.5 for all lower division coursework.

In the fourth stage, the student may make application for acceptance into the fifth-year teacher training program. 
At this point, the student selection process is conducted by a committee of educators at the university who review a candidate's commitment to program goals, academic performance, and potential as a teacher. Other factors considered by the committee are the student's perspective on cultural diversity and any successful experiences he or she may have had in working with youth. Students enrolled in this level of the program receive academic and financial support, personal counselirg, and opportunities to participate in group activities that will sharpen their skills for a career in education. Possibly the most important feature is that a commitment has been made by the cooperating school district to give priority hiring consideration to successful graduates of the program.

\section{Sample}

The participants in the study were recruited from the student group of 25 who had been accepted into the special program at the university level. Twelve, or nearly 50\%, of them volunteered to be interviewed. of the remaining 13 , several initially agreed to be interviewed but due to scheduling difficulties, were unable to participate. All who took part in the study met the following criteria: (a) they had African, Asian, or Hispanic parentage; (b) they were eligible for junior level standing; (c) they had completed course prerequisites for junior level courses; 
they were enrolled as full-time students; and (e) they had a cumulative grade point average of 2.5 or better for all lower division work.

Participants were a heterogeneous group of minority students representing African-American (67\%), Asian-American (8\%) and Hispanic-American (25\%) cultures. Of the 12,9 were female, 3 were male, 3 had spent their formative years in foreign countries, and 50\% were responsible for the care of young children. The age range was between 24 and 52, with an average age of 36 . Four participants had graduated with a bachelor's degree prior to their membership in the program and then returned to the university to complete the requirements for teaching. Eight students began their college education at the community college. Of these, six were involved with components of the special program from the start of their college careers.

A limitation of the study includes the lack of survey information providing specific descriptive data on the students not participating in the interviews. Information on the non-participating students was provided by a program administrator and included estimated age, gender, race, and whether they commenced their higher education at the community college or the university. Of the 13 nonparticipants, 7 were in their mid-twenties, 2 in their thirties, 4 in the forties. Nine of the students were female and four were male. Ten of the non-participants were 
African-American, 2 were Hispanic-American and 1 was AsianAmerican. Six of these students began their education at the community college and were involved in the program prior to attending the university.

Out of the total 25 students, 12 were successfully interviewed, 4 attempted to do the interview, but canceled due to conflicting responsibilities related to school, and 9 did not respond to requests for participation. Participants and non-participants had similar descriptive indicators in the areas of gender, race, and whether they began their education at the community college (see Table 1).

Table 1

Comparison of Interview Participants vs. Non-participants

\begin{tabular}{|c|c|c|c|c|}
\hline & Age & Gender & *C. C. & $* *$ Race \\
\hline Participants & $\begin{array}{l}20 s-3 \\
30 s-5 \\
40 s-3 \\
50 s-1\end{array}$ & $\begin{array}{l}\text { Male - } 3 \\
\text { Female - } 9\end{array}$ & C.C. -8 & $\begin{array}{l}\text { Af.A. - } 8 \\
\text { H.A. - } 3 \\
\text { A.A. - } 1\end{array}$ \\
\hline $\begin{array}{l}\text { Non- } \\
\text { Participants }\end{array}$ & $\begin{array}{l}20 s-7 \\
30 s-2 \\
40 s-4\end{array}$ & $\begin{array}{l}\text { Male - } 4 \\
\text { Female - } 9\end{array}$ & c.C. -6 & $\begin{array}{l}\text { Af.A. }-10 \\
\text { H.A. }-2 \\
\text { A.A. - } 1\end{array}$ \\
\hline
\end{tabular}

*Started higher education at the community college; ${ }^{* *}$ Af. A. --African American; H.A.--HispanicAmerican; A.A.-Asian-American

The selection of interview participants was guided by two considerations: (a) participants had to qualify for junior academic standing at the university, and (b) they were to be members of the special program. In all other 
respects, the selection process was arbitrary, producing a sample of convenience. Those program members who agreed to be interviewed formed the sample. Representativeness was not essential in this sample because the focus of the study was to discover, rather than verify, key influences leading to a successful college experience.

\section{Instrument: The Focused Interview}

In this type of interview the participants are interviewed on one occasion for a period of one to two hours. During this time, the interview follows a certain set of questions pertaining to the topic being examined (Yin, 1989). The questions in the focused interview related to experiences and influences that led to the participants' decision to continue their studies. The questions also served to guide the researcher. The focused interview approach was used both to expedite the process and keep the interview relevant to the research topic.

Methods used to conduct the interviews were an interview guide (Appendix B) and face-to-face interviews that were allowed to be unstructured (Merton \& Kendall, 1945). Variables from the Metzner and Bean (1987) Conceptual Model of Nontraditional student Attrition and the Tinto (1987) Student Integration Model served as the starting point for developing the interview guide. Open- 
ended and non-directive questions were asked that allowed subjects to express themselves in their own words.

In this situation, the specific questions must be carefully worded, so that the investigator appears naive about the topic and allows the respondent to provide a fresh commentary about it; in contrast, if leading questions are asked, the corroboratory purpose of the interview will not be well served. (Yin, 1989, p. 89)

During the interview, participants were asked to talk about key influences in relation to pre-college experiences, personal commitment toward completion of a degree, social involvement with college, academic experiences, and environmental supports. Where applicable, students were asked to describe the transfer process from the community college to the university; their experiences as a minority on a predominantly white campus; any future challenges they foresaw and possible causes for delay; and finally the influence of the special program on their academic and career goals.

The final preparation for the focused interviews involved a pilot study to test the relevancy, clarity, and scope of questions in the interview guide. One program participant, an African-American woman, employed as a coordinator for the prograrn at the university, consented to participate in the pilot study and to provide feedback on the overall interview content and procedures. Following this initial interview, the questions were deemed relevant and inclusive, and the procedures regarded as conducive to a 
reliable inquiry into the students' experiences. Consequently, no changes to the focused interview questions or procedures for conducting the interviews were made.

\section{Procedures}

The program counselor at the university contacted all special program members by letter, introducing both the researcher and the study, and encouraging participation. Accompanying the letter was a brief description of the research program, a statement of its purpose, and information on how to contact the researcher if they wished to participate in the study. These letters were followed by an overview of the study presented at a regularly scheduled monthly program meeting. The meeting provided students with the opportunity to ask questions regarding the study and become familiar with the researcher.

All program members not responding to the initial request for participation in the study received a second letter. This letter was followed by a third request for participation approximately three weeks after the second solicitation. Each correspondence included a stamped addressed envelope and a form to fill in times available and to list a phone number where they could be contacted to arrange an interview. Students had a total of four requests, one in person and three by mail, to arrange an 
interview with considerable latitude in scheduling a convenient time to meet with the researcher.

Participation in the study was voluntary and no compensation was provided to the students. The interviews were scheduled for approximately one hour, with many lasting up to two hours. At the time of the interview, students signed an informed consent for the interview and filled out a brief questionnaire which solicited demographic data, pertaining to their age; gender; marital status; number of children; and education attainment of parents, siblings, and spouse.

The private interviews took place in a room in one of the campus buildings. Each student was informed ahead of time that, with his or her permission, the interview would be taped. No one expressed any objection. Following introductions and informal talk, the interview began.

The focused interview guide provided probes into the broad areas of interest to the study. These probes left it up to the participant to pick a starting point relevant to his/her own life. For example, when asked to talk about pre-college experiences, several reflected on their families and their elementary education, while others spoke about their first college or work experience. 
Analysis

All interviews were transcribed by an independent transcriber who had no affiliation with the university or any of the students. The transcription and tapes were reviewed simultaneously by the researcher to check for accuracy.

The interviews were summarized in order of the 10 categories in the interview guide, including relevant and significant quotes. Each summarized interview opened with a brief description of the student followed by one significant quote selected by the researcher. The summaries were organized in chronological order with the participants earliest experiences and influences first and future challenges last. Individual summaries were mailed to participants, providing them the chance to validate and discuss the results. All students were provided with an opportunity to call or meet the researcher at the university to discuss the results. Respondent review of the interview drafts provided construct validity to the study (Yin, 1989). only one participant contacted the researcher to correct one statement concerning age. However, informal contacts with five participants on the campus provided the researcher an opportunity for feedback. Overall respondents described their feelings about the results as very positive and the experience rewarding. One student commented that she was surprised that the interview had brought out her 
negative feelings, and it had helped her to recognize them and make some necessary changes in her work situation.

Following the verification of accuracy, the responses to each question from the interview guide were charted along with the participants code name and descriptive data. Each response was classified and sorted in order of the 10 categories covered in the focused interview guide and according to the chronological order of influences affecting persistence. In this manner, interview responses were tabulated according to the number of participants who indicated certain factors as contributing to their persistence. These in turn were closely examined for common themes and/or individual patterns. 
CHAPTER IV

THE INTERVIEW RESULTS

Introduction to the Findings

This chapter seeks to answer two research questions. First, what are the experiences of a selected group of minority students, who attend a predominantly white urban institution, that have contributed to their persistence? And second, do these students share common past and present institutional, environmental, and personal experiences which contributed to their success? The two areas of interest are examined in light of interviews conducted with student participants in the special program.

The first research question is answered through a review of participant responses to the 10 focused interview questions. Participants were questioned about the influences that had contributed to their persistence during their pre-college experience. They were asked what purposes they had in completing college and what goals they had set. other questions drew information about their social involvement, academic experiences, environmental supports, the transfer process, and experiences as a minority on a predominantly white campus. They were asked to talk about 
how the special program has influenced their lives and what challenges they saw in their futures.

The second research question is answered by a description of the common themes that emerged from the interview responses and the identification of critical success factors associated with the common themes.

Data pertaining to age; gender; ethnicity; marital status; number of children; and parents, siblings, and spouse's level of education were collected on a written survey prior to the start of the interview (see Table 2). of the 12 students interviewed, 9 are female and 3 are male. They represent African-American, Hispanic-American, and Asian-American minority groups, and have an average age of 36. Nine are first generation and three are second generation college students. Of the nine first generation students, six have siblings and/or spouses who have attended college. The other three are the first and only members of their immediate family to attend college.

The community college was the entry point for eight of the participants. of the remaining four, three completed baccalaureates at universities in Midwestern or East Coast states prior to enrolling at the study university, and one completed her undergraduate work at the same university where she is now preparing for a teaching degree. 
Table 2

Demographic Data from Participants in the study

\begin{tabular}{|c|c|c|c|c|c|c|c|c|}
\hline Name & Age & Gender & $\begin{array}{l}\text { Ethnicity } \\
\end{array}$ & $\begin{array}{l}\text { Marital } \\
\text { Status }\end{array}$ & $\begin{array}{l}\text { \# of } \\
\text { Children }\end{array}$ & $\begin{array}{l}\text { Parents } \\
\text { Level of } \\
\text { Ed. }\end{array}$ & $\begin{array}{l}\text { Siblings } \\
\text { Level of } \\
\text { Ed. }\end{array}$ & $\begin{array}{l}\text { Spouse } \\
\text { Level of } \\
\text { Ed.** }\end{array}$ \\
\hline Mary & 52 & Female & Af.A. & Divorced & 6 & Some H.S. & H.S. & H.S. \\
\hline Lenore & 36 & Female & Af.A. & Single & 2 & Elem & H.S. & \\
\hline Latitia & 31 & Female & Af.A. & Single & 1 & H.S. & College & \\
\hline Pauline & 30 & Female & Af.A. & Single & 0 & H.S. & & \\
\hline Naomi & 24 & Female & Af.A. & Single & 0 & Ph.D. & College & \\
\hline Francine & 24 & Female & Af.A. & Married & 0 & College & College & College \\
\hline Martha & 47 & Female & H.A & Married & 2 & H.S. & College & College \\
\hline Juanita & 42 & Female & H.A. & Single & 0 & Elem & H.S. & College \\
\hline Maria & 37 & Female & H.A. & Married & 2 & H.S. & College & College \\
\hline James & 46 & Male & Af.A. & Married & 1 & Elem & H.S. & College \\
\hline Michael & 32 & Male & Af.A. & Married & 2 & Elem/H.S. & H.S. & Post Grad \\
\hline Bon Nghe & 28 & Male & A.A. & Single & 0 & College & College & \\
\hline
\end{tabular}

Af.A. - African-American; H.A. - Hispanic-American; A.A. - Asian-American **Ircludes significant other. 
The interview summaries are attached as Appendix $c$. They are included so that other researchers will have access to the data base used in this study. Those interested in retention or persistence data from the student point of view can use the material for purposes of making comparisons or to extend their own studies of diverse students at various higher education institutions.

\section{Findings}

Question 1: What in your pre-college background influenced and supported you to attend college? In their responses, students reflected back on their elementary school years; or on high school years when they had first thought about college as a possibility for themselves; and to their earliest experiences with higher education.

Parental expectation combined with good academic preparation were described as influential in the lives of three students who went on to college immediately after high school. Support and encouragement available to the students when they first made inquiries about college were also seen as very helpful. The community college, which eight participants had attended, provided the most assistance with getting students on track.

A student who completed college after emigrating from the West Indies recalled no parental support, but she did describe the positive treatment she had experienced early in 
school coupled with her personal desire to get a degree, as a combination that had been largely responsible for her present commitment.

In the household these days you are always telling your kids, oK, you've got to go to college. I never heard that in my mother's house. Never! I think probably by reading and dreaming, this is where a lot of it [desire for an education] has come from. (36-year-old African-American woman)

Four students, who shared a goal of making a mid-life career change, joined the special program after completing their baccalaureates. The reports of three of them varied little in describing the initial support they received in early years. They recalled that their families had expected them to attend college and just always had known the students would accomplish completion of a degree program. These students remembered being treated as bright and talented children, and three recalled having their feelings of competence reinforced by both home and school. Only one recalled no support from home; instead, encouragement had come from teachers and other community members. In her view, her lack of support at home stood in contrast to her own personal determination. On her own initiative, she had gathered a support system of friends and faculty members at the college campus she had attended. All students from this group found niches for themselves in the university setting by working part-time on campus. And they all reported feeling heartened by their connection to other students who shared their determination to achieve a degree. 
Several students had not held college graduation as an expectation until they had direct experience with the reality of today's restricted employment opportunities. These students had an age range of 31 to 46 and had spent from 6 to 18 years in the workforce. They recalled no encouragement to attend college in their early years either from the home, community, or school. However, when they were ready to make changes in their educational status and began to make inquiries about college, their decision to attend and stay was influenced by the support, encouragement, and direction made available to them.

Even students who maintained good grades in high school had often received no encouragement or support to attend college. One student, who had maintained a $4.0 \mathrm{GPA}$, enrolled at a community college, selected a course of study, and was able to find a full-time job to finance his education all without any assistance from his high school counselors. Then he dropped out at the end of his first college semester.

If someone's parents were involved with planning how to reach their goals, then they were pretty much in the right direction. But if you were doing it yourself, you didn't know what questions to ask. I think that when you don't know where you want to go, it's difficult. If you don't have anybody to ask that's knowledgeable to tell you, "why don't you take some entrance exams and see where you stand?" I was a 4.0 student. There is no reason why I couldn't have gotten a scholarship to go to college. I didn't know about these things. (32-year-old African-American man) 
Two of the male participants, both African-American, had enlisted in the military and, upon completion of their service, had gone to work for major corporations in the private sector. Both men later found themselves jobless after long terms of employment. In the recession of the 1980s, they found their job opportunities severely limited because of the cutbacks and restructuring of work forces carried out in major corporations. When their attempts to find new jobs met with failure, and they returned to college, neither received much support from their immediate families. One went through a divorce mainly as a result of his lack of employment and subsequent return to school.

One traditional college-age student, whose parents were both college graduates, described a combination of influences that included her family and her awareness of the dire circumstances of friends or other community members who did not pursue an education as preparation for a career.

In the community you see people that don't have anything. They don't have good jobs and they are on drugs or whatever. They are denied a lot of opportunities because they are not educated. That has influenced me. (24-year-old African-American woman)

An African-American woman, in her early fifties at the time of this study, had begun to aspire to a college education years earlier when her children were small. She had attended college-related classes made available through extension programs. Her initial success with those studies encouraged her to give college a try. When she was in her 
early thirties and all six of her children were in school, she enrolled full-time, but that first college experience did not go well. Faced with the burden of work, family, and feeling estranged in a group of students who were quite a bit younger than she, she eventually quit. Nearly 20 years later the director of the special program, who was familiar with her work with students, encouraged her go back to school and get her credentials for teaching. She followed the advice, and this time, with fewer parental responsibilities and a better academic and counseling support system, her efforts have been successful.

For many of the students who started at the community college, it was a counselor or instructor who provided the essential support and academic assistance to set them on a rewarding course of study that would in the end yield a baccalaureate degree. Support was available at a critical time: when they were ready to make a change in their lives. Many of those students started school with only a vague sense of what they could or wanted to do. They needed those who could show them new possibilities for opportunity in the work world; they needed help in planning their studies in preparation for new careers.

Those who joined the special program at the community college level were stimulated by the enthusiastic reception and skillful assistance they received from faculty and administrators when they first went back to school. For 
these students encouragement to go to college had been missing from their early years, but when it came later in life it was powerful. Friends or other community members, co-workers, and counselors at the community college often became supporters and were instrumental in bringing about a decision to go on to a degree program.

Encouragement from home and school appear very important to college attendance, regardless of the age or family circumstance of student. Encouragement and support combined with practical assistance is effective, especially when a person is experiencing a significant life situation change.

Question 2: Tell me about your reasons for starting or going back to college and the goals you have for yourself. Prior to acceptance into the special program all members were expected to consider and clearly articulate career goals, including an expressed commitment to pursue a career in education on a full-time basis. To be eligible to continue with the program and receive tuition waivers, they were expected to maintain a minimum cumulative GPA of 2.5 . Selection into the program was competitive. The articulation of goals was an important step in a student's process of clarifying his or her purpose in attending college and the level of commitment that would be needed. A first generation student, whose first attempt at college had 
resulted in him leaving after one term described his lack of goals and feeling of uncertainty at the time.

For a long time I didn't have any goals, I didn't have any counselors to aid me. It was pretty much hit and miss. I had no direction. (46-year-old African-American man)

Perhaps because they had already reviewed, discussed, and clarified their career goals before being accepted into the program, participants' answers to the question about their reasons for completing college elicited personal and specific rather than general or vague responses.

The reasons for going to college included the desire for a sense of personal achievement and increased selfconfidence, and to be a role model for family and others in the community. The main goal of all students was to be prepared for a career they perceived as one in which they could grow and that would provide them with opportunities for advancement.

The majority of African-American participants, male and female, expressed the desire to be a role model for their families and communities, but such a desire was not at all expressed by other represented minority groups. First generation college students hoped for a successful college experience, thus making it a feasible option for others in their family.

Actually, I'm the first person in my immediate family to go to college. It makes a difference, to show the family that we can do it. My father didn't get past the sixth grade, so it's something to prove to the family, hey, it's possible to do. 
Then the younger generation can follow. (32-yearold African-American man)

I have six kids altogether, five graduated from high school and are working. I have one daughter who graduated from college and is now trying to get into law school. Out of the other five, three of them are thinking about going back to school. They think that if Mom can do it, so can they. (52-year-old African-American woman)

Nearly all the women expressed a belief that college would boost self-confidence. Some expressed college attendance as a long held desire and they saw the opportunity to pursue their goal with assistance from the program as a very worthwhile experience.

I feel I deserve it. I have worked very hard to be part of the program and to become a teacher. I know that I am capable of doing it. I am doing it for me. I don't think I could have done it and stayed focused for anyone else. (31-year-old African-American woman)

Their personal reasons for college attendance and their expressed goal of preparing themselves for work which they perceived as valuable crossed boundaries of age, gender, race, and educational attainment of parents. However, some minor differences among the students was evident. Students with siblings and/or spouses who attended college described their goals and commitments not only in light of how a college education could expand their opportunities for career advancement but also as it would confer upon them greater credibility and authority in their social groups and communities. 
Students with parents who were college graduates

expressed their desires to be taken seriously in today's

workforce, to work in an academic environment, and to be in

the company of people they perceived to be accepting of

diversity.

Among the students who had been in the labor market for

a lengthy period, the recognition of the increasing

limitations on job opportunities beyond the minimum wage

level was an overwhelming influence to complete their

degrees. One student's attempts to secure employment had

been repeatedly met with frustration. His long-term work

experience acted as a deterrent to potential employers who

might be able to offer him a new career away from the

business sector.

I was speaking to a recruiter at a job fair held

at the community college. She looked at my resume

and told me, "You have supervised people that will

be supervising you at that level." I asked her if

she had ever been unemployed since she entered the

workforce. She said "no." I said, unemployment

can be whatever percent in the city, in the state, or in the nation, but when you're unemployed it's

$100 \%$. I also indicated to her that I realized

that I was not going to come in at the salary I

left, nor the position. I don't mind coming in at

an entry level because I know I have the skills,

the work habits, the attitude, the tenacity to

persevere, but I can't do that if I'm on the

outside. She said, "I don't think you'll be

happy." (47-year-old African-American man)

The students expressed both personal and utilitarian

values toward completing their degrees. They saw that the

nature of the workforce was changing and the need for

college credentials increasing. The realization that 
without a degree they would always have trouble competing came at different times for the students. But they all understood. A few had been prepared for the reality by their parents, and the majority came to understand only after many years of working. All participants came to recognize the importance of having a combination of self confidence, advanced knowledge, and skills in order to enter the professional workforce.

Question 3: Tell me about some aspect of your social involvement with college that you feel has influenced your decision to persist? Except for two African-American women of traditional college age, social connection of the students to college activities and events was minimal. of the two women, one dropped out of college her first year as a result of having given too much attention to the social aspect of college life. The second described her social connection to other students of color and her involvement in multicultural activities as essential to her persistence.

Anyone of color, I would talk to, as far as a person to reach out to for information. My first year here I could say there were less than 20 entering freshman that I knew. You have to find someone that you can relate to. If you don't have a support system you won't be here very long. (24-year-old African-American woman)

However, affiliation with program related events, another criteria for program membership, was important. often it was the only social connection a student had at the university. The regularly scheduled monthly meetings and 
colloquiums further provided members the opportunity to become acquainted with administrators and professors and allowed them to become familiar with the support services available to students.

We had colloquiums where we'd get together and you'd see middle school students and they'd see you; it was really important. When I was in high school, we never met people who were going to college or thinking of going; it wasn't goal oriented. You'd see people and could say, they did it--I could do it. (32-year-old AfricanAmerican man)

The opportunity to drop by the counselor's office to talk informally was welcomed by the students. They felt if any problems or concerns, personal or academic, came up they had someone on campus readily available to assist them. As one 31-year-old African-American woman said, "there is security in knowing that I can contact someone if I need them."

Several felt more time to meet informally and discuss their college experiences without the imposition of an agenda and presence of program administrators, could improve the social connection among the program students.

Because these students had responsibilities to family and work, the possibility for a range of social activities was limited. As one student said when asked about her social connection to college, "Do I have a life? Basically no, I don't. As a matter of fact, I leave this college, go to work from 5 to 9 and come back here till the library closes" (31-year-old African-American woman). 
The one Asian-American student expressed a strong sense of isolation from people who spoke English. The language barrier he faced, even though he had been in this country for nearly 15 years, had isolated him from activities he might have otherwise participated in.

I didn't speak much even for the whole high school to when I graduated from college. I didn't speak much and I was shy to raise my hand and ask questions. If I had any questions I asked the professor. I was embarrassed to ask in front of the class. (28-year-old Asian-American man)

For these students, particularly those working, contact with other students took place mainly in the classroom. other than the monthly program meetings, forming friendships or even alliances with other students who might be going through similar experiences was left entirely up to the individual and to chance.

Question 4: Tell me about the financial supports you have in place to assist you with full-time attendance? Consideration of financial arrangements necessary to attend college full-time worried all the students. Their tuition, provided they stayed enrolled full-time, was paid by the special program, but adequate funds for living expenses and other extraneous school-related expenses required students to work and rely on family members to help out.

of the 12 students, 2 worked full-time and 9 part-time. The one student not working had saved some money from prior years of full-time work and was living with a parent. That arrangement enabled her to attend full-time. "I wouldn't be 
able to go to school full-time and keep up my grades. I've been out of school for over 20 years and everything slows down by then" (42-year-old Hispanic-American woman).

The two working full-time were both at the postbachelor degree level. Both felt obliged to readjust their work load shortly after joining the program, so that they would be able to keep up with their studies. Working fulltime had become oppressive. On the other hand, the students working part-time had job arrangements that were comfortable for them. Those working on campus were the most pleased with their schedules and had the most support for their studies from co-workers. But they realized adjustment would have to be made to make it through their final year when student teaching would be required.

Seven students received financial support from their spouses or significant others. Of the remaining students, one was a male and the other a single-parent female with two young children. Both were without families to fall back on, and both had a difficult time making ends meet.

The majority were concerned about incurring debts that they might not be able to repay if they were to finance their education through loans. Budget cutting by the cooperating school district was threatening the priority hiring status the students otherwise would have expected to be granted upon graduation. Two students who completed their baccalaureates by financing them solely through loans 
were worried that they might not be able to pay them back on schedule.

I want to say one thing about loans that many students take out because they need them. I'll tell you, I made up my mind that I was not going to get into debt. I have seen my nephews get into debt and the trouble they had. The availability of jobs when you are finished is so limited. I'd rather just not go. When I got my first loan, I had a year before I had to pay it back, but at that time there were a lot more jobs available than now. (42-year-old Hispanic-American woman)

As members of the program, all students were granted tuition waivers and all had at least two sources of income to cover their other costs. Those working part-time in supportive environments, on or off campus, were most pleased with their situation. Those working full-time were experiencing the greatest amount of stress and were simultaneously having the most problems with course-work. Finding alternative sources of income was on everyone's mind. One student suggested that the university might be able to help students by searching out scholarships for them.

There should be some consideration for those of us coming into the program with experience. If not, hook us up to a service that (we) can use to search for scholarship money. If the program can't do that, at least pay the fee for an agency to do a search and get the information back to us. Then we can apply for them [scholarships]. By myself, there's not the time to go and do the extensive research I need. (46-year-old AfricanAmerican man)

For those students with children to care for and no families to fall back on, financing college was especially 
difficult. They thought the sacrifice was well worth the effort, as long as there was the possibility of being considered for employment at the conclusion of the program. Only one student expressed concern that his efforts might not materialize into the job for which he had prepared. "I'm afraid that once you try to achieve a goal [teaching credentials], you won't have the opportunity to use it" (28year-old Asian-American man).

Question 5: Tell me about influences and supports from your family, friends, and work environment that encourage your persistence?

I think if you meet someone who is in college, it's easier for them to push you or for you to push them to continue the program. If you meet someone out of school then you really don't have much of a support system. A lot of people that started school with me did not graduate, for different reasons. But I think that meeting the people that I did the first year was very instrumental in my continuing with school. (24year-old African-American woman)

Family members, co-workers, friends, administrators, professors, and counselors in the immediate surroundings were environmental supports for the students, providing much needed encouragement for them to complete their degrees. The support they gave included an encouraging word, helping with an assignment or housework, and financial support. Professors, counselors, parents, spouses, significant others, co-workers, and peers who shared similar goals also were important to the students' persistence. "I think what has helped keep me on track is first, motivation from 
within, and second, supportive people to help me" (42-yearold Hispanic-American woman).

All participants mentioned program related support, such as academic and personal counseling and financial aid, as influential in their success. Only two women, an African-American and a Hispanic-American, said that those supports did not make a significant contribution to their resolve to continue their studies. While not essential to their persistence, they acknowledged that for some other program members, these supports made the difference between success and failure.

Counselors and professors were mentioned as the second most significant influence in the academic environment. Many were of great help in bolstering students' confidence to proceed in what was often perceived as alien territory.

The course structure you can get from a book. It was more their [professors] warm presence that made me feel special. They made me keep on wanting to impress them. (24-year-old AfricanAmerican woman)

Those students who started their college careers at the community college felt they had established rapport in their relationships with instructors and counselors.

The people that are involved, that have helped me and guided me through taking classes and what not, have been a tremendous help. For me, I saw this as a way to get back into the labor force. Unfortunately, my wife didn't and the support has not been there as one needed it. The people at the community college were like a family to me because they were genuinely interested. (46-yearold African-American man) 
All attributed a relaxed environment to the size and intimate nature of the community college. Professors and counselors who encouraged students to consider a career in teaching had the most noteworthy influence on those who had returned to college for the sake of increasing their opportunities or making a career changes. When the students demonstrated an interest in pursuing such a course of action, the financial and academic support that was forthcoming became an added incentive.

Students felt satisfied and developed a sense of confidence and pride when they were being treated respectfully and receiving encouragement from those who knew them or believed in their potential. On the other hand, when they were confronted with administrators and professors who had little regard for them or time to listen to their problems, the effect could be devastating. The student often interpreted such treatment as stemming from a belief that he or she was less worthy of attention and not good enough to succeed.

Assigned advisers did not fare well as supporters of persistence either. Several students met with them only when it was absolutely necessary. Many sought out other faculty members who were recommended by the program administrators or fellow students to assist them with academic problems.

I should go more often to see my adviser, but it's making the time. You hear horror stories about 
them, so you're kind of hesitant. Does he really know what he is talking about? Sorry to say that, I'm sure there are some good advisers. (42-yearold Hispanic-American woman)

When a spouse or significant other took over the family responsibilities for the women with children, the stress they were under eased, and they were freed to apply themselves to studies and work. With the support of a working spouse, the men also experienced partial relief from the stressful burden of total financial responsibility for the family. But the picture was not as tranquil for others. When a student's significant other had discouraged their entrance into college, the couple underwent difficulties that resulted in divorce. "Most of my help comes from my husband. He is a tremendous support to me. Financially I cannot complain because everything has been there for me" (47-year-old Hispanic-American woman).

Working on campus or in an off-campus setting with other students was described as a positive and supportive experience. "It was a neat environment, everyone at the workplace understands what it means to be a student and that classes come first" (31-year-old African-American woman). One student described his employers as at first very supportive, providing him with a flexible work schedule to fit in the necessary time for classes. However, the accommodation did not last and eventually he felt constrained to quit. He then found part-time employment on campus, a situation that pleased him. 
With the exception of the two students working fulltime and one not working at all, students managed to balance work and school. Only one described a conflict between his family's expectations and his post graduate studies. The family attributed his lack of significant employment to too much education. "They would expect me to go to college for a bachelor's degree and that's enough. They don't want me to study too much" (28-year-old Asian-American man).

For participants who came into the program with a vision of a college degree becoming reality, each had some individual(s) who had encouraged their dream. That they had received such encouragement was unrelated to the education level reached by their family. Seven students said they had considerable support and encouragement in their home environment. Those who went to college directly from high school described their informal expectation that they would go. College, for them, was something they always knew they would do. For those first generation students with no home encouragement, a combination of self determination and meeting supportive professionals at the college, were vital ingredients in their success. Those students who had no parental or other family support relied on friendships they developed with other students at the college.

Question 6: How are things going academically for you and have there been any classes that have significantly influenced your persistence? This group of participating 
students had demonstrated academic potential, a criteria for their acceptance into the program. At the time of the present study all had maintained a minimum GPA of 2.5 , and consequently none faced major academic barriers. Those who were struggling with some subject were able to access tutorial services to assist them with their coursework. When students were asked about their most influential classes, the majority described their personal feeling concerning multicultural classes, particularly Black studies. They recognized, too, that many in this society do not hold similar values toward these classes.

She [the professor] was intense. She gave all her knowledge and energy to the class. She was dedicated and she let you speak your piece. Her tests were intense, all essay. After leaving that class, I felt like I could take any history class. A lot of the faculty were against her being female and teaching African-American multiculturalism. This is not well liked in certain places. A lot of people think it's immaterial, but I think it is very important. (32-year-old African-American man)

They described the sense of empowerment and confidence the classes gave then as they were striving to understand themselves and their experiences as minorities in this country. Many had the experience in common of being asked to provide answers and clarifications to African-American issues. Their ability to contribute to the academic discourse on minority issues by responding from a historical perspective elevated their self-esteem. "A lot of times you're the only Black person in class. You're expected to 
represent your people, and represent them well. You're expected to know everything about Black history" (31-yearold African-American woman). "They [multicultural studies] were a very positive experience. I had all As and was able to reproduce and use the information from the class" (24year-old African-American woman).

As a woman of color, to be able to respond to and deal with racism in an assertive manner is important. It has helped me discipline myself in terms of wanting to study and have the facts easily accessible. (24-year-old African-American woman)

One student was struggling to maintain a sense of confidence. In one of her classes she had been unable to articulate her lack of preparedness to the professor, and it didn't occur to her that she might solve her quandary by making an appropriate change to a different class. She was very discouraged and suffered mental stress from her feelings of failure. Because of the episode, she questioned her competency and ability to complete the degree program as planned. Too late she found that there was a prerequisite introductory course to the troublesome class.

The program gives you two years at the community college and two years at the university. It would have made my year at the university a lot easier if I had went ahead and stayed that extra year at the community college and taken the lower division courses. (52-year-old African-American woman)

Academic supports, available to all students attending the university, are essential to persistence and are especially so for students who cannot arrange study groups 
with other members of the class. For several students, the absence of familiar academic supports was a key factor in their withdrawal from college during their first try. "I had a tough time. There was nobody to talk to, nobody to get help from. I just withdrew and stopped going. I thought it would be easier to work" (31-year-old AfricanAmerican woman).

one student advises incoming minority freshman to be aware that they must take personal responsibility for getting the information they feel they need in order to succeed.

Be prepared to be ignored. At the college level you are basically on your own. You can request a tutor in different subjects and there are support services, but basically be prepared to work hard and be prepared to find out a lot of things. People don't come up and tell you. You have to go looking for information and ask. (24-year-old African-American woman)

Academic success provided the students with the confidence to continue their studies. A support structure, whether formal, as in the tutoring services, or informal, as in study groups, was important for the students. Multicultural studies, particularly important to AfricanAmerican students, supplied the information the students would need when called upon to respond to racial issues raised in classes or other groups at the predominantly white campus.

Question 7: Describe your experiences with transferring from the community college to the university? 
Eight participants transferred from the community college to the university. Six found the transfer a smooth process and made the change with little difficulty. For two there was an initial shock, but through assistance from the special program, they managed to meet the challenge and ease themselves into their new university environment. of the students who found the transition smooth, four were geographically and logistically familiar with the campus, because they had taken classes prior to their membership in the program, or they had friends or family members who attended the university.

I didn't have a hard time. I heard comments about other students really being intimidated. My sister used to be here years earlier and I used to come and pick her up. I think that helped. (42year-old Hispanic-American woman)

When I transferred it was a smooth transition. I didn't have any problems and I didn't have any horror stories like some students have. One snag was with financial aid, but it was taken care of right away. (46-year-old African-American man)

One student was concerned about her ability to meet academic requirements had been offered a place in the program in the hope that her fears would be alleviated. Because she was very apprehensive about her ability to successfully transfer, she was given an opportunity to attend a six-week transitional program at a private university. The experience increased her confidence in being able to successfully complete university level coursework. 
For those having a rough transition, the size of the campus was a major cause of distress. After the close, comfortable, and familiar environment of the community college, their lack of familiarity with the landscape, layout, and people troubled them. "You know, I was afraid I was going to get lost in transit" (31-year-old AfricanAmerican woman). "Here at the university it's a lot bigger and people and schedules are busier. You have to make appointments so they [professors] are harder to get to" (52year-old African-American woman).

Five transfer students cited the orientation process, program meetings, pre-registration, and familiarity with program administrators and students as helpful influences to their successful transition. Academic support at the university, although available, was less utilized at first, mainly due to a lack of familiarity with the tutors. The insensitivity and lack of concern on the part of professors was another unsettling aspect of the university experience. In view of the many students that professors are charged with, the majority of students has concluded that such an attitude could not always be helped.

Unfortunately, I have come to the conclusion that here at a four-year institution the professors have a lot of their own work to do, and they leave most of the class work in the hands of the students. Many in a good way with a jot of guidance. Some of them leave it up to the students with almost no help at all. That, I don't think, is the best way for students. (47year-old Hispanic-American woman) 
Some students did not make a transfer but made a transition from undergraduate to graduate studies. Finding it difficult to get information on their own, they found the program helpful in clarifying the graduate school application process. A connection to a knowledgeable and sympathetic adviser within the department was often invaluable. The adviser usually could enlighten them at those times when they had received conflicting information from other sources.

Question 8: From your own experience how would you describe the racial climate on campus? The term racism was first introduced into the interview responses by the student subjects. It has been adopted for use also in the text of this study to mean a belief that different physical characteristics inherent in a race render it inferior to the majority race.

A student who had served in the military described racism as a given in any situation where there are only a few people of minority races present. While the majority of participants acknowledged the existence of some interracial discomfort, the few who did not respond appeared to be too uncomfortable to discuss the issue with the researcher. Nearly all students in this study had experienced integrated environments when they attended elementary and high schools or at their work or in the military. One student described an African-American friend's experience of 
coming to the university having had only very limited experience in integrated settings. She left, because she could not tolerate her discomfort in integrated groups.

students who spent their formative years in a foreign country did not describe personal problems with racial tensions, but did acknowledge their awareness of its presence in this country. One student attributed her more easygoing attitude toward racism to being raised in a society where she was not a minority.

In terms of my classes, it has been great. In terms of minority versus majority, often I have been the only one. Sometimes there may be two or three of us, but because of the background I came from [West Indies], we never focused on that [race]. So it has been easier for me. (36-yearold African-American woman)

The younger African-American women and one HispanicAmerican woman described how racism has affected their lives and reported that issues of race relations were largely ignored on the campus. They felt that unless the problems of accepting minority students on a predominantly white campus were openly confronted, they would only escalate. Some of the women considered it their personal and collective responsibility to challenge and respond to racism.

They [white men] just seem so scared and angry with me all the time. Racism is visible and the professors see it. There's a few white women in the classes, but they never say anything. I don't know if they're afraid of not getting a date or what they're afraid of. They don't say a word. (24-year-old African-American woman) 
We [minorities] have to know a lot more about how to maneuver in this environment than any of the faculty or administrators. We have to be aware of our feelings and our cultural differences. What I'm saying is on a day-to-day basis. Those people have nothing kicking them in the butt to know about us, whereas we have to know all the maneuvering or our files get lost or we just get swept under the rug. (37-year-old HispanicAmerican woman)

one student felt it should be a priority of the special program to help members to develop their skills in constructively handling issues of race relations. As future teachers they will be required to associate with a broad spectrum of society and will need to know how to develop strategies for counteracting racism.

Prior experience in an integrated environment and an understanding of the history of minorities in this country were important determinants to the success of minority students in the predominantly white institution. These two elements in a student's background left the student with confidence to cope with and challenge a racist environment.

Question 9: Tell me how your involvement with the special program has contributed to your persistence? The program has played a central role in the persistence of this group of students by providing structure, tuition waivers, academic support, connection to knowledgeable professors and administrators, advising, and early registration. Affirmation of self worth, confidence in their ability to achieve, and connection to other students of color became both reward and motivator for further persistence. The 
participants commended the program for making it possible for them to work toward their degrees on a full-time basis. "One thing the program does offer is support, and I think that's why a lot of people you have been interviewing have been successful" (31-year-old African-American woman). "The opportunity was here when I came. I believe in God, and I believe in fate. When I came here, I was in the right place at the right time" (36-year-old African-American woman). "Meeting people who come from the same or similar backgrounds, who share the same goals, and who support each other makes a difference" (42-year-old Hispanic-American woman). "I always thought, yes, I'm going to be a professional, but it never really crystallized in my mind as to how that was going to happen until I got into the program" (24-year-old African-American woman).

When students described the application process an indirect effect of the program was highlighted. Their experience of having administrators, counselors, and instructors affirm their potential increased their sense of worth. Because members were required to clarify their personal goals and commitment and articulate them to a review committee, they were then able to plan a realistic strategy for attaining their college degree. The process reinforced their belief in the possibility and probability of success.

It was such a big pat on the back, telling me "You are really worth it." I always knew that 
eventually I was going to do it, but I never knew how. Being accepted into [the program] clarified the how and provided the support and encouragement. I was told, "We think that you are very important, we think that you'll be good for the [program]." It was a real boost. (24-yearold African-American woman)

In a program whose members' ages and levels of education were varied, participants learned to assess their future prospects and understand the kinds of students they would eventually teach. Program meetings involving a varied age range in the field of education, middle school through minority professionals, gave the students a view of the interdependent relationships of the people engaged in the educational process.

We had colloquiums where we'd get together and you'd see middle school students and they'd see you. It was really important. When I was in high school, we never met people who were going to college or thinking of going. It wasn't goal oriented. You would see people and could say, they did it, I could do it. (32-year-old AfricanAmerican man)

More than one technique was necessary to inform students and make the program available to a diverse group of minority students. Four students learned of the program from their counselors at the community college after they had initiated first steps in application to the university, three learned of the program at their employment site, two responded to an advertisement in an ethnic newspaper, and the remaining three were informed of the program by community members and acquaintances. 
The program promoted minority inclusion in careers in the field of education. Students described the implied component of leadership in the area of race relations and multicultural perspectives as an expectation held for them in their future role as educators. One student felt not enough instruction was provided for participants to confidently fill this role.

What's missing is head-hand-heart support for students in the [program]. They are expected to be leaders not only in the field of teaching, but in the community as well. This is an expectation set by themselves and the program. But, we are not provided the necessary tools to deal with racism that exists in the daily environment, and what we will meet as teachers. For example, how to deal with racism among children, our colleagues, and parents. (37-year-old HispanicAmerican woman)

Not all students felt such an absence of support. For the most part, the program was central to their success. It made a complicated and confusing educational process more accessible by furnishing appropriate supports. And finally, the prospect of having their years of study rewarded by being placed on priority hiring status with the cooperating public school district made all their efforts seem worthwhile.

Question 10: Tell me about the challenges and possible delays you see ahead for yourself? The challenges perceived by the students were varied and included combining school, work, and family responsibilities; successfully completing 
the program; then going on to be accepted in a predominantly white profession.

Two African-American students described their concern with fitting into a career that was dominated by white professionals. While they felt they would be able to meet the requirements of their professional positions, they worried about the more subtle barriers they might face.

The only major challenge I'm trying to figure out right now is in terms of trying to change the structure. How many minorities are in the teaching profession? What worries me is at the end of the program, will I be accepted as a minority in a profession dominated by whites, will I be given a chance and given help? (36-year-old African-American woman)

I'm not going in with the idea that when I get there they'll have to take me because I'm a Black male. I want them to take me because I'm a good teacher, that's the only reason, not because I'm male and Black. (32-year-old African-American man).

The women with young children were bothered by fatigue and worried about their capacity to combine work with raising their family. This was true even for those who had spouses or significant others who worked and shared the household chores. One student, who was getting married and planning on having children, was apprehensive about the time commitment she would have to make while still finding time to attend to her home life. "The major challenge is the fatigue and being able to continue to push myself and being able to fit it [school] with all these other important things" (31 year-old African-American woman). 
The perceived possible causes for delay were unanimously health related. If the students, their children, or spouses were to become ill, they would have to withdraw either to recover or care for an ill family member. or if the spouse could no longer support the family, they would be forced to find alternate work.

other challenges mentioned by the students included fears of not being accepted into the advanced coursework in the teacher training program, not being able to sustain the self-discipline necessary to finish, and then not finding a job when they had completed school.

\section{Common Themes}

A group of themes emerged which serves to expand our understanding of the dynamics of experiential influence on student resolve: positive experiences in pre-college education; influences from family members, other community members, college or university staff and faculty; and the economic problems of financing basic living without a college degree, or college expenses without the presence and/or assistance of spouse or family are all powerful in their effect on student commitment.

Commonalties are identifiable in the influences coming from institutional, environmental, and personal experiences. Some of the students had had similar influential experiences at some time earlier in their lives. Others had similar 
experiences in the kinds of support received while they were attending the university.

By institutional influences is meant the policies and practices of an institution that are carried out by its personnel in responding to student needs. Environmental influences refer to the combination or interaction of economic and social forces on behavior that the students themselves have little control over but that either directly or indirectly affect them. Personal influences are those characteristics and traits of the students and of their families that foster the student's persistence in the pursuit of goals.

\section{Institutional Influences}

What an institution does to support and encourage a student matters to his or her progress in college. This includes pre-college through degree completion. The students interviewed stressed the importance of academic preparation as a factor in success. Seven of the students felt academically prepared to attend college through a combination of good grades stressed in the home and a challenging curriculum at the high school level. Those less sure of their capabilities were confident that the academic support available at the college would be sufficient to assist them in keeping up with demanding college courses. However, having good grades did not always lead to a recommendation to attend college. Often, the systematic and 
direct support starting with the application process to locating funding sources and support to go on to college was not available.

The students who had progressed through the higher education system with relative ease and confidence had grown up believing in their abilities and knowing they would eventually attend college. For one of the students, college was not within the experience of her immediate family and so was never mentioned. However, her teachers in early years, recognizing her ability, had given her responsibilities and provided experiences that built her confidence. Later, when she was living away from her nuclear family, she was able to pursue her education on her own initiative.

of the eight students who began their education at the community college, only two said they had heard talk about college during their early elementary or high school experiences. The remaining six recalled no mention of college as a possibility for them. Three of these students started college independently of their families, selecting courses and finding the financial aid or jobs they needed. All three dropped out the first year. One joined the military, and two went to work. One student was a dropout from a four-year residential college, and one resumed her college education after years of work, transferring credits she had earned from previous studies. 
It was at the community college and then through their acceptance into the special program that this group of students was able to undertake courses of study that would make a degree and a career in education a reality. The students who had a history of strong support from home and school were able to negotiate the community college without too much assistance. Yet the warmth of the reception they received was more than just a welcome addition to their efforts; it well may have forestalled the level of discouragement that had led to previous failures.

How students are treated by all affiliated with the university, from receptionists to professors, matters to the well-being of students and to their concomitant efficiency. Interaction of college personnel with students plays an important part in building a sense of belonging to the institution.

Lack of minority faculty can be a drawback for minority students. The availability of someone the students perceive to be understanding of them is too often missing at predominantly white institutions.

I don't know what to say about faculty, that's definitely a problem. If there were minority faculty and a young person of color was having a problem, they could go to this person and say, "I really don't understand what's going on, can you tell me something?" They would have a resource. There is a tendency for minorities to go to minorities for help because you figure that is the only person who is going to listen to you. (24 year-old African-American woman) 
The links between the university and the community college that eased the transfer process for the students made continuation in the program more manageable for them. Six called attention to those links as having been important. But students had different needs in relation to the transfer. One of the students was fearful that she wasn't prepared for the change. She was directed to a sixweek summer session at a private four-year institution so that she could adjust to the demands of upper division coursework.

The minority students benefited from having assistance with registration and being introduced to faculty and staff. Meeting with other students on campus also provided them with a network for the exchange of information on classes and professors.

Multicultural studies courses played an important role for several of the African-American students. They were able to contribute confidently to a dialogue on race, because they had learned to place their experiences within a historical framework. That seemed particularly important for the students as potential teachers, role models, and spokespersons for today's diverse elementary and high school students.

A work situation that accommodated the student's hours in an environment with supportive co-workers and bosses was a valuable adjunct to persistence. The students most 
comfortable with their work arrangement mentioned both the hours and the people. Those whose work was unrelated to education and at a location outside the educational institution were less satisfied.

Financial supports provided by the institution were important but not deciding factors for all students. The students' level of need for finances varied depending on individual circumstances, such as the size of their prior savings and outside offers of financial help from a spouse or significant other or family. Those students who were independent and working toward a degree to increase employment opportunities were having the most difficult time. For students needing to spend additional time in tutoring sessions, the more hours they worked the more stress and discouragement they underwent. If a student wanted to complete college without taking on the burden of a job, their individual situations, requiring different amounts of money, warranted a variety of strategies. Familiarity with college aided persistence. Once enrolled and pursuing a course of study, opportunities to participate in multicultural studies, find jobs in supportive work environments, and obtain individualized financial support all became important institutional influences in determining persistence. 


\section{Environmental Influences}

Social environments have borne the brunt of an economic stratification that has failed to serve integration. Instead, people have been polarized according to their economic status. Such a division by class often keeps minorities segregated.

Students' experiences in integrated environments sharpened their abilities to deal with day-to-day occurrences of different treatment based on their race, and they could then place those events in a more objective framework. All of the students had had prior experiences in integrated environments, whether in elementary or high school, military or work environments. Those students who spent their formative years in foreign countries seemed the least concerned with issues of race. One African-American man described an acquaintance who had a very difficult time in integrated environments because he had had so little experience. He in turn described his own understanding of racism. It was to be expected, he said, in any situation where the majority of people were white. Understanding this fact made dealing with recurring incidents of racism less burdensome for him.

The experience of having tried to earn money without a college degree and discovering the extent to which job choices are limited was another major influence. The majority of these students understood the bleak economic 
prospects they would face if they had no postsecondary education, and it strengthened their determination to persist. The students who were in the workforce were well aware of its changing nature and the increasing disparities in the pay of workers who have an education from those who have not.

All of the students recognized that there were no guarantees that a good paying job would be forthcoming following their completion of a degree. However, many knew from the experience of losing their jobs and being stuck in low paying positions, that their employment opportunities would be improved when they completed school. For those already holding a degree, the prospect of being trained for a teaching position was a very attractive career option.

The students harbored no illusions about today's economic climate. They saw the program as an opportunity for them to move up the economic ladder. Students in their late thirties or older felt their credibility in the workplace and the community would be augmented if they held a college degree.

Experience with group behaviors in integrated environments fostered courage in the students, while an understanding of the changing nature of the workforce and the attendant need for advanced training drove students to persist. Fear of a struggle to survive economically loomed 
in their minds whenever they contemplated job hunting without benefit of a college degree.

\section{Personal Influences}

on a personal level, the role played by family, friends, and community members together with personal experiences, goals, and aspirations combine to nourish a student's commitment to persist with college.

Encouragement to pursue an education and a career was present throughout only a few of the students' elementary and high school years. However, at some point in all of their lives, someone had encouraged and supported their desire to go back to school, often when the students were ready to make a major life change. Events that triggered such changes were failure to find work in one's initial career choice, being discontented with one's job, being laid off from work, being on welfare, or being freed of restricting family responsibilities.

The common experience of these students was that assistance, support, and encouragement in their early school years was absent. While some students had assistance from parents and friends, only one, the Asian-American, described his high school adviser as assisting him with every aspect of the process, including a search for financial aid. This was true even in the case of an Hispanic-American woman who attended an academy for academically gifted and college bound students. 
For one student in her fifties the encouragement of the program director, persuaded her to return to school, for another encouragement came from a community member active in the educational community, and still another received support from a counselor who met with the student when a return to college was first considered. At some time in their lives, others were encouraged to go to school by their parents, teachers, siblings, or spouses. Most important, for these nontraditional students, the support came when they were ready to make a change in their lives and able to accommodate the demanding tasks of college classes.

Those with parents, siblings and or spouses who attended college were more assured of their ability and required less assistance with the application process. For the first generation students--that is, those who were the first in their families to go to college--assistance with the application process and securing financial aid followed by continued academic support were essential features in their determination.

Those least familiar with the college experience needed the most help and support through the process. When this assistance was not found in their immediate environment, some made major adjustments in their lives, which in one instance included divorce. In all cases the students had the capability to complete degrees, and somewhere along the 
line, their desire converged with the opportunity and support needed to carry them forward in their quest. Common themes which came to light from an examination of the interview responses showed that these students were encouraged and supported in their pursuit of a degree by spouses, parents, counselors, instructors, and/or coworkers. For some, encouragement started in their early years, for others, in mid-life when they were exploring new career options. Some students were acting on an inherent and long held aspiration toward self improvement. Others in the prime of life blamed their dead-end economic situations on the lack of a degree. Still others wanted to become role models who would generate an expectation of a college education within their families. All of the students were aware of the increasing necessity of a college degree as an entree into the mainstream workforce beyond the minimum wage service sector.

A variety of events affected student success in the program. Family support helped some to make it through in the traditional four-year period of time plus the fifth training year. One returned for training in order to reenter the workforce after caring for an elderly parent in the home for an extended time. Some students developed personal support systems to make up for the absence of family support. Others were supported in their high schools through all steps of the application and college selection 
process. Still others were encouraged to try again after failing a past attempt in college. Some made a smooth return to college after a stop-out period. One student saw college attendance as a preferred alternative to welfare. Economic recession affected all of them to a greater or lesser degree.

Nine success factors were evident in the experiences perceived to have had a significant impact on the success of this group of students. These success factors, described in the following section, extended back to childhood experiences with encouraging and supportive adults through present and ongoing personal, financial, and academic support.

\section{Success Factors}

1. Academic preparation and academic support. A common thread running throughout the experiences of this group of successful minority students was that their early secondary schooling adequately prepared them for college and academic support was available for then in area they felt lacking.

Four of the students recalled their families setting the expectation that they would attend and complete a college degree. This expectation, reinforced by an academically challenging curriculum high school, left no discrepancies between the personal determination, and 
academic competencies necessary to succeed in the college environment. For one student, the lack of incentive to pursue a college degree at home was supplemented by supportive high school teachers who recognized her potential. Once a student was admitted, academic supports (tutoring, advising, and an early registration process) played an important part in the academic success of students. Assistance with the transfer process from community college filled a need and contributed to a determination made early in the process to achieve the degree goal.

The program set requirements for academic standards and provided supports to meet the standards. This group of participating students had demonstrated academic potential, a criteria for their acceptance into the program. At the time of the study all had maintained a minimum GPA of 2.5, and consequently none faced major academic barriers. The program was designed for, and taped into, a constituency of academic capable minority students providing them with the supportive environment and financial assistance to complete the program. These results counteracts the stereotypical notion of minority students as being more in need of remedial assistance than their non-minority counterparts.

2. Faculty and staff contact and support. An examination of the influential experiences of the students showed that encouraging responses from faculty or staff when 
they made initial inquiries about applying for admission braced their resolve. Subsequent familiarity and cordial interactions with faculty were extremely important ingredients of persistence. Associating with other program members was not as important as having administrators and faculty members available to contact as needed. With the help of all such connections, the ethos of the college going experience was not as daunting as it might have been. Students became familiar with it and could function in it with some degree of comfort.

3. Introduction of college as a choice either early in the students' lives or when they were ready to make a change. Early introduction of college as a possible and probable future choice was significant for some students. However, not having this initial encouragement did not preclude students from pursuing a college degree when they were ready to make a significant change in their lives. The students age and prior experience in the workforce were important variables in recognizing the value of a college degree. These students were appreciative of the concrete and encouraging advice presented when they initially explored the option of attending college.

4. Ethnic and multicultural studies. Ethnic studies that prepared minority students to respond on an intellectual level to inquiries about minority issues, strengthened their confidence and reassured them of their 
rightful position in the college community. These classes were of particular importance to the African-American students, who more that others, were called upon to respond to race related issues in classes with few, if any, other minority students.

5. Familiar site on campus to use as a base. For many of these students, the program office, where the students could go and everyone knew them, was one place in a tangle of rooms and a mass of buildings where they could feel comfortable. Particularly valuable to them was having an experienced spokesperson there to assist them. The space provided for them was cozy and warmed by comfortable furnishings. There they could join each other as a small community within the larger college community, which appeared to them, as it did to many who commuted, cold and impersonal.

6. The special Program. For these students, the special program served to gather together services that were key influences on student success, services which otherwise would have been difficult to access due to their fragmentation. This was true even for the graduate students, who had had prior problems getting into graduate school. For those who started at the community college, information on and involvement in the program was important to the creation of the vision of graduation and engendering students with a belief that they could develop the skills to 
pass classes at the university level. Assistance with the transfer process to the university provided the community college students with the necessary guidance and preparation for education to take beyond the personable and supportive environment provided at the community college. The inclusion of academic, social, and financial supports were essential to student persistence. The requirement of clearly articulating the intent and goals to complete the program also fostered commitment. The goal clarification that students did at the onset of the program helped by giving them a believable picture of themselves succeeding at what they wanted to accomplish.

Introduction to professional people in the field to which they aspired and becoming accustomed to the ethos of the field was a great aid to their progress and started them on a networking path. Then too, knowing that their success would earn a priority hiring status for them was a valuable stimulus.

7. Experience in integrated environments. Being a minority person living in a city that is predominantly white isn't what is meant in this study by integration. Examples of integration are such activities as attendance at predominantly white schools or being part of a busing program. Membership in the military is an experience in an integrated environment as is being in an interracial couple's relationship. Because of their daily interactions 
with the majority race in classrooms, over time the program students become more interracially adept. Consequently, they were better prepared to deal with adverse incidents of racial conflict. Race relations was not an expressed problem for three students in the group who had come from foreign countries: an African, an Asian, and an Hispanic.

8. Awareness of limited employment opportunities without a college degree. Many of these students had adverse experiences in the workforce and/or recognized their status and earning potential would always be limited without a college education. In these cases, a degree took on great value to the student who had arrived at a realistic understanding of the poor economic prospects

9. Support from family, friends, and community members combined with personal goals and aspirations. Perhaps most important of all, a student's personal determination and commitment was the indispensable ingredient that could carry him or her through to completion. The goals students held for themselves were fueled either by the support of significant people in their lives, their personal employment experiences without advanced education, and/or a lack of employment opportunities in their initial chosen field of study. These personal supports were effective when offered or experienced either early in life or when the student was ready to make a change. 
Summary

The respondents were a diverse group of minority students in a predominantly white urban university. The interview questions were aimed at learning the students' views on what had influenced them to first, enroll at the university and then, to stay, or persist, until they had attained their degrees.

While they had had divergent family and educational experiences prior to entering the special program, certain events or circumstances took place that were in many instances similar. They occurred in supportive relationships within the context of their families, their elementary or high schools or colleges, and in the broader society of which they were an integral part. Those events took the form of encouragement and positive expectations held out for them, which resulted in heightening their chances for successfully completing college courses and earning a degree.

Those who did not have positive influences early in life often experienced them in their later affiliations with friends, spouses, and others who supported their personal determination to improve their lives. For students who lacked encouragement at home or school, the path to degree attainment was longer and more complex, but the essential support described by the other students was present at some time in their lives, if only briefly. 
Institutional influences were of primary importance. Too often, especially for those who were unsure of how to navigate the administrative processes, students felt the college environment to be inhospitable. Those who carried with them the baggage of former failures were further hindered by the conditioning of responses based on those memories. Faculty and staff who would give students a positive reception and understand their needs could counteract those feelings and increase the likelihood of a student's success. That was true also for graduates who had been discouraged while making inquiries about advanced studies.

Practices of educational institutions are telling in the success of their students. They have a direct effect on a student's self image, and to ignore or short-change their importance is detrimental to the persistence of those whose self images have already been eroded over the course of their lifetimes. What is so important is that a student who has been afforded opportunities to find financial aid and suitable jobs, to take multicultural classes, and to come together with other minority students as well as racially mixed faculty and advisers for the sake of their support, is better prepared for success. A student who is provided with those things develops a good self image, one that will reinforcement his or her efforts toward academic excellence. 
The other persuasive elements of no less importance to a student's persistence were hearty support bestowed by family or significant others and his or her own aspirations and personal traits of tenacity and hopefulness. 
CHAPTER V

\section{CONCLUSIONS AND RECOMMENDATIONS}

The two question posed in this study were first, what are the experiences of a selected group of minority students, who attended a predominantly white postsecondary urban institution, that have contributed to their persistence? And second, do these students share common past and present institutional, environmental, and personal experiences which contribute to their success?

In this qualitative study, 12 students were interviewed to learn what influences and experiences they had in their background, or were having during their encounter with higher education, that they perceived as having contributed to their persistence. The conclusions, drawn from the interview results, support the methodology employed in the study and existing research on minority retention in higher education.

\section{Conclusions}

When we need information about a group of people, we need the point of view of those we want to know about. To ascertain the meanings gleaned and interpretations made by the students, a methodology based on one component of the 
sociology of everyday life, symbolic interactionism, was adopted. This theoretical construct is based on the idea that the meaning that things have for people arises out of social interaction. These interactions are in turn modified through an interpretative process used by the person. Understanding how they interpret interactions and events aids our understanding of how these interactions affect persistence. The students' description of the application process for admittance into the program as an affirmation of self worth, confidence in their ability to succeed, and future potential highlights the interpretative process and how interaction with others serve to redefine the self. This process was described by the student as increasing their self-confidence, pride, and belief in their potential. The meaning behind the interview designed to select participants was interpreted by the students as a validation of potential and competencies.

on the other hand, when students were confronted by administrators and professors who had little time or regard for them, they interpreted this to mean they were less worthy of their attention and not good enough to succeed. Discouragement with classes and the inability to articulate needs to professors was also interpreted as an indication of lack of competency to complete a college degree.

This group of students was pleased to be asked to describe their perceptions of the college experience. They 
were reflective and thoughtful, often responding with tremendous pride in their accomplishments, at other times expressing pain felt because of the obstacles. They were eager to share their experiences in the hope that the information could be used to inform and improve the situations for those who might follow them.

This research study has demonstrated that students have a lot to tell us about what influences and experiences support their persistence. Colleges and university who are failing to increase minority retention rates, would be well served to go to the source, i.e. the students, to solicit the information necessary for making informed decisions on policies and practices designed to increase minority retention rates.

social integration into the college environment was a contributing success factor for this group of students. Tinto's (1987) Student Integration Model, and Metzner and Bean's (1987) Conceptual Model of Nontraditional student Attrition were used to inform the study. The major distinction between the models is the type of students who contributed to defining the variables supportive of persistence. Tinto's model focused on traditional students attending four-year residential colleges and Metzner and Bean focused on nontraditional students. The nontraditional students were found to be more influenced by the academic and environmental aspects of postsecondary 
experiences and less by the social activities of campus Iife.

This held true, to a certain extent, for this group of students. The majority of students interviewed had little, if any, social contact on campus excluding activities associated with the special program. However, isolation from students and campus events was not the norm. The regularly scheduled monthly program meetings provided a welcomed opportunity for students to acquaint themselves with their peers, administrators, and professors affiliated with the program. More often than not, these events were the sole circumstances of socialization on campus outside of in-class interactions.

The absence of social integration into campus life outside the program did not preclude the importance of having a site on campus for formal and informal contacts with other program students. This site, the program office, administered by the program coordinator at the university, was central to the students' well being. Not only did access to the program office enable them to promptly deal with personal and academic concerns, it provided an informal meeting place with others familiar with their experiences at the university.

These results, however, do not contradict the finding that support Metzner and Bean's proposition (Fox, 1986; Pascarella, Duby, \& Iverson, 1983) that social integration 
factors play less of a role in decisions to persist among nontraditional student. The results define these positive social interactions, all program related, as having a comfortable and welcoming place to visit on campus, having peers who share similar experiences and goals, and knowing minority and majority faculty and professionals. These interactions were consequential for those who had minimal contact with college social activities exclusive of the program

The impact of the role of this collaboration for the success of the students' efforts to succeed in college cannot be over emphasized. The program made connections among and between the institutions the students were interacting with by providing a support structure, financial aid and more importantly, the personable and hospitable environment in which to interact with other minority students and professionals. The enhanced opportunity for employment upon successful completion of all teaching qualifications clarified the goal, and the support along the way made the goal attainable.

The initial intent of the program was to introduce students at the middle school level to careers in education and progressively introduce teaching as a career option, while increasing the contact with teaching opportunities in the high school and community college. As the program developed, it became evident that college follows a more 
complex path for a majority of students. These students represented individuals at varying points in their education and careers, ranging from a woman in her fifties looking for a career change to a graduate student finding time and sufficient family support and finances to return to school full-time and achieve a long held goal of teaching. Many entry points exist for students to return to college. structuring a supportive program only for individuals currently in the educational system may be to narrow an approach for colleges and universities to pursue.

The study supports the underlying basic assumptions of persistence/withdrawal decisions. Three underlying assumptions shared by the Metzner and Bean (1987) Conceptual Model of Nontraditional Student Attrition and Tinto's (1987) Student Integration Model and supported by responses in the student interviews include: (a) withdrawal decisions are complex; (b) different types of students leave for different reasons; and (c) some leave because they do not fit in, although fitting in depends on the actions of students and the institutions (Hossler \& Bean, 1990). The following is a brief summary of how the basic assumptions of persistence decisions relate to these students' lives during their first encounter with college.

These assumptions were supported by the description of four students, three African-American women and one AfricanAmerican man, in the special program who did not stay in 
college on their first try. Each one had started with an intent to persist. Difficulties that they had not anticipated began for them during their first term. Having no perceived supports and feeling they were failing, they wanted to make a fresh start. They sought alternatives. Three found employment that required no college education, and one joined the military.

These four students faced a variety of problems when initially in college. They sometimes felt out of place because of the difference in their age from that of the majority of students. One became too immersed in the social life on campus and failed to attend to the academic requirements. Others were unable to successfully combine work and school. A decision to leave was based on a fear of failure combined with the belief that working would be easier than school.

While these four have returned to college and have been successful in their second attempt, findings of this study suggest that it was a combination of their personal determination and institutional supports that helped to keep them on track the second time around.

These four students made considerable adjustments in their lives to allow them to complete their education, and they were influenced by an array of experiences. For several of the women, their responsibilities to family were eased or lessened enough to provide them with time to pursue 
an education. The realization that the lack of a college degree would severely limit their opportunities for employment had great influence. Then too, the opportunity to be a part of a special program with clear goals and practical supports was attractive, while the possibility of priority hiring status and a job upon successful completion of their college program was a lure hard to resist. Most of them hoped to complete their coursework and realize their long held desires to graduate with a college degree. Psychological and environmental variables were important, however, organizational variables were especially critical to the persistence of this group of students. The critical success factors gleaned from the interviews provide substantive data providing context to persistence influences and support the interactive models proposed by Tinto (1987) and Metzner and Bean (1987). This group of nontraditional minority students were influenced by the interaction of psychological, environmental and organizational variables. However, the most consequential variable, the one that combined the necessary factors to meet the needs of this group of students, was the organizational variable.

What the educational institutions provided to these aspiring students mattered. Students prepared academically to meet the rigors of college coursework were at an advantage and more likely to be successful in their attempts to complete a college degree. Postsecondary faculty and 
staff who provided support and assistance to students through the early application process and understood the diverse racial and ethnic make up and needs of students had an impact on the success or failure of these minority students.

For this group of students, three educational institutions established a formal partnership in order to increase the minority applicant pool of qualified teachers. Attention to academic, social, and economic supports was given to meet the needs of this select group of students. Consideration was given to recruiting students who articulated clear goals and intentions to complete their teaching credentials, demonstrated academic potential to meet the program requirements, and expressed commitment to the time and supports necessary to successfully attend college full-time.

It is incumbent upon each institution to learn the specific needs of students and not rely solely on replicating programs and policies that have been designed to fit other groups. Expansion of recruitment techniques beyond high school students to include adults in transition and those in community colleges is essential. Various points of entry exist, and having some connectors within and between the various levels is necessary for easing the transition between institutions. 
Research has confirmed that short-term, quick fixes are insufficient to adequately alter the current statistics on minority retention (Cohen, 1980; Mortenson, 1991). Institutions can improve practices if they infuse their efforts with a knowledge of specific cultures affected (Kempner, 1990). This study has demonstrated that much can be learned from a handful of students who are asked about their experiences.

\section{Impliçations}

The present study contributes to our understanding of the nontraditional minority student who must assume the demanding role of attending college while shouldering the added one of representing a minority culture in a predominantly white environment. The research supports what has been already acknowledged in the literature on successful retention. More importantly, it calls attention to the effectiveness of certain practices that contribute to a student's success in college.

Educational institutions can initiate many supports to help minority students to maintain the needed staying power throughout the course of their college studies as they prepare themselves for a broader range of employment options. 


\section{Elementary and Secondary}

Schools

Policy makers and educators need to encourage and support inc:eased funding for early childhood programs, which have been shown to lay the groundwork for success

throughout the educational process. Early success in school leads to a healthy level of self-esteem and confidence (Macchiarola, 1989; Schorr, 1988), which are often difficult to remediate at later stages of development.

Practices should be implemented in elementary and secondary schools that effectively will prepare students to go on to college if they choose. First consideration needs to be given to the support of those educators who will accept the challenge of educating all children under their care without regard for racial and cultural variation. "It is therefore imperative that the schools be organized to deal with all children and make them feel that they have a positive and welcome role to play in school" (Macchiarola, 1989 , p. 173).

Educators need to examine, acknowledge, and challenge practices which contribute to the stigmatization of students according to racial stereotypes or social class differences. Failure to do so continues educational practices that "differentiate the socialization of the young for work along lines that conform to parents' occupational roles" (Carnoy \& Levin, 1985, p. 128). 
We must recognize that effective educational practices at every level will bring the result of increased college degree attainment. All educators have a role to play in the endeavor. We must acknowledge that higher standards means a greater application of efforts to assure that the greatest possible number of students succeed. Avoidance of that will result in the deprivation of encouragement and support, a form of inadvertent neglect that relegates students to inferior positions on the economic scale.

Community colleges and Universities

Literature on persistence and withdrawal behavior of students recommends educational institutions design policies and practices appropriate to institutional needs, involve the majority of staff and faculty in policy making and practices conducive to a hospitable environment for minority students, and employ strategies that respond to the unique needs of specific minority groups (Fox, 1986; Richardson \& Bender, 1985; Richardson, Simmons, \& de los Santos, 1987; wittstruck, Hess, \& Stein, 1988).

Colleges and universities need to reflect on the impact of their policies to determine if they are producing a deleterious effect on the environment of students who already lack confidence and who may feel unwelcome as they enter the educational setting. According to a variety of research studies on persistence: 
These studies consistently indicate that, net of entering characteristics, what happens to students after they arrive on campus has a greater influence on academic and social self-concepts than does the kind of institution students attend. (Pascarella \& Terenzini, 1991, p. 184)

A starting point for improvement is to acknowledge the barriers identified by the targeted population, and then to involve a broad spectrum of university personnel, including faculty along with classified and administrative staff, in staff training programs on interpersonal relationships within a diverse college population.

Successful strategies implemented to increase the retention of minority students and documented by various states (Wittstruck, Hess, \& Stein 1988) are somewhat similar to the special program implemented at this university and include: collaborative programs between high schools and colleges, recruitment strategies for undergraduate and graduate programs, and comprehensive services designed to promote a positive learning environment for minority students. Attention to the effectiveness of the special program on a long-term basis at each educational institution involved will require close scrutiny and ongoing evaluation.

\section{Collaborations}

Partnerships and collaborations between educational institutions have increased in the past decade. Over 1,286 colleges and universities responded to a AAHE publication for inclusion in The National Directory of School-college 
Partnerships (Wilbur \& Lambert, 1991). The trend is promising and follows the direction proposed by Hodgkinson (1985) for educational institutions to move away from the vision of individual and distinct entities to a vision that incorporates education as All one system. These new partnerships reflect a unity among institutions and their communities.

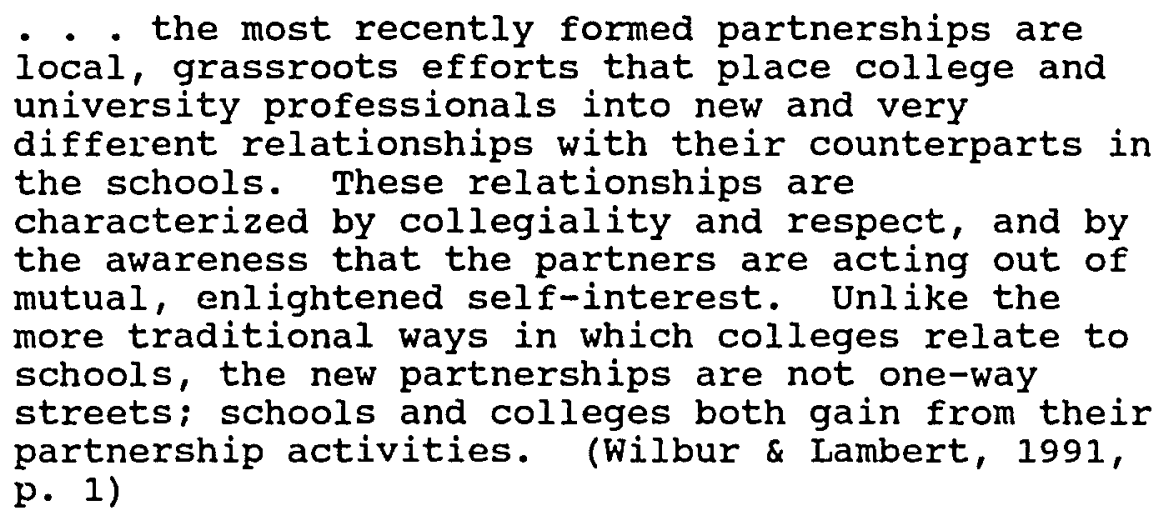

The tri-institutional partnership demonstrates

successful grassroots efforts designed specifically for the needs of one educational community. Involving other educational institutions creates a broader and more systematic effort for improving retention rates.

\section{Broad Policy and Practices}

According to Richardson, Simmons, \& de los Santos (1987), a receptive campus environment is one crucial requirement for student involvement and success. Another is the hiring of more minority faculty and the strengthening of administrative commitment. strong commitment to good educational practices, supported by favorable state policies 
increase the likelihood of success. In successful environments, strategies for retaining students are comprehensive and systematic, not fragmented and sporadic.

Pascarella and Terenzini (1991) recommended strategies and practices that may serve to increase retention of a diverse student population.

- . it is not too soon to begin reviewing and changing institutional policies and programs that create or tolerate activities or conditions that are acadernically and socially uncongenial, if not downright hostile to nonwhite students. These would include (but not be limited to) policies and programs relating to increased minority faculty and staff recruitment and retention, institutionwide faculty and staff recruitment rewards, student housing and financial aid, social organizations, instructors' classroom attitudes and behaviors, and any other conditions that sustain or permit educational inequalities for minority students on predominantly white campuses. (pp. 644-645)

In local settings where attrition rates have a history of being high, institutions must reinforce their commitment to the development of polices and strategies which will support incoming students. Awareness and attention to activities or conduct hostile to minorities students requires an on-going inquiry into the circumstances and events which either hinder or strengthen minority degree attainment at the local level. As they come to understand the conditions and circumstances surrounding the complex decision to achieve a college education, and the strength of will required of students, institutions committed to 
increasing minority graduation rates, will want to act to remove any barriers that still exist.

From early childhood programs through secondary school, educational institutions can make major contributions by adopting practices shown to be effective in encouraging student persistence. The perspective that views education as "all one system" (Hodgkinson, 1985) maintained that educational institutions should be an interconnected system as opposed to distinct institutions working in isolation and having no familiarity with the needs and experiences of other levels.

It is assumed that if people can begin to SEE the educational system as a single entity through which people move, they may begin to behave as if all education were related. It seems self evident that such a perception is good. (p. 1)

Historically, the educational system has been used as a means of achieving social mobility (Carnoy \& Levin, 1985). Cultural and racial minorities continue to utilize the educational process to enter professional and high-skilled positions of employment. As long as the commitment to achieve ethnic and racial parity in the professions continues to be a mission espoused by our educational institutions, attention to bridging the cultural and economic gap by the inclusion of minority students in the mainstream of the student population must remain a priority. 
Future Research

From the existing literature, we know at a very general level what works to increase retention rates for minorities and all students. Future studies need to focus closely on the specific needs of specific disparate ethnic and racial groups outside the mainstream of educational attainment. It is important that these specific groups evaluate the practices of educational institutions serving them. What is most important for success is to go to the source, i.e. the students, to solicit the information necessary for making informed decisions on policies and practices. Alliances of institutions which would adopt the most promising practices, across their different educational levels, would heighten their overall effectiveness in retaining minorities.

For instance, more minorities may be successful in college if each locale, whether urban or rural, would promote more use of locally initiated qualitative studies using qualitative methods to examine sub-groups within their own minority populations. Such individualized attention would yield cogent results that the imposition of conclusions from established research would not, because it would have been performed elsewhere. Staff indifference, bias, or lack of understanding of multicultural students may be uncovered using the above mentioned techniques, and staff may require training in how to conduct themselves in interpersonal relations with minorities. 
Several significant issues requiring further research to clarify relationships and long-term affect on minority students as they advance into professional positions requiring baccalaureate degrees and beyond include:

Acknowledging and confronting the issue of racial bias, from students, staff, and faculty on campuses. Some minority students describe racism as a given in this society. While some just accept it as fact, others, particularly women in this study, articulated the need to confront and expose racism. Tolerance for racial and ethnic diversity is deteriorating (Crossen, 1987; Hedegard, 1971; Smith, 1989). Existent racial, ethnic and class antagonism, on the nations campuses, left unattended will continue to create an alienating experience for those coming from racial, ethnic and economic nontraditional backgrounds. Examining how campuses confront and pro-actively support students in acknowledging and adjusting existing racial bias. This is necessary, as is a more insightful analysis of the affect of segregated vs. integrated educational environments for minority students and the long-term affect of these environments on student success in the broader integrated workforce.

Examining the affect of multicultural studies at the high school and college level. These classes were significant for some of these students and a closer examination of their influence on persistence is essential. 
Bearing the burden of representing a minority culture without having background information to support and challenge assumptions compromises ones feeling of adequacy and overall competencies. On the other hand, awareness of one's racial, and ethic background and history contributes to overall feeling of competence and heightens one selfesteem. The extent and scope of knowledge of one's racial and ethnic history may have an impact on the curriculum of high school and college history classes and necessitate moving beyond one introductory course offered at many college's and universities. Gender studies should be included in this research agenda, particularly for women preparing for predominantly female professions such as teaching where their influence on young girls developing self-esteem is substantial.

The on-going study and examination of the basis of racial conflict. The issue of racial conflict was not really dealt with head-on in the university where this study was conducted. Discussion of this issue glanced off on tangents and was not confronted at an interpersonal level. Faculty, staff, and students, need to examine how interpersonal behaviors go wrong and how they might be brought about to become more considerate and respectful in diverse groups. All educators need to develop the skills and information to carry on the task of confronting issues of race relations. 
Summary

In the face of today's socio-economic realities, minority students do not fare well. Tension between the races is high, competition for jobs keen, and prevailing efforts to increase retention rates are unsuccessful. Practices conducive to supporting the persistence of this group of students including strong academic preparation and experiences in integrated environments must be encouraged.

In integrated environments, minority and majority students become more familiar with each other and are able to understand and cope with daily interactions. Mainly due to the economic divisions, minority interactions in integrated environments are not an experience of many of our nation's minority public school students. "Only 9.0 percent of California's pupils are Black, as are 8.9 percent of Wisconsin's. Nevertheless, over $70 \%$ of their youngsters attend segregated schools" (Hacker, 1992, p. 162). Also, race relations are strained at colleges and universities across the nation. A U.S. news survey of 550 student editors pertaining to race relations on campuses found:

64 percent of the editors at schools enrolling more than 10,000 students and 49 percent of all respondents characterized the state of race relations on their campuses as "fair" or "poor." (Elfin \& Burke, 1993, p. 53)

These broader social concerns must be examined in the context of how they influence the future generation of prospective minority students. 
Colleges and universities need to continually reflect on and confront the meaning of their policies and practices and their impact at a personal and organizational level. They also need to examine whether existing policies and practices have an adverse effect on students coming from varied racial and ethnic backgrounds. A major part of the educational agenda initiated by some washington based national associations in the 1980 s was to recognize the increasing racial, ethnic, and cultural diversity of the student population. They set out to ensure that institutional staffing, services, and social climate would provide a hospitable environment where differences are a source of enrichment and not conflict (Eaton, 1991). These issues remain important to the agenda as we move through the 1990s.

The study here presented has provided insight into one group of diverse minority students. We can use the information as the beginning of a data base of student perspectives of the college experience. It is hoped that it can serve also as a starting point for a dialogue between faculty, staff, and students in their struggle to understand each other and the dynamics of student achievement in diverse college populations. 


\section{REFERENCES}

Abalos, D. (1986). Latinos in the United States. South Bend, IN: University of Notre Dame Press.

Astin, A. (1982). Minorities in American higher education. San Francisco: Jossey-Bass.

Attinasi, L. (1989). Getting in: Mexican Aunericans' perceptions of university attendance and the implications for freshman persistence. Journal of Higher Education, 60(3), 247-277.

Bean, J., \& Kuh, G. (1984). The reciprocity between student-faculty informal contact and academic performance of university undergraduate students. Research In Higher Education, 21(4), 461-477.

Bean, J., \& Metzner, B. (1985). A conceptual model of nontraditional undergraduate student attrition. Review of Educational Research, 55(4), 485-540.

Bennett, C. I., \& Okinaka, A. M. (1989, March). Factors related to persistence among Asian, Black, Hispanic, and white undergraduates at a predominantly white university: Comparison between first and fourth year cohorts. Paper read at the American Educational Research Association, San Francisco.

Blumer, H. (1969). Symbolic interactionism: Perspective and method. Englewood cliffs, NJ: Prentice-Hall, Inc.

Bogdan, R. C., \& Biklen, S. (1982). Qualitative research for education. Boston, MA: Allyn and Bacon.

Bond, A., LeBold, W. \& \& Thomas, M. (1977). Recruitment and retention of Black Americans in engineering at Purdue (Grant No. SED-74-18725). Washington, DC: National Science Foundation. (ERIC Document Reproduction Service No. ED 177 932)

Boyer, E. (1987). College: The undergraduate experience in America. New York: Harper and Row. 
Brint, S., \& Karabel, S. (1989). The diverted dream: Community college and the promise of educational opportunity in America. New York: Oxford University Press.

Cabrera, A., Castaneda, M., Nora, A., \& Hengstler, D. (1990, November). The convergence between two theories of college persistence. Paper presented at the Annual Meeting of the Association for the study of Higher Education, Portland, OR.

Cabrera, A., Nora, A., \& Castaneda, M. (1992). The role of finances in the persistence process: A structural model. Research in Higher Education, 33(5), 571-593.

Carnegie Foundation for the Advancement of Teaching. (1987, May/June). Minority access: A question of equity. Change, 19(3), 35-39.

Carnegie Foundation for the Advancement of Teaching. (1990, January/February). Native Anericans and higher education: New mood of optimism. Change, $\underline{22}(1), 27-30$.

Carnoy, M., \& Levin, H. (1985). Schooling and work in the democratic state. Stanford, CA: Stanford University Press.

Carter, D., \& Wilson, R. (1991). Minorities in higher education: Tenth annual status report. Washington, DC: American Council on Education.

Chacon, M., Cohen, G., Camarena, M., Gonzalez, J., \& Strover, S. (1982, July). Chicanas in postsecondary education. Stanford, CA: Stanford University, Center for Research on Women. (ERIC Document Reproduction Service No. ED 223 186)

Clague, M. W. (1989, May). Legal aspects of minority participation in higher education. Education and Urban Society, 21(3), 260-281.

Cohen, A. (1980). The minority student controversy. Los Angeles: California University. (ERIC Document Reproduction Services No. ED 183 228)

Cohen, A. (1990, April). The transfer function. Paper presented at the Annual Convention of the American Association of Community and Junior Colleges, Seattle, WA.

Cohen, A., \& Brawer, F. (1987). The collegiate function of the community colleges. San Francisco: Jossey-Bass. 
Crossen, P. (1987). Environmental influences on minority degree attainment. Washington, DC: Office of Educational Research and Improvement (ED). (ERIC Document Reproduction Service No. ED 292 415)

Dougherty, K. (1992). Community colleges and baccalaureate attainment. The Journal of Higher Education, $63(2)$, 188-214.

Douglas, J., Adler, P., Adler, P., Fonyana, A., Freeman, C., \& Kotarba, J. (1980). Introduction to the sociologies of everyday life. Boston: Allyn and Bacon.

Duran, R. (1986). Prediction of Hispanics' college achievement. In M. A. Olivas (Ed.), Latino college students (pp. 221-245). New York: Teachers College Press.

Eaton, J. (1991). The unfinished agenda: Higher education and the 1980s. New York: Macmillian Publishing.

Elam, A. (Ed.). (1989). The status of Blacks in higher education. New York: University Press of America.

Elfin, M., \& Burke, S. (1993, April 19). Race on campus. U.S. News and World Report, pp. 52-56.

El-Khawas, E., Carter, D. , \& ottinger, C. (1988). Community college fact book. New York: Collier Macmillan Publishers.

Fordham, S, (1993). Racelessness as a factor in Black students' school success: Pragmatic strategy or pyrrhic victory? In H. S. Shapiro \& D. Purpel (Eds.), Critical social issues in American education (pp. 149-178). New York: Longman.

Fox, R. (1986). Application of a conceptual model of college withdrawal to disadvantaged students. American Educational Research Journal, 23(3), 415-424.

Grosset, J. M. (1991). Patterns of integration, commitment, and student characteristics and retention among younger and older students. Research in Higher Education, $\underline{32}(2), 159-178$.

Grubb, w. N. (1991). The decline of community college transfer rates. The Journal of Higher Education, $\underline{62}(2), 194-222$.

Hacker, A. (1992). Two nations: Black and white, separate, hostile, unequal. New York: Charles Scribner's Sons. 
Hedegard, J. M. (1971). Experiences of Black college students at predominantly white institutions. In E. G. Epps (Ed.), Black students in white schools (pp. 4359). Worthington, OH: Charles A. Jones Publishing Company.

Hodgkinson, L. H. (1985, June). All one system: Demographics of education: Kindergarten through graduate school. Washington, DC: Institute for Educational Leadership.

Hossler, D. \& \& Bean, J. (Eds.). (1990). The strategic management of college enrollments. San Francisco: Jossey-Bass.

Hurtado, S. (1992). The campus racial climate: contents of conflict. Journal of Higher Education, 63(5), 539-569.

Jones, J. C., \& Lee, B. S. (1992). Moving on: A cooperative study of student transfer. Research in Higher Education, 33(1), 125-140.

Karabel, J. (1972, November). Community colleges and social stratification. Harvard Educational Review, $\underline{42}(4), 521-562$.

Kempner, K. (1990). Faculty culture in the community college: Facilitating or hindering learning? The Review of Higher Education, 13(2), 215-235.

Kempner, K., \& Kinnick, M. K. (1990). Catching the window of opportunity: Being on time for higher education. The Journal of Higher Education, 61(5), 535-547.

Kempner, K. , \& Stapleton, G. (1986). Challenging complacency: Are community colleges really serving the needs of minority students. Community/Junior college Quarterly of Research and Practice, 10(4), 267-279.

Kerzner-Lipsky, D. , \& Gartner, A. (1989). Overcoming school failure: A vision for the future. In $F$. Macchiarola \& A. Gartner (Eds.), Caring for America's children (pp. 149-158). New York: The Academy of Political Science.

Kinnick, M. K. , \& Kempner, K. (1988). Beyond "front door" access: Attaining the bachelor's degree. Research in Higher Education, 29(4), 299-318.

Kinnick, M. K., \& O'Brien, A. (1992). The academy for future educators: Guidebook. Portland, OR: Portland State University School of Education. 
Kinnick, M. K. \& Ricks, M. F. (1990). The urban public university in the United states. Research in Higher Education, 31(1), 15-38.

Kinnick, M. K., \& Ricks, M. F. (1993, February). Student retention: Moving from numbers to action. Research in Higher Education, 34(1), 55-69.

Lee, V. (1985, May). Access to higher education: The experience of Blacks, Hispanics, and low socio-economic status whites. Washington, DC: American Council on Education.

Macchiarola, F. (1989). Schools that serve children. In F. Macchiarola \& A. Gartner (Eds.), Caring for America's children (pp. 170-181). New York: The Academy of Political Science.

Magner, D. (1990, March 28). Difficult questions face colleges that require students to take courses that explore issues relating to race. The chronicle of Higher Education, $36(28)$, A 19-21.

McGrath, D., \& Spear, M. (1991). The academic crisis of the community college. New York: State University of New York Press.

Mead, G. H. (1982). The individual and the social self: Unpublished work of George Herbert Mead. Chicago: University of Chicago Press.

Merton, R. K., \& Kendall, P. L. (1945). The focused interview. American Journal of Sociology, 51, 541-557.

Metzner, B., \& Bean, J. (1987). The estimation of a conceptual model of nontraditional undergraduate student attrition. Research in Higher Education, $\underline{27}(1), 15-38$.

Middleton, E., \& Mason, E. (Eds). (1988). Recruitment and retention of minority students in teacher education. Dubuque, IA: Kendall/Hunt.

Mingle, J. (1987). Focus on minorities: Trends in higher education participation and success (Publication No. ECS-SHEEO-MP-87-2). Denver: State Higher Education Executive Officers.

Moore, W., \& Wagstaff, L. (1974). Black educators in white colleges. San Francisco: Jossey-Bass. 
Morgan, D. (1988). Focus groups as qualitative research. Newbury Park: Sage Publications.

Mortenson, T. (1991). Equity of hiqher education opportunity for women, Black, Hispanic, and low income students (Act Student Financial Aid Research Report No. 91-1). Iowa City, IA: American College Testing Program.

National Commission on Excellence in Education. (1983). A nation at risk: The imperative for educational reform. Washington, DC: U.S. Government Printing Office.

Neumann, w. (1985). Persistence in the community college: The student perspective (Doctoral dissertation, Syracuse University, 1985). UMI Dissertation Information Service, Ann Arbor, MI.

Nora, A. (1990). Campus-based aid programs as determinants of retention among Hispanic community college students. The Journal of Higher Education, 61(3), 312-331.

O'Banion, T. (1989). Innovation in the community college. New York: Macmillan Publishing Company.

Olivas, M. (1979). The dilemma of access. Washington, DC: Howard University Press.

Olivas, M. (1986). Latino college students. New York: Teachers College Press.

oregon Research on Education. (1990). Degrees awarded by oregon's degree-granting colleges and universities, 1989-90. Salem, OR: Office of Educational Policy and Planning.

Oscar, P. (1989, March). The influence of institutional control on the persistence of minority students: A descriptive analysis. Paper presented at the Annual Meeting of the American Educational Research Association, San Francisco, CA.

Pascarella, E., \& Chapman, D. (1983). A multiinstituitional, path analytic validation of Tinto's model of college withdrawal. American Educational Research Journal, 28(1), 87-102.

Pascarella, E., Duby, P., \& Iverson, B. (1983). A test and reconceptualization of a theoretical model of college withdrawal in a commuter institutional setting. Sociology of Education, 56(2), 88-100. 
Pascarella, E., Duby, P., Miller, V., \& Rasher, S. (1981). Preenrollment variables and academic performance as predictors of freshman year persistence, early withdrawal, and stopout behavior in an urban, nonresidential university. Research in Higher Education, 15(4), 329-349.

Pascarella, E., \& Terenzini, P. (1979). Interaction influences in Spady's and Tinto's conceptual models of college attrition. Sociology of Education, 52 (4), 197210 .

Pascarella, E., \& Terenzini, P. (1991). How college affects students. San Francisco: Jossey-Bass.

Phelan, D., \& Kirkland, T. (1990, April). A study of the relative effect of the community college on transfer students: Achievement and satisfaction. Paper presented at the American Association of Community and Junior Colleges 70th Annual Convention, Seattle, WA.

Preer, J. (1981). Minority access to higher education (ASHE-ERIC Higher Education Report No. 1). Washington, DC: George Washington University.

Ramirez, B. C. (1992). Can we all get along? Examining our capacity for diversity. Educational Record, 73(4), $42-46$.

Richardson, R., \& Bender, I. (1985). Students in urban settings (ASHE-ERIC Higher Education Report No. 6). Washington DC: George Washington University.

Richardson, R., \& Bender, L. (1987). Fostering minority access and achievement in higher education. San Francisco: Jossey-Bass.

Richardson, R., Simmons, H., \& de los Santos. (1987, May/June). Graduating minority students. Change, $\underline{13}(3), 20-27$

Richardson, R., \& Skinner, E. (1990). Adapting to diversity: Organizational influences on student achievement. The Journal of Higher Education, 61 (5), 485-511.

Richardson, R., \& Skinner, E. (1991). Achieving quality and diversity. New York: Macmillian Publishing Company.

Schorr, L. (1988). Within our reach. New York: Anchor Books/Doubleday. 
Smith, D. (1989). The challenge of diversity (ASHE-ERIC Higher Education Report No. 5). Washington, DC: George Washington University.

Snyder, T., \& Hoffman, C. (1992). Digest of educational statistics. Washington, DC: U.S. Government Printing office.

st. John, E. P. (1991). What really influences minority attendance? Sequential analysis of the high school and beyond sophomore cohort. Research in Higher Education, $\underline{32}(2), 141-158$.

st. John, E. P., \& Noell, J. (1989). The effects of student financial aid on access to higher education: An analysis of progress with special consideration of minority enrollment. Research in Higher Education, $\underline{30}(6), 563-581$.

Stage, F. (1990). Research on college students: Commonality, difference, and direction. The Review of Higher Education, 13(3), 249-258.

Task Group on Undergraduate Retention at Portland state University. (1990). Interim report. Portland, OR: Portland state University.

Terenzini, P. T. \& Pascarella, E. T. (1991). Twenty years of research on college students: Lessons for future research. Research in Higher Education, 32(1), 83-92.

Thompson, C., \& Fretz, B. (1991). Predicting the adjustment of Black students at predominantly white institutions. The Journal of Higher Education, 62(4), $437-450$.

Tierney, W. G. (1992). An anthropological analysis of student participation in college. The Journal of Higher Education, 63(6), 603-618.

Tinto, V. (1975). Dropout from higher education: A theoretical synthesis of recent research. Review of Educational Research, 45(1), 89-125.

Tinto, V. (1986). Theories of student departure revisited. In J. Smart (Ed.), Higher education: Handbook of theory and research, vol. II (pp. 359-384). New York: Agathon Press.

Tinto, V. (1987). Leaving college: Rethinking the causes and cures of student attrition. Chicago: University of Chicago Press. 
Tinto, V. (1988). Stages of student departure: reflections on the longitudinal character of student leaving. Journal of Higher Education, $\underline{59}(4), 438-456$.

Trujillo, C. (1986). A comparative examination of classroom interactions between professors and minority and non minority college students. American Educational Research Journal, 23(4), 629-642.

Van Gennep, A. (1960). The rites of passage (M. Vizedon \& G. Caffee, Trans.). Chicago: The University of Chicago Press.

Vasquez, J. A. (1988). Contexts of learning for minority students. The Educational Forum, 52(3), 244-267.

Wambalaba, M. (1989). Minorities in education: An examination of the obstacles and solutions in increasing minorities in higher education and the teaching profession. Unpublished manuscript, Portland State University, School of Education, Portland, OR.

Wilbur, F. P., \& Lambert, L. M. (1991). Linking America's schools and colleges. Washington, DC: American Association for Higher Education.

Williams, J. B. (Ed). (1988). Desegregating America's colleges and universities. New York: Teachers College Press.

Wilson, R., \& Melandez, S. E. (1984). Minorities in higher education: Third annual status report. Washington, DC: American Council on Education.

Wittstruck, J., Hess, R., \& Stein, R. (1988, November). Challenges and opportunities: Minorities in Missouri higher education. Jefferson City: Missouri Coordinating Board for Higher Education. (ERIC Document Reproduction Service No. ED 310821 )

Yin, R. (1989). Case study research: Design and methods. London: Sage Publications.

Zachary, L. (1982). Affirmative action values and attitudes of administrators, faculty, and counselors compared among community colleges. Community/Junior college Quarterly. $6(2), 111-120$. 
APPENDIX A

INTRODUCTORY LETTERS TO STUDENTS 


\section{Portland State University}

P.O. Bux 751. Pontand. OR 97207-0751

April 20, 1992

Dear

I'm writing on behalf of Annmario O'Brien, a doctoral student here at PsU writing a disgertation on student experiences with higher oducation. Annmarie is interested in identifying the kinds of supports that have holped you atay in college and is requesting your participation with her research. Bhe has been involved with the Academy of Future Educators, a primary component of the PTP, as the evaluator since 1989.

Annmarie views the PTP as a distinctive project and feels the members have a valuable contribution to make by aharing their experiences with higher education. The interviows will be confidential and the resulto will not inolude any references to individual prp members. This proposed study has been reviewed and approved by the Human subjects Review committee here at pSU to ensure the researcher protects the rights and welfare of all participants in the resoarch profect.

I encourage your participation as it is essential to the success of this atudy and 18 an opportunity to help other students. The results can directly effect programs that serve minority students and effect tho ability or this univorsity to serve people of color in the future.

gincersiy

Educational Advancement programs Coordinator 
April 20, 1992

I am writing to request your participation in a research project on the student experience with higher education. The study is part of the requirements for my doctorate in Educational Leadership at Portland state University.

Colleges and universities across the country are examining ways to increase retention rates. At this time, very little information exists on student experiences and needs related to this goal other than from freshman who enter college straight from high school. My research project will provide important information from the student perspective to fill this need. I feel very strongly that your experiences will provide valuable information concerning the kinds of supports that have assisted your continued involvement with college.

The study will include students enrolled in the PTF. As both minority and nontraditional students, I feel you have an important story to tell concerning your experiences with higher education both before and during your involvement with PSU.

The interviews will take approximately one hour and are confidential. I would be happy to meet with you here at PSU at a time convenient for you afternoons or evenings Monday through Friday. Your perspective is essential for developing an understanding of student experiences and your participation will be greatly appreciated.

please call this number, (503) 725-4752, and leave your name and phone number. Your call will be returned and an interview will be scheduled; or if you prefer, please fill out the enclosed form telling me how you can be reached, drop it in the mail and $I$ will contact you for an interview.

sincerely,

Annmarie O'Brien

Portland State University

P.O. Box 751

School of Education

Portland, OR 97207 (503) $725-4752$ 
APPENDIX B

FOCUSED INTERVIEW GUIDE 
The following questions are designed to serve as a guide for the focused interview pertaining to the nontraditional minority students' perceptions of factors influencing their persistence with higher education.

Key topics to be covered during the interview include: precollege experiences; personal goals and commitments to completing a degree; social, financial, environmental, and academic experiences; experiences with the transfer process; perceptions of the racial climate on campus; role of the special program; and perceived challenges and delays.

\section{setting}

All interviews will take place in quite and private room located in the school of Education.

\section{Tape Recorder}

The interviewee will have signed an informed consent form and will be advised, prior to the scheduled interview time, regarding the use of a tape recorder.

\section{opening}

The purpose of the study, stressing the importance of the students' personal perspectives and feeling about the questions, will be reviewed. All participants are to be informed that any questions they feel uncomfortable responding to do not have to be answered.

Looking back over your educational experiences prior to and during college, reflect on those that have influenced and assisted your continued involvement in college. Try to reflect on the meaning of the experiences and influences that have contributed toward your decision to persist in working toward your degree.

\section{Questions}

1. What in your pre-college background influenced and supported you to attend college?

2. Tell me about your reasons for starting or going back to college and the goals you have for yourself?

3. Tell me about some aspect of your social involvement with college that you feel has influenced your decision to persist?

4. Tell me about the financial supports you have in place to assist you with full-time attendance? 
5. Tell me about influences and supports from your family, friends, and work environment that encourage your persistence?

7. Describe your experiences with transferring from community college to the university?

8. From your own experience, how would you describe the racial climate on campus?

9. Tell me about how your involvement with the special program has contributed to your persistence?

10. Tell me about the challenges and possible delays you see ahead for yourself. 
APPENDIX $C$

INTERVIEW SUMMARIES 
The following interview summaries are presented in four sections separated by gender and race. The first section includes interview summaries from six African-American women, one of whom is from the West Indies. The second section includes interview summaries from three HispanicAmerican women, two of Mexican heritage and one from South America. The third section includes interview summaries from two African-American men. The last interview summary is from an Asian-American man who immigrated from Southeast Asia to the United States in his early teens. The summaries describe participants' influences relating to college attendance beginning with pre-college experiences and concluding with perceived future challenges.

\section{African-American Women}

\section{Interviow \#1}

Mary is an African-American divorced woman in her early-fifties. She will be the second person in her family to graduate from college, the first being her daughter. She commenced her education at a community college after being encouraged by her supervisor to apply to the program. At the time of this interview she was in the final quarter of her third year.

I have six kids altogether, five graduated from high school and are working. I have one daughter who graduated from college and is now trying to get into law school. Out of the other five, three of them are thinking about going back to school. They think that if Mom can do it, so can they.

Mary was a homemaker until her youngest child started school. She worked as a teacher's aide while her children attended school and is currently employed full-time at a private tutoring center. Her first involvement education after high school was with an extension program designed for parents to assist their children with schoolwork. During her period of employment as a teacher's aide, she took various classes to improve her performance in the classroom.

Following several years employment as a teachers aide, she arranged to attend college full-time. This initial experience was difficult. Mary felt unprepared for the rigorous demands of college life, particularly when combined with family responsibilities. Age was also a factor in her discomfort and she described feeling out of place compared to the predominately traditional-aged college students. Completing assignments on campus was important for her due 
to the interruptions and responsibilities from her family which left her little time to study at home.

I tried to spend as much time on campus as I could to do all my studies. At home, I had the kids and I needed to study with them.

She remained in college for one school year before leaving to work at a private tutoring center, where she is currently employed. In the late 1980s, her supervisor told her about the program for encouraging minority participation with careers in education and encouraged her to enroll in college and apply she did so, and found she was able to transfer a full year of college credits from her previous classes, leaving her three years of college work before she could qualify for a baccalaureate and apply to a fifth-year teacher education program.

It took Mary nearly twenty years to return to college and pursue a degree after her initial attempt. At the time of this interview, she was working full-time and experiencing difficulty with the combination of work and school. She was also beginning to recognize that some changes regarding work needed to be made in order to successfully finish the requirements for her teaching credentials.

Her family of six grown children and colleagues at work are supportive and encourage her persistence with college. other key people in her life who support her endeavors and provide encouragement include professors at the community college and the special program administrators.

Scholastic achievement is important and sometimes difficult aspect of college for her. During her first attempt with she college she felt academically unprepared and feared she would not be up to the challenge the second time around. This fear was alleviated at the community college with the available academic assistance programs.

The transfer from the community college to the university was difficult, mainly due to a class she felt both unprepared for and wrongly advised to enroll in. During the interview she broke down in tears and described how her feelings of competency had been diminished by this situation. This situation was made more distressing because she believed a failure would disqualify her from the program. She described the university as very different and less hospitable for the community college. At the community college academic supports were stronger, classes smaller, and assistance more familiar and readily available. 
Here at the university it's a lot bigger and people and schedules are busier. You have to make appointments so they are harder to get to.

The program gives you two years at the community college and two years at the university. It would have made my year at the university a lot easier if $I$ had went ahead and stayed that extra year at the community college and taken the lower division courses.

The transfer from the community college to the university was somewhat eased due to advanced registration and the orientation provided by the special program. However, class assignments and advisor recommendations were often confusing and difficult for her to follow. While she started the year with confidence, the prospect of falling behind and not keeping up her grades diminished her feelings of competency.

Initially, she started her education for self-improvement and to assist her children through school. At present, she feels committed to finish due to the three years already invested and a strong desire to graduate and demonstrate to her children one is never to old to return to college.

She would like the opportunity to be more involved with social activities at the university, but has little time for anything other than program related events which she described as informative and enjoyable. Financial resources to fund her education come from program tuition waivers and full-time work.

The academic advising, counseling, and financial supports provided by the special program have been crucial to her continued involvement in college. However, she feels the program could improve on certain aspects of course placement, specifically making sure students have the necessary prerequisites prior to enrolling in required classes.

Major challenges and possible causes for delay include balancing full-time work with classes, and maintaining the necessary GPA to remain in the program.

\section{Interview \#2}

Lenore is an African-American woman in her late thirties and a single mother of two preschool children. she is the first person in her immediate family to attend and complete college. She joined the programs a graduate student looking to make a career change. At the time of this interview she was completing the 
prerequisites for admission to the fifth-year teacher education program.

In the household these days you are always telling your kids, okay, you've got to go to college. I never heard that in my mother's house. Never! I think probably by reading and dreaming, this is where a lot of it [desire for an education] has come from.

Lenore is a first generation college student and sole member of her family to attend and complete college. She completed her secondary schooling in the West Indies and her baccalaureate at a college on the East coast. She maintains that it is both a combination of luck and her own personal determination that has influenced her college attendance. She reflected on influences that encouraged her interest in education starting in her elementary school years. These influences included an environment that was warm, caring, and supportive of her emotional and academic well-being. The acceptance in this nurturing environment and being treated as a capable student made a difference in her attitude toward education.

Lacking the financial means to attend an academically oriented high school, she was encouraged to attend a commercial school and was trained in clerical and secretarial skills. She felt this area of study not the best for her, but more desirable than no secondary education. After graduation she found employment with the government, but soon found civil service work effortless and boring. Following the footsteps of an admired teacher who emigrated to the United States and completed her Ph.D., she left her home country, and commenced her academic career on a part-time basis while working at her own business and as a domestic.

Her immediate family was not helpful or encouraging in her academic endeavors. She felt that if anything, they discouraged her ambitions because they represented a different perspective than other family members. Lack of support from her family did not deter her commitment to complete her education, and she purposefully developed friendships with individuals supportive of her endeavors.

While attending college in the United States always appealed to her, the specifics of what the education would apply to in the world of work was not as clear. prior to enroliing in college, she did not review any programs with advisors, and continued studying the familiar area of business. In the long term, she felt this area of study was not the best for her. She also felt a considerable amount of time was 
wasted due to not having a clear direction and vision of how the degree would apply toward a long term career.

When she first arrived in the Pacific Northwest, she explored classes at the local community college with the intent of exploring a career change. She was told informally about the special program designed for minorities interested in education by a non-minority student. When she inquired about the program she was directed a counselor at the university, applied to the program, and was accepted in time for the fall term. The necessary prerequisites for application to the teacher education program were outlined by an advisor, who's position it was to oversee the students progress, assist with financial aid, and class selection.

The opportunity was here when I came. I believe in God, and $I$ believe in fate. When $I$ came here, $I$ was in the right place at the right time.

Seeking academic support has not been difficult for her. She credited herself with having an assertive personality and feels confident to ask questions and seek assistance with anything she does not clearly understand. She also described the support that was often structurally a part of her classes as providing the atmosphere to question and clarify information with professors and students.

She has little, if any, involvement with university social activities outside of program related and family oriented events. The commitments of working at the university, caring for two young children, and studying occupies all her time. Financial resources to fund college attendance include program funds applied toward tuition, loans, and part-time work as a graduate assistant. When finances get tight she is confident that friends will provide support.

As a minority student attending a predominantly white postsecondary institution, race relations have not been a negative factor for her, mainly due to being raised in a country where there is little focus on race.

In terms of my classes here, it has been great. In terms of minority vs. majority, often I have been the only one. Sometimes it may be two or three of us. But, because of the background I came from, we never focused on that. So, it has been easier for me.

However, the experience of working several years as a minority woman in corporate America was very negative. She felt very strongly that the emphasis on competition worked against her personal value of cooperation. 
The most important aspects of the special program for her are the availability of knowledgeable people at the college assisting with events/crisis as they arise; the direction, clarity of course requirements; and concise time frame. She spoke very highly of the administrators of the program and their involvement and support of the students, particularly their sensitivity when providing assistance for personal as well as academic related problems.

Her major challenge after completing the requirements for her certification is being accepted in a predominantly white profession.

The only major challenge I'm trying to figure out right now is in terms of trying to change the structure. How many minorities are in the teaching profession? What worries me is at the end of the program, will I be accepted as a minority in a profession dominated by whites? Will I be given a chance and given help?

As the sole support for two young children, she considers the lack of assistance and support for parents with young children, specifically the lack of affordable, quality child care, as a major obstacle to completing her advanced studies. She described the situation at the child care center affiliated with the university, where the capacity is insufficient to meet the needs of current staff and students, as an example of the lack of institutional support for parents. Other than delays due to lack of adequate child care, only concerns with her health or that of her children's would delay her completing her graduate degree.

At the time of this interview, her goal is to complete the necessary requirements for her teaching certificate and put her life experience and cultural background to work in an educational setting. She feels strongly about her desire to be a teacher and to take advantage of the opportunity the program. She feels uncommitted to working exclusively in minority schools and feels whites have a lot to learn from having African-American teachers, particularly those from different cultures. She acknowledges the necessity of rejecting extraneous material needs, accepting delayed gratification of material comforts, and the importance of focusing on the long-term benefits of having teaching credentials to keep on task.

\section{Interviow \#3}

Letitia is an African-American woman in her early thirties and a single mother of one child. She has one sibling who has attended college and works as a 
professional. She started her education at a community college and joined the program prior to transferring to the university. Her significant other is a college graduate. At the time of this interview, she was completing the last term of her senior year and had applied to the graduate school of education.

A lot of times you're the only black person in class. You are expected to represent your people, and represent them well. You're expected to know everything about black history.

Letitia attended a predominantly white elementary school in a suburb on the west Coast. Other than her brother, she was often the only African-American at the school. She recalls a fifth grade teacher promising $\$ 100$ to anyone in the class who went directly to college from high school. She felt at that time, like others in the class, that she would earn the money. However, she acknowledged that the teacher was right. Neither herself nor the majority of her graduating class went to college immediately following high school. Her choice was to go to work.

She described her family as one full of strong women and recognizes how resourceful they have had to be without an education. While very proud of them, she clearly recognizes life could have been greatly improved had they had the opportunity to attend college. Her younger brother graduated from college and she feels he has been an important role model for her. She found it very helpful to watch him go through the process and learned from his mistakes and successes. She is aware of the importance of having a role model to follow and feels strongly about being a positive influence on her niece and daughter. Wanting to be more in control of her life, along with the recognition that she would very likely be the sole support for herself and her daughter, inspired her commitment to completing college.

She acknowledged that the jobs she held prior to returning to school did not encourage continued education, if anything, they discouraged it. She worked mainly in clerical positions after high school, spending an average of two to three years at each job site. A period of unemployment and being a welfare recipient influenced her decision to return to college at the age of twenty-five. She believes a college degree is something she needs for her confidence and recognizes that without a degree hex options for employment will always be limited.

opportunities provided by the state welfare program set into motion her academic career. Before moving to the Pacific 
Northwest, she lived in a state that provided single welfare mothers the option of attending college. She was provided with child care, academic support, and career counseling. This was her first college experience and her current studies are a continuation of this initial endeavor. When she started out in college, her intention was to study drug rehabilitation. Upon advice of a counselor assigned to her in the early stages of college, she was provided the opportunity to examine what this entailed and decided to change her major to education. She felt very fortunate to have had an advisor what was up front, available, and supportive in relation to exploring possible areas of study.

I luckily found someone who made me very aware that this is the time to make choices based on what you really want, what you really can see yourself doing.

Her current funding for college comes from a variety of sources including a graduate assistantship, tuition waivers, and support from her significant other and family members.

I'm definitely willing to live on a very tight budget. I think it's well worth it. Doing this solely on one's own would be very difficult.

When she re-enrolled in the community college to continue her studies, she met with a counselor who familiarized her with the campus, academic courses, and support services available. He assisted her in making contact with other students and community organizations, informed her of the special program for minorities interested in educational careers, and assisted her in planning out a program of study that would transfer to the university.

I know that he was one to see me succeed, like counselors do. He was also a key for me to this new community I had just moved into. He was a great help.

Prior to transferring, her concern that academic requirements at a university would be too demanding was alleviated by her involvement with a six week residential summer program at a four year college. The program was designed to provide students the experience of an upper division, full-time course load. The summer program increased her confidence and self-esteem in relation to feeling capable of continuing her studies at the university.

At the start of her third year, following her counselors advise, she applied to the special program and was accepted. Regularly scheduled meetings, early registration, tuition waivers, and familiarity with administrators, counselors, and students were all crucial aspects of the project for 
her. However, she expressed the need to have time to informally talk, and share experiences with other students in the program.

The accessibility of this urban institution by public transportation and having a special place to go when she needed to talk to someone about academic or personal matters have contributed to her successful persistence. Working part-time on campus has also eased the transition to the university and familiarized her with other students.

It is a neat environment. Everyone at the workplace understands what it means to be a student and that classes come first.

At this point in her life, with family and work commitments, she is able to discipline herself to study and seek out tutoring when necessary. While tutoring services are offered to students at the university, she feels uncomfortable seeking help from strangers. Instead, she seeks assistance from students in her classes and others involved with the program.

Significant classes that have strengthened her resolve to continue her studies include Black studies and Sociology, particularly those classes that examine American society, how it works, and her place in it. She felt unfortunate to have had to wait until college to become familiar with her personal ethnic and racial history. Often she is the only person of color in her class, and due to this distinction, student and professors often look to her to provide clarification and explanation of the African-American experience. She considers herself lucky to have had the opportunity to become familiar with African-American studies. Being able to respond to inquiries concerning her history contributes to her growing confidence in her capabilities as a student and teacher.

As a woman of color she has experienced what she terms as "elitist professors" and has felt she has had to prove herself not only as a African-American but also as a woman. still, she does not feel out of place in a predominantly white university. She credits this to her attendance at predominantly white schools as a child and being involved in an interracial relationship. She feels racism is present at the university and must not be ignored, but also that it should not run her day to day life. At the same time, she is aware of the difficulty and discomfort felt by some African-Americans raised in segregated neighborhoods.

Race is something I don't dwell on. I just think it's factual. 
She often feels there is a obvious tension, particularly among the white men, when the topic of race comes up in class discussions. She feels the real issues of race relations are not addressed at the university and need to be. Students should be provided the opportunity to examine and discuss their feelings and values regarding race relations as opposed to ignoring and avoiding the topic.

She acknowledges the recurrent conflict between family and career that is exacerbated by her upcoming marriage and subsequent plans to have more children. At the same time, she wants to move ahead in her studies and complete a graduate degree. Other major challenges she sees ahead include fatigue, facing another year of school, and the mounds of paperwork involved in applying to the fifth-year program. The most difficult challenge is finding a way to merge and balance the life choices of family, school and work.

The major challenge is the fatigue and being able to continue to push myself and being able to fit it in with all these other important things.

The only causes for delay she perceives in spite of all that is going on in her life is not being accepted into the fifth-year teacher education program. She has considered her options and feels strongly that if she is not accepted, she will apply to a college in a state where students have the option of substitute teaching while working on their teacher certification.

\section{Interviow \#4}

Pauline is a single African-American woman in her early thirties. She will be the first person in her immediate family to attend college. Her parents attended high school and worked in blue collar jobs. She commenced her education at the community college after being encouraged to join the special program. At the time of this interview she was completing her third year.

One thing the project does offer is support [financial, academic and personal], and I think that's why a lot of people you have been interviewing have been successful.

Pauline could remember no discussion or encouragement to attend college during her elementary or high school years. However, she did recall one elementary teacher she was very impressed with and whom she would like to model herself after. The teacher was very dedicated, encouraging, and 
open to sharing her culture with her students. While in the fifth grade she was involved with a district bussing program, which she described as a major change in her life, bringing her away from family and friends. Following the change in school location from predominantly AfricanAmerican to predominantly white, she recalls no mention of careers or college attendance. During her high school years she returned to her neighborhood school. In this environment, education was a low priority among her peers. Although she was not interested in higher education at the time, she was very aware of students positioned on the upper track and headed for college. The support she received was just to graduate and she was involved in a "stay in School" program.

Her first college experience was with a community college which she attended mainly due to the financial support of her parents. While attending the college, she continued to work with the "Stay in school" program and the majority of classes initially went well. However, the math component of the program created an obstacle and she quit.

I had a tough time. There was nobody to talk to, nobody to get help from. I just withdrew and stopped going. I thought it would be easier to work.

Her career goals developed as she matured and she recognized, after years of clerical work, that without some form of higher education she would not go far in the world of work. The growing awareness of the bleak situation facing her friends who dropped out of school and became involved with self destructive behaviors, and the desire of her parents for her to go to college, encouraged her to examine her options and return to school.

She heard of the special program to involve minorities in education through a church member, a minority principal, in the public school system that is an institutional partner in the special program. In spite of the stringent time

requirements, the program has been crucial in getting her on track toward a college degree and supplying course structure, encouragement, and financial support. This principal was very instrumental in assisting her with clarifying her goals and completing the application process. She also provided her with much needed encouragement to give education a second try.

The social aspect of college has no relevance to her life. Her time is consumed with school, studying, and part-time work. 
Do I have a life? Basically no, I don't. As a matter of fact, I leave this college, go to work from 5 to 9 and come back here till the library closes at 11 . Then I go home.

As she is her sole support, she finds finances very tight. She has tuition paid by the special program, works parttime, and occasionally gets assistance from her mother. At the time of this interview she was looking for alternative financial supports. If they are not available, she will increase her work hours or, if necessary, take out a student loan. While concerned about getting into debt, she believes the benefits will eventually outweigh the disadvantages.

The most difficult subject in relation to academics for her is math. Discouragement with this subject was very influential in her decision to withdraw from college during her first experience. The second time around, academics were still not easy, but the main difference included academic supports in place to use when necessary. She feels she has succeeded so far due to the availability of this assistance.

If I do ok with statistics, that's going to be the determining factor in the type of degree I get. If I have problem with statistics, then I'm going to have to leave [the class] and take a couple of terms longer to complete the program.

The transfer process from the community college to the university went very smooth. The main changes included atmosphere, campus size, and general environment. She described the community college as warm and inviting with a friendly and casual relationship existing between the students and the instructors. This relaxed atmosphere encouraged a freer exchange of information and ideas between students and faculty than found at the university. The biggest change was the size of the campus and not knowing many people. Having a place on campus to go visit with familiar people relieved some of her anxieties.

You know, I was afraid I was going to get lost in transit.

The special project provided orientations, meetings with other students, pre-registration, and advising. She currently struggles with 15 credit hours at the 300 and 400 level and is having to spend summers in school just to keep up.

It's hard. The average student coming here would need to spend at least 5 years to get a bachelors. Those of 
us coming over with 2 years are expected to finish in 4 years.

She feels as a minority there have been times when she did not receive all the necessary information required to complete an assignment, but also feels she is developing the necessary assertiveness and no longer has trouble asking for the information she needs.

It [racism] makes me work harder, but it's nothing blatant. This has occurred with students and teachers but is not a deterrent.

Major challenges ahead for her include the required testing for teaching credentials, math classes, and being accepted into the fifth-year program, particularly with the increasing competition for positions in the program. The only cause for delay would be the difficulty balancing work and study while attending full-time.

The biggest monster ahead of me is the NTE and C-Best. I'm going to talk to students that have taken it, purchase some study guides, and get together with students to prepare.

\section{Interview \#5}

Francine is an African-American married woman in her mid-twenties. Her husband is attending graduate school. Both her parents and siblings are college educated professionals. At the time of this interview she was finishing the requirements for her teaching certificate. She joined the program after completing her bachelors degree.

Anyone of color I would talk to as far as a person to reach out to for information. My first year here I could say there were less that 20 entering freshman that I knew. You have to find someone that you can relate to. If you don't have a support system you won't be here very long.

Throughout her early years, education was stressed by parents, siblings, and community members, a combination of these influences instilled in her the significance of college attendance.

In the community you see people that don't have anything. They don't have good jobs and they are on drugs or whatever. They are denied a lot of 
opportunities because they are not educated. That has influenced me.

While in high school, she took the basics for graduation without attending to their relationship to college. requirements. Faculty and advisors kept track of her records to make sure she was taking what she needed for graduation and nothing more. While this lack of guidance was not detrimental to her own personal goals, she felt many minority students, including those tracked for college, were academically neglected, pushed ahead, given grades they did not earn, consequently leaving them the long term losers.

This [academic neglect] works against them when they are in college. This happens at the university with athletes and they end up not learning anything. you have to make the professors at the university accountable to teach you something.

Francine enrolled in the university in 1985, and found herself on her own in relation to course selection. Initially she felt stranded until she formed a friendship with other students of color, particularly the African students. She described how they took her under their wing, explained how the university worked, and provided the necessary guidance in relation to course selection for a major. In retrospect, she acknowledged that these students were relatively easy for her to meet as there were so few of students of color on campus. She felt her affiliation with students sharing similar goals was critical to her persistence.

I think if you meet someone who is in college, it's easier for them to push you or for you to push them to continue the program. If you meet someone out of school then you really don't have much of a support system. A lot of people that started school with me did not giaduate, for different reasons. But I think that meeting the people that I did the first year was very instrumental in my continuing with school.

She became involved with the social life of the university through part-time work on campus and becoming involved in activities sponsored by International studies department. During her tenure as an undergraduate student, many important support structures have been added to the university system to encourage minority persistence.

Her selection of a major developed came about as she took classes relating to her personal interests. During her. first two years, she found she had accumulated enough credits in African studies to apply toward an International 
Studies Degree and made this her major. She first met with an advisor when she was close to finishing the program.

I found out about the advising department by the time I was ready to graduate. I basically figured out what to do by trial and error.

Financial supports have included working part-time on campus, loans, grants, parent support, and living at home for part of her undergraduate years. She recently married and her husband is currently her major source of financial support.

Other key influences exclusive of her early supports, included a family of three brothers from Africa and a professor in the Black studies Department. She described them as providing consistent support and encouragement during her undergraduate years. She also developed a friendship with a woman professor who provided her with scholarship information, internships, and notified her of important classes to take.

Her most significant classes were African-American Studies. She acknowledged that often in classes, when the subject of African-Americans or multiculturalism came up she was expected to defend or refute the topic under discussion.

They [Black studies] were a very positive experience. I had all A's and was able to reproduce and use the information from the class.

She described the experience of a friend on campus. A professor teaching a class on minority groups claimed during a discussion on rape that "black woman don't feel anything." Her friend, the only black woman in the class was appalled at the statement. She discussed the situation with a professor on the staff in the same department and asked her to speak to the professor. The woman spoke with the professor, he denied it the intention of the remark and claimed the student misunderstood him. No further action was taken as a result of the professor's comments.

I don't know what to say about faculty, that's definitely a problem. If there were minority faculty and a young person of color was having a problem, they could go to this person and say I really don't understand what's going on, can you tell me something. They would have a resource. There is a tendency for minorities to go to minorities for help because you figure that is the only person who is going to listen to you. 
In relation to her personal experiences with racial climate on campus, she felt it was her responsibility to prove all the stereotypes of black people wrong. To counteract some stereotypes of African-Americans, she made it a habit to always be on time and sit in the front of class. One example of racist attitude she experienced was being asked if she had any problems with the English language prior to having any yerbal exchanges with the professor. She described this as a very significant and bitter experience. Her response was to continue with the class despite of the derogatory remark. She expressed great satisfaction with her success and persistence with the class.

She learned of the special program for minorities via a friend at the university and joined as a post-bachelor's student. She believes that if it were not for the project, she would not be in the graduate teacher program. She had applied to the School of Education on her own three times and believes she was consistently provided inadequate information concerning requirements and deadlines. Through involvement with the program, she was directed to a faculty member who provided the necessary and accurate information. Her recommendation to incoming minorities is-

Be prepared to be ignored. At the college level you are basically on your own. You can request a tutor in different subjects and there are support services, but basically be prepared to work hard and be prepared to find out a lot of things. People don't come up to you and tell you. You have to go looking for information and ask.

Major challenges ahead for her are financial and include finding work and being able to pay back the loans accumulated while in school. At this time she sees no cause for delay as she is too close to completion.

\section{Interview \#6}

Naomi is a single African-American woman in her midtwenties. Both parents are professionals, siblings are college graduates, and her significant other is attending graduate school. She transferred from the community college and became involved with the special project after reading about it in a local AfricanAmerican newspaper. At the time of his interview she was in the last semester of her senior year.

I always thought--yes, I'm going to be a professional, but it never really crystallized in my mind as to how that was going to happen until I got into the project. 
Naomi grew up in an academically supportive home environment complimented by college attendance being a social

expectation among her peers. Her initial interest in a profession, expressed while she was in the fourth grade, was taken seriously and nurtured throughout her elementary and high school years by both her parents and teachers. While in high school, she involved herself in academic activities, providing herself with valuable skills for use in professional fields. Currently she is working on campus in an environment with other students who support and share similar goals in relation to completing their degrees.

Like the majority of her high school peers, she started college as a full-time student at a residential four-year state university. The experience was far more that she could handle socially and she dropped out her spring term. This was her first major setback. After leaving college she went to work for a large corporation in the city, and rapidly became disillusioned with the corporate world. She described a strong feeling of alienation as a woman of color working in an environment with predominantly white men. This negative work experience was a major catalyst to return to school.

Shortly after quitting her job, she enrolled in a community college and began her second attempt at college attendance. Initially she felt very self-conscious attending a community college because she felt it was a step below her high school peers and her own personal expectations. These original feelings concerning attending the community college hindered her social connections tc events and students, but continued involvement increased her perception of the status of the college and she often reflects on the causes of those initial negative feelings.

Now when I try to give people advice, I'm always singing the praises of ' because it's an excellent community college, one of the best.

She acknowledged her awareness of a college degree as essential in this society, and believes there is no alternative if wants a career and to be taken seriously. She expressed a determination to complete her education and continue with advanced studies either after working a few years, or continuing shortly after finishing undergraduate work. At the time of this interview, she was struggling with this decision because she felt an obligation to keep her initial commitment to the program. This obligation included applying to the teacher training program, completing the program, and teaching in a public school. 
Her parents financed her education immediately after high school, but provided minimal support the second time around in an effort to encourage her sense of responsibjility. She finances her education through part-time work, parental support, and tuition waivers granted as a member of the special project.

A key person who influenced her academic pursuits, exclusive of her immediate family, was a professor from the Black Studies department. She described this relationship as her first opportunity to be around a black male with a Ph.D. at that level in the university. This experience helped her feel confident in pursuing and developing relationships with other professors. She took great pride in the fact that a professor thought she had something to say and spent the time sharing ideas and listening to her. She believed this fueled and encouraged her curiosity and eagerness to learn. This level of communication with faculty was missing from her first college experience. However, she feels unlike this experience, she did not seek this communication out, and the school was not to blame.

I didn't make any effort. I didn't go into any professor's office and sit and talk with them at all.

Other experiences with college administrators at the community college were very significant to her. She described their interest in knowing who she was, asking about her progress, providing clear direction and a concise time frame to complete classes as the many aspects of support they provided. Being recognized and familiar with professors and administrators was very important to her persistence, more so than networking with other students.

The [course] structure you can get from a book. It was more their warm presence. They made me feel very special. They made me want to keep impressing them.

The transition from the community college to the university was very smooth for her. Periodically she would enroll in classes at the university and when the time came for her to transfer full-time, she was very familiar with demographics, expectations, and layout of the campus. Having this familiarity with the university setting made the transfer a manageable and smooth process.

Following her transfer, she found an advertisement in a local African-American newspaper describing the special program for minorities interested in education related careers. She inquired about the project, applied, and was accepted prior to the start of her third year. She felt acceptance into the program was a affirmation of her self- 
worth and potential as a student. The patterns, structure, finances, and clear expectations were major contributors to her completing her degree.

It was such a big pat on the back, telling me "You are really worth it." I always knew that eventually I was going to do it, but I never knew how. Being accepted into [the project] clarified the how and provided the support and encouragement. I was told, "We think that you are very important, we think that you'll be good for the [project]." It was a real boost.

Networking and meeting with other minority students was not an important aspect of the project for her. She had the support at home and the know how in relation to what to expect and how to negotiate the academic environment. The academic advising, course planning, support, and affirmation of her abilities coming from administrators and professors, were influential in supporting her successful persistence with college.

Classes most influential in her academic experiences were those affiliated with Black studies. They supporced her own personal growth and development and her ability to respond intelligently to inquiries of the African-American experience.

As a woman of color to be able to respond to and deal with racism in an assertive manner is important. It has helped me discipline myself in terms of wanting to study and have the facts easily accessible.

In relation to experiences with racism and sexism, she perceives a lot of anger directed against her both as a woman and as an African-American.

They [white men] just seem so scared and angry with me all the time. Racism is visible and the professors see it. There's a few white women in the classes, but they never say anything. I don't know if they're afraid of not getting a date or what they're afraid of. They don't say a word.

She feels there is a level of tension among white males when a black woman is present. This situation stimulates her desire to respond to racism and sexism in a calm and rational manner, with facts to back up her responses. An example of racism/sexism she described

I am in the student lounge, the only other student there. Two white males in suits are discussing a paper 
they are turning in--"I don't know how he is going to grade, he could really rape us on this one."

Some challenges she sees ahead of her include having the personal discipline she believes necessary to keep working toward her academic goals. Only pregnancy and/or lack of finances would interfere with her continued graduate studies.

Hispanic-American women

\section{Interviow 7}

Martha is an Hispanic-American married woman late in her late forties with two school age children. Her spouse attended college and works in a professional field. Several of her siblings attended college. She was raised and attended elementary and high school in South America. Upon arriving in the United States, she studied English and business. She commenced her education at a community college and joined the project after enrolling at the university. At the time of this interview she was completing her third year of college.

I always had it in the back of my mind that I wanted to have a degree no matter what.

Martha attended an academically-oriented high school and felt well prepared for college attendance. In her early twenties she left her home for the United States, studied the English language, and enrolled in business administration classes at a community college on the East coast. College credits from her initial attendance transferred to a West coast college where she continued general studies on a part-time basis. She worked at a suburban school district as an interpreter for the Hispanic Community. After several years with the district, she made the decision to resign from her position and returned to school full-time to complete her degree.

The purpose of attaining her degree was twofold. First, to give herself more authority and credibility, and second, to advance in the public school system. She feels that by focusing on teaching she will be able to continue her involvement with Hispanic-American students. At the time she decided to return to school the district was experiencing an influx of spanish speaking students, and the need for teachers familiar with the language was growing. 
Her career goals include teaching ESL, Spanish, and being more influential in the decision making process of school and the district. She intends to remain in school full-time until the completion of her Master's degree.

Due to the demands on her time of part-time work and fulltime classes, little time is left for social activities at the university, other than program-related events. She found a special niche for herself working as a teaching assistant in the Spanish Department. This position, combined with friendships formed with other students, provided her with a solid and positive connection to the university.

Financial supports come from a variety of resources including occasional part-time work, tutoring, teaching noncredit classes at the community college, summer employment, tuition waivers paid by the special program, and support of a working spouse.

Most of my help comes from my husband. He is a tremendous support to me. Financially I cannot complain because everything has been there for me.

Key people who influenced her to pursue higher education include a literature teacher in high school, her parents whom she described as demanding, artistic, and

intellectually active people, and instructors, particularly a professor at the community college. Her first experience with an advisor was disappointing as she could not get in contact with him for several weeks and consequently

requested another advisor due to his unavailability. On her own, she sought out a supportive instructor who provided her with the necessary advice on course selection. Still she has minimal contact with her current advisor at the university and feels he is a very busy person, with little time to communicate with her.

With little advance planning, she left her job and enrolled in the community college, taking classes in general studies transferable to the university. She was not new to this educational environment, as she has taken classes on and off since her children were small. She happened upon information about the special project for minorities while reading a newspaper.

I never thought about it. Nobody told me anything. Just by accident, I found the advertisement. I realized I had all the requirements they're asking for, so I decided that I was going to try for it. 
Full-time college attendance is far more demanding that she had anticipated, but she has been able to make the adjustment due to the support of her family, other students, and the special project. The transfer process was very smooth, as the majority of the paperwork was cooperatively completed with project members and administrators. She felt the advanced registration was most helpful, mainly because it guaranteed students the classes they needed for graduating. other than getting used to taking a full course-load, she has had no problems at the university.

The project has been very helpful particularly with the administrative aspect of school.

They keep us informed of all the events that are happening and provide us with a perspective on the profession. One thing I would like to see is more enthusiasm toward the children in high schools and earlier to help them focus or to open their minds about what they want to do. Their recruitment part should be reaching for the very early grades. To me that is crucial for minorities.

She has experienced no overt racism but has experienced insensitivity by some professors. She described a faculty member with a negative and unprofessional attitude toward students in the class. Several students gave an oral complaints to the department but were reluctant to put them in writing. Many of them felt uncomfortable with the thought of having to continue in the class following registering a complaint

Unfortunately, I have come to the conclusion that here at a four-year institution the professors have a lot of their own work to do and they leave most of the class work in the hands of the students, many in a good way with a lot of guidance. Some of them leave it up to the at all. That, I don't think, is the best way for students.

Major challenges and possible causes for delay include getting accepted into the school of Education, finding a job in an era of increased competition, mid-life crisis, and health related reasons.

Health reasons probably, because if the health goes everything else will go. 


\section{Interview \#8}

Juanita is a single Mexican-American woman in her early forties. Her parents attended some elementary and high school. Her siblings have high school and college degrees and work in trades and as professionals. She returned to the community college for a career change, and was directed to the project after expressing an interest in teaching. At the time of this interview she is in the third quarter of her senior year.

Meeting people who come from the same or similar backgrounds, who share the same goals, and who support each other makes a difference.

I think what has kept me on track is first you have to be motivated from within, and second supportive people who help you.

Juanita spent her youth, exclusive of school, in a Spanish speaking environment. She does not recall any friends, family, or teachers, who had any expectations of her going to college. During her high school years, classes were self-selected and based on interest and credit hours required for graduation.

Her first higher education experience was with a business college attended immediately after high school. Having no funds to attend school, she took out a loan to cover expenses for a one year program. Upon graduation she took a clerical job for a large company. Following this period of employment, which lasted several years, she remained at home full-time to care for an ailing parent. To re-establish herself in the workforce, she became involved with an urban volunteer project. After this experience she enrolled in a four week refresher business course at the local community college and returned to clerical type work. After nearly five years at this job, recognizing a personal need for change, she enrolled in a program at a local community college for instructional assistants.

I decided I needed a change. I mean how attached can you get to a machine. Although I enjoy working with figures and using my hands, I wanted something more meaningful. I decided on the program for instructional assistants at the community college. That's how I got started. Once I was in the program I had exposure to the classroom. Right then and there I found out that's what I wanted to do. 'That's where I made the decision to go all the way for it [teaching credentials]. 
Her interest in pursuing her degree was encouraged by administrators involved with the program supporting minorities to get involved with teaching careers. The program helped facilitate her successful progress with college. Along with providing her with the course structure, financial support, and familiarity with educational careers, the special program has provided her with the encouragement in her ability to succeed.

It makes a big difference because you don't feel alone, and that helps. When you are feeling low or you want to just stop by [the program office], having someone there makes a difference.

Her current goals are to become a certified teacher with an endorsement in special education. She is very committed to this goal since she has invested so much time and energy into this major career change in her life.

I've gone so far I better finish, I invested so much time and effort, and it hasn't been easy. I can understand why some students just don't get this far. Especially once you are married and you have a family. I'n very fortunate.

She has very little social connection with students other that at regularly scheduled program meetings. Her family continues to be her main priority and she spends most of her free time helping with a disabled parent and with nieces and nephews.

others in the program are so involved and busy too, between their work and school. It makes a difference to see them in the hallway and say, "Hello, how are you doing," to know that they do care and are behind you.

Funds to support he full-time college attendance come from a variety of sources including tuition waivers provided by the program, living with a parent, and savings from former years of work. She feels very strongly that without her family support she couldn't afford to attend college full-time. She acknowledged that if she had to work, even part-time, she would not have been able to keep up the with course requirements.

I want to say one thing about loans that many student take out because they need them. I'll tell you, I made my mind that I was not going to get into debt. I have seen my nephews get into debt and the trouble they had. The availability of jobs when you are finished is so limited. I'd rather just not go. When I got my first loan, I had a year before I had to pay it back, but at 
that time there were a lot more jobs available than now.

An encouraging and supportive person, met in her first year at the community college, was her supervisor. Even though she was attending a branch of the campus without a chapter of the special program, she was encouraged to travel to another campus, apply and get involved.

She has had many positive experiences and few negative ones with her professors. She described the differences in relation to personalities, with some being more tolerant and easy to get along with than others. As a minority woman, she did not interpret negative interactions with faculty and students in relation to race, and described no overt racist incidents directed against her personally.

Her transfer from the community college to the university was described as comfortable. She was logistically familiar with the campus and could find her way around.

I didn't have a hard time. I heard comments about other students really being intimidated.

My sister used to be here years earlier and I used to come and pick her up. I think that helped.

In relation to course selection, she took it upon herself to review the college guidebook and prepared her own course of study following the university guidelines. She did have some scheduled time with an advisor to review classes and the necessary requirements to enroll in the fifth-year teacher training program.

I should go more often to see my advisor, but it's making the time. You hear horror stories about them, so you're kind of hesitant. Does he really know what he is talking about? Sorry to say that. I'm sure there's some good advisors.

Major challenges ahead for her include competition for getting into the program, working as a team with other professionals, and developing the interpersonal skills necessary to work in a cooperative type of environment. After the time and effort spent on coming this far she does not see any immediate cause for delay other that illness.

\section{Interviow \#9}

Maria is a Hispanic-American woman in her late thirties, married with two elementary school age 
children. She attended college immediately after high school, graduating four years later with a bachelor's degree. She joined the project after returning to the university. to complete her teaching credentials. College was always an expectation in her family, although neither of her parents are college graduates. Her spouse has some college and works in a professional field. At the time of this interview, she was completing the necessary prerequisites for admission into the fifth-year teacher education program.

For students of color, I think a major package of those tools is learning how to confront it [racism], deal with it, how to interrupt it and not be targeted or repressed by it.

Maria was raised in an environment where education was highly valued and college attendance was an informal expectation from both the home and school. Role models were available as older siblings went off to college, succeeded, and were a source of pride to her parents. She attended a college preparatory high school in a large Midwestern city where students were selected for admission on the basis of standardized test scores. Although she was tracked for college attendance, counselors at the school did not support her application process or counsel her in relation to possible areas of study to pursue.

In retrospect she felt she may have received less assistance because she was Chicana and believes she was discouraged from applying to top quality schools. Her selection of a university was done solely by recommendation of friends who shared her interests in the fine arts. She applied to college and sought the necessary financial aid on her own. Her parents were not involved with her education once she left home. This was mainly due to the geographic distance between home and school. She completed her degree in four years and worked in her selected field of study until shortly after she started her own family.

I don't know what I would have done if I hadn't latched on to theater. I wasn't really clear on what I wanted to do, it was sort of like I was following a pattern that had been set out for me. I knew I was expected to do this, but I wasn't really clear on what specifically I vanted to do.

Following her first child's birth, she became very interested in child development and studied the topic on her own, while working in the theater. She found the demands of her employment too strenuous and the hours very inconvenient especially with the responsibility of caring for a young 
child. To direct her new found intersst, and accommodate her child, she found employment in teaching-related jobs. Following her second child's birth; she joined a child care cooperative and was hired as a full-time preschool teacher.

At this period in her life she began to examine racism on an intellectual level, connecting childhood rearing practices and schooling to social conditioning. She realized early education was laced with subtle inferences of racism and these attitudes influenced her own development and life choices. These experiences stimulated her desire to be certified to work in the public schools and change the curriculum which she felt minimized the influence of minority contributions.

The opportunity and assistance to return to school presented itself to her through the special program encouraging minority participation in teaching-related careers. Informed of the project by a colleague, she applied and was accepted. At the time she did not have the resources to finance graduate study necessary for a career change, and the financial support available was eminently instrumental in her return to school. Other important aspects of the program included breaking the isolation from other people of color, connection to others committed to multicultural education, structure, and stringent program requirements.

When she returned to college to take the necessary prerequisites for the graduate teacher education program, she had little, if any, social connection to the university. Part-time work, full class load, assignments, and family life consumed all her time. Multiple sources of financial supports were in place prior to her decision to return to college, including part-time work, tuition waivers available from the special project, and a supportive spouse, the latter being essential to her successful transition back to school. At the start of her program she continued to work full-time for the first semester, but found courses too difficult under this arrangement and changed to part-time.

Her primary source of encouragement and academic support in her work environment is a colleague who acts as her mentor. The relaxed work environment and high level of support from her home life provides her the time and environment to apply herself to her studies. She acknowledges the importance of her combined home and work support, but also believes the opportunity to meet and share ideas with other students of color involved with the special project has been a major source of encouragement. A concern she has with the project is the implied leadership role she and others in the project are expected to play. An example is in the area of race relations, where minimal support is available from project 
staff in developing the skills necessary to take on this important issue in the schools.

What's missing is head-hand-neart support for students in the [project]. They are expected to be leaders not only in the field of teaching, but in the community as well. This is an expectation set by themselves and the program. But, we are not provided the necessary tools to deal with racism that exists in the daily environment, and what we will meet as teachers. For example, how to deal with racism among children, our colleagues, and parents.

She described her classes as being emotionally, not academically difficult. She is often the only person of color in class, and feels she has the confidence and support from her professors to challenge racist attitudes expressed by her fellow students. An example she gave was the a student demonstration of the color black. He affiliated it with darkness, blindness, and other negative connotations. She challenged the connection and felt encouraged to speak her mind by the instructor even though the class consensus was not supportive of her views. This experience and others impressed her with the caliber of the professors and their ability as facilitators of discussions challenging internalized racist assumptions.

In spite of the expertise of individual instructors, she feels the university has a long way to go in addressing the core issues of racism found on campus. At present she feels it is on the shoulders of the minority student to accommodate and understand the white culture.

We have to know a lot more about how to maneuver in this environment than any of the faculty or administrators. We have to be aware of our feelings and our cultural differences. What I'm saying is on a day-to-day basis those people have nothing kicking them in the butt to know about us, whereas we have to know all the maneuverings or our files get lost or we just get swept under the rug.

For her, the application process to the fifth-year program was a nightmare. She felt she was given misinformation, and treated with animosity. She felt frustrated and demeaned when told she was responsible for the misinformation. She acknowledged the response she received may not have reflected prejudice, but an overall attitude of hostility toward students in general. Still she believes recruiting and supporting minority students are not priorities of the university. She had the opportunity to discuss the 
situation with the program administrators who she described as supportive, understanding, and helpful.

Some major challenges she sees ahead in relation to completing all the necessary requirements for her teaching certificate include the time commitment, the methods classes, particularly one she has noticed is tagged at the end of the program called teaching in a multi-ethnic setting, and student teaching.

On one hand, I'm pleased that it is there. On the other hand, I'm wondering why this isn't interwoven into the entire program instead as a little tourist trip at the end. I'm wondering how I'll keep my mouth shut about it, or how I will challenge it in a proactive and productive way.

The only obstacles and causes for delay include serious illness of herself or a family member and/or an unplanned pregnancy.

\section{African-American Men}

\section{Intexview \#10}

James is an African-American married man in his midforties He will be the first person in his immediate family to graduate from college. He commenced his education at the community college and joined the project his first year. At the time of this interview, he was completing the first half of his third year.

I realized that without a college degree, my entering the labor force, doing something other that menial tasks or working for $\$ 4.25$ and hour, attempting to assist in supporting a family, was not possible. So for me a college degree was very important because I had the experience, but I didn't have the degree.

Prior to graduating from high school, James had no aspirations for attending college. Although good grades were stressed in his home, there was no encouragement to continue his education. He enrolled in the Air Force shortly after high school. Following his discharge from the military and subsequent employment in the business sector, he enrolled in classes at community college and those offered through his employment. At the time he returned to college full-time he had accumulated nearly 80 college credit hours in business related classes. While the classes 
were job related, few transferred to his present area of study.

After nearly eighteen years working in the private sector, he was laid off as a result of corporate cutbacks and the ongoing recession. He is currently committed to finding and securing employment in a profession where he would be less expendable. He believes, from his personal experiences, that his current employment status is related to having no college degree.

He expressed considerable frustration on being in a position of being over-experienced and under-educated for the current job market and related the following experience of being interviewed at a job fair.

I was speaking to a recruiter at a job fair held at the community college. She looked at my resume and told me, "You supervised people that will be supervising you at that level." I asked her, if she had ever been unemployed since she entered the workforce. She said, "No." I said," Unemployment can be whatever percent in the city, in the state, or in the nation, but when you're unemployed it's 1008." I also indicated to her that I realized that I was not going to come in at the salary or the position I left. I told her I don't mind coming in at an entry level. I know I have the skills, the work habits, the attitude, the tenacity to persevere, but I can't do it if I'm on the outside. She said, "I don't chink you'll be happy."

His primary means of support comes from educators, administrators, and students involved with the special program for minorities interested in careers in education.

The people that are involved, have helped me and guided help. For me, I saw this as a way to get back into the labor force. The people at the community college were like a family to me because they were genuinely interested.

He has applied for a position as a tutor at a neighborhood education center both to gain experience with working with children and to keep contact with others committed to education. He recognizes that children have changed from the time of his youth and feels he needs to get in touch with them and gain a better understanding of their needs.

His social connection to college is limited except for program related events. While not involved in school activities, he is very involved in community and church related youth programs. 
The transfer process has been relatively smooth with staff from the program assisting him with the necessary applications. He found a major difference in course requirements from the community college and the university and feels his grades suffer when he works too many hours. The orientation to the university provided by the special project offered prior to the opening of the term was very helpful in relation to getting him acquainted with the campus.

When I transferred it was a smooth transition. I didn't have any problems and I didn't have any horror stories like some students have. One snag was with financial aid, but it was taken care of right away.

He was told of the special project informally by administrators at the community college when he first was exploring possible areas of study. He felt that he would not be back in school without this program. Administrators of the program have supported and guided him with planning a program of classes that will lead to a degree. He is well aware that academic support is available if and when necessary.

The opportunity to complete a college degree with the support of the special program is perceived as a vehicle to escape low paying jobs as well as a means to secure a position doing work he views as valuable. He feels the program should try to locate additional funding sources for students, like himself, who are having difficulty making ends meet. His financial resources to attend college fulltime include tuition waivers, full-time work, and a spouse who also vorks full-time. Currently he is looking for additional sources of funding including grants and scholarships.

There should be some consideration for those of us coming into the program with experience. If not, hook us up to a service that they can use to search for scholarship money. If the program can't do that, at least pay the fee for an agency to do a search and get the information back to us. Then we can apply for them [scholarships]. By myself, there's not the time to go and do the extensive research I need.

Major challenges ahead and causes for delay include not having adequate time to put into his studies and continuing to work while attending college full-time. He believes working is important and may positively influence his acceptance into the fifth-year program. 
Working with students will give me a little more experience so when my application is submitted to the school of education, because my GPA may be lower, I will have the work experience and there will be enough people who are willing to speak on my behalf.

\section{Interviow \#11}

Michael is an African-American male in his early thirties, married with two children. He is the first person in his immediate family to attend college. He commenced his higher education at the community college and has been enrolled in the program since his first year. His siblings completed high school, and his wife completed college. At the time of this interview he was in his third year at the university.

Actually I'm the first person in my immediate family to go to college. It makes a difference, to show the family that we can do it. My father didn't get past the 6th grade. It is something to prove to the family, that it is it's possible. Then the younger generation can follow.

There are so many African-American kids, males mostly, out there who are in trouble. You know, I feel this pain, there's something I could do and I'm not doing it.

When Michael was in high school he had both the grades and desire to attend college however, no direction, encouragement, or assistance for applying to college was provided by the counselors or teachers. Without their assistance, he selected an area of study, secured financial aid, and enrolled in a community college with an interest in studying the criminal justice system.

If someone's parents were involved with planning on how to reach their goals, then they were pretty much in the right direction. But if you were doing it yourself, you didn't know what questions to ask. I think that when you don't know where you want to go, it's difficult. If you don't have anybody really to ask that's knowledgeable to tell you--"why don't you take some entrance exams and things like that and see where you stand." I was a 4.0 student. There is no rtison why I couldn't have gotten a scholarship to go to college. I didn't know about these things.

He dropped out shortly after starting due to the difficulty of combining full-time work with his studies and joined the 
military. His intention was to take classes while in the service, an arrangement agreed upon prior to enlisting. With the arrangement not forthcoming, he left the military under a breach of contract. After a short time working at low skill, low pay jobs, he re-enlisted in a different branch of the military and was trained in vehicle maintenance and other vocational-type skills. He felt the experience did prepare him for the understanding the process of learning new tasks but the vocational skills did not transfer well into civilian work.

He described his personal goals as developing as he matured and had experiences which expanded his understanding of opportunities available to him.

For along time I didn't have any goals. I didn't have any counselors to aid me. It was pretty much hit and miss. I had no direction.

An episode that acted as a catalyst to return to college was a nationwide strike against a company he was employed with long term and his growing awareness of the limited opportunities available for securing comparable employment. At this time his employment status was undermined as his former company underwent major changes and his union went on strike. He was encouraged by older fellow workers, counselors, and administrators at the community college where he made initial inquiries, to complete his college education and prepare for a major career change.

After his return to school, a part-time work environment allocated a flexible time schedule to include full-time school. The accommodation did not last, as his employer became more demanding and less accommodating. Eventually he made the decision to quit and use other resources for financing his education. Resources he tapped included parttime work, hardship grants due to being on strike, and tuition waivers provided by the college for his involvement in course work toward a teaching career. He would consider taking out loans to finance his education because their repayment would not financially burden him. This is due to the fact a benefit he receives as an Army Reservist is the repayment of all student loans by the government.

His personal life was undergoing major changes when he returned to school. His first wife felt threatened by his education and did not support his efforts. This conflict, compounded by changes in employment status, lead to many changes, including divorce, loss of home, and remarriage to a professional who is supportive of his long range career goals. His wife works full-time and assumes the financial responsibility for the family. 
His academic standing during his tenure as a student has been very encouraging for him. He maintained a 4.0 during the first four terms and had access to and utilized tutoring services offered by the college. He described a growing sense of academic and personal successes which, in turn, gave him a sense of accomplishment and pride.

He was impressed with African-American history classes taught by an Hispanic instructor. He considered her an excellent teacher who involved the students in activities sponsored by the African-American community.

She was intense. She gave all her knowledge and energy to the class. She was dedicated and she let you speak your piece. Her tests were intense, all essay. After leaving that class I felt like I could take any history class. A lot of the faculty were against her being female and teaching African-American multiculturalism. This is not well liked in certain places. A lot of people think it's immaterial, but I think it is very important.

The prospect of training to become a teacher was discussed with him when he first met a counselor at the community college. Criteria for acceptance to and continued involvement in the special program was outlined. Involvement with the program put him on track for planning course work that would transfer to the participating university. His counselor assisted him by reviewing, in detail, an outline of transferable coursework. She also helped him clarify the questions he needed to ask about the program, school, and education in general.

When it came time for him to transfer, he found the difference between the community college and the university a shock, particularly the size of classes and the campus in general. In spite of the initial difficulties, he was ready for a change and felt the classes were challenging and exciting. The transition was eased somewhat by the assistance of the professors, administrators of the special program, and students who made the transfer with him. Meetings and seminars offered through the special program also eased the transition and provided him with necessary contacts and introductions to important people affiliated with the university.

He described his initial experience at the university with exploring a major area of study as discouraging. He had pre-registered for general classes and spoke to several department chairs that said they would help him plan a major area of study. An appointment was made, when he showed up, the professor was busy and did not interrupt his activities 
to keep the scheduled meeting. He left feeling very discouraged with the experience and chose not to pursue this area of study for his major. His second experience, with a faculty member familiar with the special program, was helpful and positive, with the professor taking the time understand his needs and familiarize him with the outline of the second selected area of study.

His involvement with a supportive program for minorities began during his first year at the community college and continued through his transfer to the university. The project provided information about course registration, maintaining a high GPA, and academic support services available. It also provided him with the necessary connections to other students sharing similar concerns and needs. He spoke of the importance of meeting graduates who completed their degrees, overcame the barriers and hurdles, and successfully coped with all the difficulties of being a student. More importantly, he felt the meetings provided members of the project the opportunity to talk with others sharing similar goals and values at different stages of their education and careers.

We had colloquiums where we'd get together and you'd see middle school students and they'd see you. It was really important. When I was in high school, we never met people who were going to college or thinking of going. It wasn't goal oriented. You see people and could say, they did it, I could do it.

He was not unfamiliar with being in a predominantly white environment due to military and private sector work experience. He claims he doesn't have problems with racism, yet, it's presence at the university didn't come as a shock. In his experience, racism is a reality and a given in any situation where there is a limited number of minority students. He anticipates a mixed reception in a predominantly white profession and expresses some anxiety about dealing with the reception he may receive.

I'm not going in with the idea--well when I get there they'll have to take me because I'm a black male. I want them to take me because I'm a good teacher, that's the only reason, not because I'm male and black.

He sympathizes with minority scudents coming from segregated environments, where being put in the situation of being a minority among predominantly whites is an uncommon experience. He also feels that at the university, there is a lack of support among African-Americans. 
I find people of color don't really deal too much with each other here. Out on the street they will speak, but within the doors of the schools they won't. I can't understand it except not want to be associated with me being a brother.

Major challenges ahead for him include developing the necessary skills he needs to feel comfortable and confident in educational settings and developing an understanding of today's youth. Causes for delay include illness in the family, his own or his wife's, which would necessitate his return to full-time work.

\title{
Asian-American Man
}

\section{Interviow \#12}

\begin{abstract}
Bon Nghe is a single Asian-American man in his late twenties. His parents and siblings are college educated. He left his home country and parents when he was in his teens and has lived in the United States with his older siblings. He has recently completed an advanced degree in physics and engineering. He was encouraged to return to school and get his teaching credentials by co-workers, and joined the program prior to starting at the university. He is working as a graduate assistant and as an aide at a public elementary school. At the time of this interview he was taking prerequisites for admittance into the fifthyear teacher education program.
\end{abstract}

I didn't speaik much even from high school up to when I graduated [from college]. I didn't speak much and I was shy to raise my hand and ask questions. If I had any questions I asked the professor. I was embarrassed to ask in front of the class.

Bon Nghe attended the first eleven years of school in Southeast Asia learning and speaking three languages including some English. He always understood the expectation in his home was to go to college and become proficient in some professional field. As early as the seventh grade he had the desire to teach foreign languages.

While in high school, his proficiency in math and sciences developed, and he was encouraged by his teachers to continue this field in college. He was provided assistance and direction for college attendance by his counselor who helped him with applications, course selection, and financial aid. 
She helped me take the courses that I required, so I followed whatever she told me to do.

He completed his studies in the traditional time-frame and went directly on to graduate school following the successful completion of his baccalaureate. Upon completion of his graduate studies he found employment opportunities in his field limited and, out of necessity, found work in the minimum wage service sector. He described feeling most comfortable in educational environments and returned to the university and found part-time work as a tutor and as a classroom aide in the public school.

While working at the public school, he was informed of the special program for minorities interested in teaching. While he j.nitially put aside the idea of becoming a teacher due to the language barrier, his interest was rekindled by the program, influx of Southeast Asian immigrants, and the lack of job opportunities in his initial field of study. His goal is to eventually be a researcher and a professor.

$I^{\prime} m$ interested in science and will probably want to learn for the rest of my life.

His involvement with the program has been an important and constructive experience for him. He was informed of it by a staff member at the school he was working at as a part-time teacher's assistant. He believes it is important for the public schools to have more minority teachers, but is also aware that, in general, there is an abundance of teachers. He does not view this program as having any responsibility toward him in relation to assisting him with developing greater proficiency with the English language. He feels the program has provided him the opportunity to merge his math and science skills with a profession, and helps considerably with funding his continued studies.

His main goal is to find a productive and adequate paying job to support himself, begin to pay back college loans, and gain a better command of the English language. While his commitments are strong, due to the present economic conditions, he recognizes that no complete employment guarantees exist and he may, as in the past, have to settle for any type of employment. His insecurity with the English language diminishes, in his eyes, his potential for productive employment opportunities. He believes it is essential for him to be employed in a work situation that requires constant use of the language for him to achieve acceptable proficiency for professional types of employment.

His social connection to college life has been limited even while attending a four-year residential university as a 
traditional college student. He described his insecurity with the language as a key hindrance to socializing with students other than those from similar ethnic backgrounds and who shared his interest in math and the sciences. His current social connection to college at this time is also very limited. Contact with English language speakers comes from working and meeting other minority students involved with the special program.

As a single man with no external supports from family or friends, financial assistance is a constant concern. He carries heavy debts incurred while attending graduate and undergraduate school and must keep attending college to defer payments. His experience working full-time in the minimum wage service sector left him in further in debt, as the combination of living expenses and loans due was higher that his wages. At present, financial supports come from a variety of sources including tuition waivers and part-time work. He feels he cannot request support from family members because his advanced studies are frowned upon.

They would expect me to go to college for a bachelor's degree, and that's enough. They don't want me to study too much.

His co-workers at the public school and the college and his former professors encouraged him to stay with the teacher training program and recommended he continue with school while he is young, single, and without family. responsibilities.

In relation to his experiences as a minority attending predominantly white educational institution, he described no negative experiences directly, but did know of some problems friends of his had with white students. He did not elaborate on these problems.

It's hard for me to remember. I just heard about this from my friends, I can't say, I wasn't there.

His main challenge is to be more articulate in the English language. Other challenges include passing the English writing part of the C-Best, and earning enough money to support himself and pay back his loans. If he does eventually get a job teaching he has a concern that students will blame him for their failures because they will not be able to understand him. He described the frequent observation of foreign teaching assistants being criticized and blamed for students' failure to master the material. 
I will probably have to deal with those who really don't study, and will blame me because they didn't understand my English.

It is crucial for him to keep working while attending classes. His major concerns are that the combination of work and school will eventually become too difficult to manage and a teaching position will not be there for him when he is finished with the fifth-year teacher training program.

I'm afraid that once you try to achieve a goal [teaching credentials] you won't have the opportunity to use it. 